\title{
Synthesis of a Panel of Carbon-13-Labelled (Glyco)Sphingolipids
}

\author{
Patrick Wisse, ${ }^{[a] \mid+1}$ Henrik Gold, ${ }^{[a] \mid+]}$ Mina Mirzaian, ${ }^{[b]}$ Maria J. Ferraz, ${ }^{[b]}$ Ginger Lutteke, ${ }^{[a]}$ \\ Richard J. B. H. N. van den Berg, ${ }^{\text {[a] }}$ Hans van den Elst, ${ }^{\text {[a] }}$ Johan Lugtenburg, ${ }^{\text {[a] }}$ \\ Gijsbert A. van der Marel, ${ }^{[a]}$ Johannes M. F. G. Aerts, ${ }^{[a, b]}$ Jeroen D. C. Codée, ${ }^{*[a]}$ and \\ Herman S. Overkleeft* $*$ a]
}

Keywords: Sphingolipids / Glycolipids / Ceramides / Metathesis / Isotopic labeling

The synthesis of a focussed library of sphingolipids differing in the number and position of ${ }^{13} \mathrm{C}$ labels is described. The synthesised sphingolipids differ in substitution at both the sphingosine amine (either palmitoylated or unmodified) and the sphingosine primary hydroxyl (unmodified or glycosylated). Moreover, ${ }^{13} \mathrm{C}$ atoms are incorporated into either the sphingosine or the palmitate moiety, or both. This set of compounds is intended for use in relative quantitative lipidomics studies to gain insight into sphingolipid metabolism in healthy and diseased (lysosomal storage disorders) patients and animal models.

\section{Introduction}

Sphingolipids and their derivatives (glycosphingolipids, phosphosphingolipids, sphingomyelins) are important structural components of mammalian cell membranes. The biosynthesis of sphingolipids is a tightly controlled process, and disruption of a specific metabolic step can lead to disease. A variety of genetic disorders linked to sphingolipid metabolism occur in man. Often, these diseases are characterised by mutations in genes that encode for enzymes or chaperones involved in a specific metabolic step in the lysosomal degradation of sphingolipids. Prominent examples of such lysosomal storage disorders are Gaucher disease (inherited defect in acid glucocerebrosidase, GBA1 - the enzyme responsible for the hydrolysis of glucosylceramide to glucose and ceramide) and Fabry disease (inherited defect in lysosomal $\alpha$-galactosidase - the enzyme responsible for the hydrolysis of globotriaosylceramide to galactose and lactosylceramide).${ }^{[1]}$

In the past decade, we have studied both diseases in molecular detail, and we have found that both are characterised by, in addition to storage of the substrate of the genetically impaired enzyme (i.e., glucosylceramide in

[a] Leiden Institute of Chemistry, Gorleaus Laboratories, Einsteinweg 55, 2300 RA Leiden, The Netherlands

E-mail: jcodee@chem.leidenuniv.nl h.s.overkleeft@chem.leidenuniv.nl http://biosyn.lic.leidenuniv.nl

[b] Department of Medical Biochemistry, Academic Medical Center,

Meibergdreef 15, 1105 AZ Amsterdam, The Netherlands

[\%] Patrick Wisse and Henrik Gold contributed equally to the work, and both should be considered as first authors.

$\square$ Supporting information for this article is available on the WWW under http://dx.doi.org/10.1002/ejoc.201500025.
Gaucher and globotriaosylceramide in Fabry), the occurrence of alternative metabolic pathways. ${ }^{[1-3]}$ We also obtained evidence that metabolites produced by these alternative pathways - lysoglycosphingolipids in both cases - may be involved in or perhaps even causative in the onset and development of the disease. We made these discoveries thanks in part to stable-isotope-labelled $\left({ }^{13} \mathrm{C}_{5}\right)$ sphingolipids, which we synthesised for this purpose. Based on these findings, we reasoned that a comprehensive set of sphingolipids differing both in structure and in the number of ${ }^{13} \mathrm{C}$ atoms embedded in both the sphingosine and the $N$-acyl (palmitate) moieties, as represented by the general structure in the insert of Figure 1, would be a very useful set of research tools. A selection of the sphingolipid biosynthetic pathways are shown in Figure 1. At the basis of the biosynthesis of all sphingolipids is sphinganine 1, itself the condensation product of serine and palmitate. In a reaction catalysed by sphinganine acyl transferase (SAT), the free amine in $\mathbf{1}$ is condensed with a fatty acid, here shown as palmitate but in reality one of a number of saturated or partially unsaturated fatty acids of varying size. In the next step, the resulting dihydroceramide (i.e., 2) is dehydrogenated through the action of dihydroceramide dehydrogenase (DCD) to produce ceramide 3. At this stage, a number of different pathways can take place, giving rise to a wide variety of sphingolipids featuring different polar head groups. Glucosylceramide (4) is the product of the glucosylceramide synthase (GCS) catalysed condensation of $\mathbf{3}$ with UDP-glucose. Glucosylceramide (4) in turn is the starting point for the synthesis of a wide variety of glycosphingolipids and gangliosides featuring oligosaccharides of different sizes and natures, and including branched oligosaccharides. After its synthesis, glucosylceramide is modified to more 


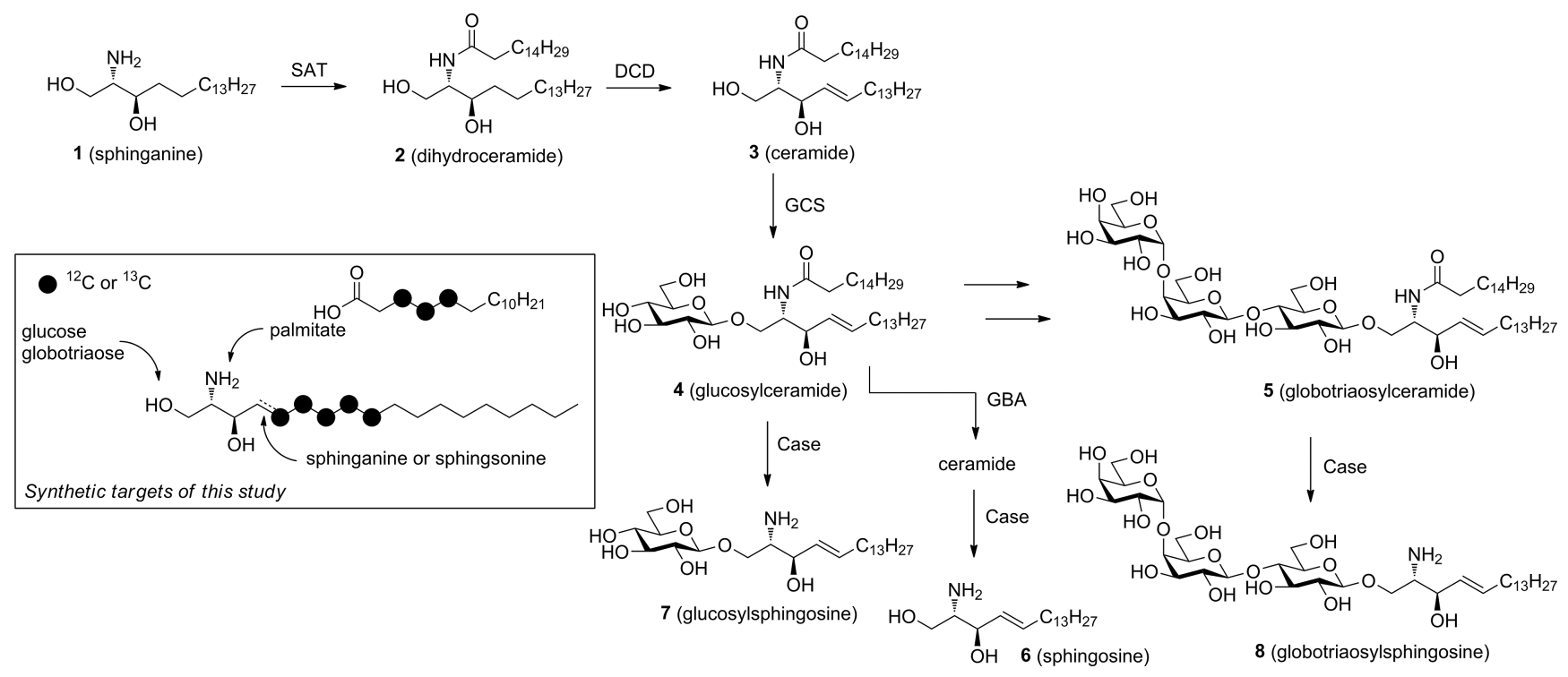

Figure 1. Partial overview of sphingolipid metabolism in man, and the target structures (insert) of the studies presented here.

complex glycosphingolipids by the sequential action of glycosyltransferases. As a representative example, globotriaosylceramide (5) emerges after sequential $\beta$-galactosylation and $\alpha$-galactosylation of glucosylceramide (4) effected by two independent glycosyltransferases. ${ }^{[4]}$ In time, sphingolipids are internalised by endocytosis, and transported to the lysosomal compartments, where they are degraded. The degradation of glycosphingolipids is commonly viewed to take place in a stepwise manner, with the product of one enzyme acting as the substrate of the next enzyme of the disassembly line. In this fashion, globotriaosylceramide (5) is transformed by the action of lysosomal $\alpha$-galactosidase into lactosylceramide. Lysosomal $\beta$-galactosidase next removes the $\beta$-galactose residue to deliver glucosylceramide, which in turn is deglucosylated by GBA1 to give ceramide as the penultimate degradation product. Finally, acid ceramidase (ACase) hydrolyses the amide bond to produce sphingosine (6; Figure 1) and palmitate for reuptake into the cytoplasm as new building blocks for catabolism.

In contrast to common belief, a few years ago, we found that in tissue from Fabry patients, as well as in animal models, which are characterised by elevated levels of globotriaosylceramide due to genetically and partially disabled lysosomal $\alpha$-galactosidase, the $N$-acyl chain of a portion of the accumulated globotriaosylsphingosine is removed, resulting in the formation of the lysoglycosphingolipid, globotriaosylsphingosine (8).$^{[2]}$ Later, we discovered the existence of a related alternative pathway that occurs in Gaucher patients: accumulated glucosylceramide, caused by partially dysfunctional GBA1, is partially deacylated to produce glucosylsphingosine (7). ${ }^{[3]}$ These alternative pathways are probably occurring through the action of ACase, although this needs to be confirmed. The generation of stable-isotope-labelled $\left({ }^{13} \mathrm{C}_{5}\right)$ globotriaosylsphingosine (8) and glucosylsphingosine (7) allows the detailed study of such alternative metabolic pathways. Stable-isotope analogues are also very use- ful for the diagnosis of both diseases and for monitoring their treatment, with corrections for glycolipid metabolism being reflected by lowered levels of lysolipids in tissue samples. ${ }^{[5-7]}$ With this reasoning in mind, we set out to construct a focussed library of stable-isotope (glyco)sphingosine and (glyco)sphingolipid derivatives. In our design, we chose to incorporate five ${ }^{13} \mathrm{C}$ atoms into the sphingosine base, and three into the palmitate, to obtain compounds that would be easily detected, together with their unlabelled counterparts, from complex biological lipid fractions. The details of their synthesis, relying on a cross-metathesis reaction to give stable-isotope-labelled sphingosine for further elaboration into a library of 24 compounds, are reported here.

\section{Results and Discussion}

Ready access to $\left[{ }^{13} \mathrm{C}_{5}\right]$-sphingosine, the common backbone of all of the target structures, is crucial to the synthesis of the panel of $\left[{ }^{13} \mathrm{C}_{n}\right]$-sphingolipids. To this end, and based on literature precedent, ${ }^{[8,9]}$ we designed a synthetic route based on the cross-metathesis of $\left[{ }^{13} \mathrm{C}_{5}\right]$-pentadeca-1-ene (20) with aminodiol 21. ${ }^{[10-16]}$ The insertion of the labels into 20 was achieved using $\left[{ }^{13} \mathrm{C}\right]$-potassium cyanide and $\left[{ }^{13} \mathrm{C}_{2}\right]-$ acetic acid, which was converted into Horner-WadsworthEmmons (HWE) reagent $\mathbf{1 2}$ in a four-step procedure as shown in Scheme 1. Transformation of acetic acid $\mathbf{9}$ into bromoacetic acid $\mathbf{1 0}$ by a Hell-Volhard-Zelinsky reaction ${ }^{[8]}$ was followed by treatment of $\mathbf{1 0}$ with oxalyl chloride and addition of $\mathrm{N}, \mathrm{O}$-dimethylhydroxylamine in an one-pot fashion to give a mixture of bromo- and chloro- $N$-methoxy- $N$ methylacetamides (11). Subjection of this mixture of Weinreb amides to Arbuzov reaction conditions gave the target HWE reagent (i.e., 12) in 74\% yield over four steps.

Next, 1-bromononane $(\mathbf{1 3})$ was treated with $\left[{ }^{13} \mathrm{C}\right]$-potassium cyanide to give nitrile $\mathbf{1 4}$, which was partially reduced 


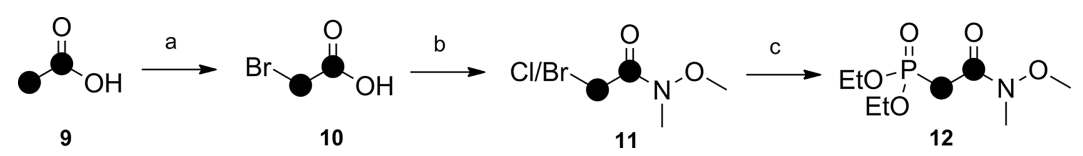

Scheme 1. Reagents and conditions: (a) (i) TFAA (trifluoroacetic acid anhydride), $\mathrm{Br}_{2}$, room temp., $20 \mathrm{~h}$; (ii) water $88 \%$; (b) (i) oxalyl chloride, DMF, $\mathrm{CH}_{2} \mathrm{Cl}_{2}, 0{ }^{\circ} \mathrm{C}$ to r.t., $2 \mathrm{~h}$; (ii) $\mathrm{N}, \mathrm{O}$-dimethylhydroxylamine, $-78{ }^{\circ} \mathrm{C}$ to r.t., $2 \mathrm{~h}, 97 \%$; (c) triethylphosphite, $150{ }^{\circ} \mathrm{C}, 3 \mathrm{~h}, 95 \%$.

to aldehyde 15 using DIBAL-H (diisobutylaluminium hydride) ( $87 \%$ over two steps; Scheme 2$)$. This aldehyde was treated with reagent 12 and $n \mathrm{BuLi}$ to give unsaturated $\left[{ }^{13} \mathrm{C}_{3}\right]$-Weinreb amide 16, the $\mathrm{C}=\mathrm{C}$ double bond in which was reduced to give $\mathbf{1 7}$ in $82 \%$ yield. A similar sequence of events - reduction of the Weinreb amide in $\mathbf{1 7}$ to the aldehyde, followed by HWE olefination with 12 , and $\mathrm{C}=\mathrm{C}$ reduction - provided the corresponding Weinreb amide (i.e., 19), which was transformed in two steps (reduction to the aldehyde, followed by Wittig reaction with in-situ-generated $\mathrm{Ph}_{3} \mathrm{P}=\mathrm{CH}_{2}$ ) into $\left[{ }^{13} \mathrm{C}_{5}\right]$-pentadeca-1-ene (20) in 93\% yield.

With the $\left[{ }^{13} \mathrm{C}_{5}\right]$-pentadeca-1-ene in hand, we went on to investigate the cross-metathesis of $\mathbf{2 0}$ with alkene $\mathbf{2 1}$ under the conditions advocated in the literature (i.e., Grubbs $2^{\text {nd }}$ generation catalyst, dichloromethane, 20:21 = 1:2). ${ }^{[9]} \mathrm{How}-$ ever, close examination of the metathesis product revealed the partial elimination of one or two methylene units, leading to truncated cross-metathesis products. This came as a surprise, since there are several literature reports that describe the synthesis of unlabelled sphingosine using essentially the same procedure as described here, and none of these report the formation of truncated $\left(\mathrm{C}_{17}\right.$ or $\left.\mathrm{C}_{16}\right)$ sphingosines. ${ }^{[1-16]}$ Methylene eliminations have, however, been reported as side-reactions in (cross) metathesis studies unrelated to the synthesis of sphingosine. These events are thought to be the result of alkene-isomerisation of terminal alkenes while bound to the ruthenium metal centre. ${ }^{[17-19]}$ This isomerisation can be prevented by the addition of acetic acid to the cross-metathesis reaction mixture. ${ }^{[20]}$ Indeed, we found that the addition of acetic acid (20 mol- $\%$ relative to 21 ) to an otherwise unchanged reaction mixture led to a clean cross-metathesis reaction to give $\mathbf{2 2}$ as the major product in $81 \%$ yield. Sphingosine 22 was transformed into a suitable substrate for the ensuing glycosylation by protecting-group manipulation. Benzoylation of the secondary alcohol in $\mathbf{2 2}$ and removal of the isopropylidene with a catalytic amount of $p \mathrm{TsOH}$ in methanol/ethanol to suppress unwanted Boc (tert-butoxycarbonyl) cleavage led to the isolation of the key building block.

$\left[{ }^{13} \mathrm{C}_{3}\right]$-Palmitoyl chloride (30) was obtained starting from commercially available $\left[{ }^{13} \mathrm{C}_{3}\right]$-myristic acid (24; Scheme 3). Labelled acid $\mathbf{2 4}$ was converted into the corresponding Weinreb amide (i.e., 25) by treatment with oxalyl chloride, and subsequent addition of $\mathrm{N}, \mathrm{O}$-dimethylhydroxylamine. The two-carbon elongation of $\mathbf{2 5}$ to give $\mathbf{2 7}$ was realised by reduction with DIBAL-H, and subsequent subjection of the
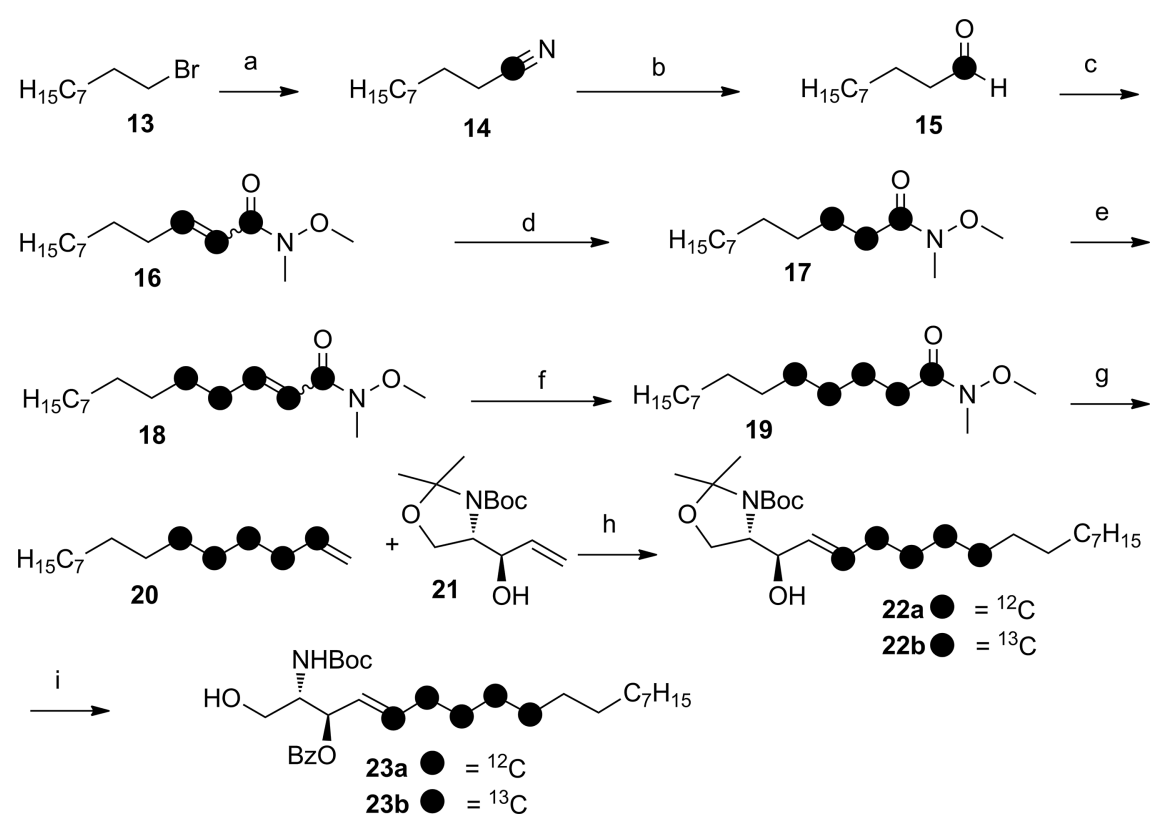

Scheme 2. Reagents and conditions: (a) $\mathrm{K}^{13} \mathrm{CN}$, EtOH/ $\mathrm{H}_{2} \mathrm{O}, 80^{\circ} \mathrm{C}, 20 \mathrm{~h}, 95 \%$; (b) DIBAL-H, THF, $0{ }^{\circ} \mathrm{C}$ to room temp., $2.5 \mathrm{~h}$, acidic work up, $92 \%$; (c) (i) $12, n \mathrm{BuLi}$, THF, $0{ }^{\circ} \mathrm{C}, 10 \mathrm{~min}$; (ii) $\left[{ }^{13} \mathrm{C}_{1}\right]$-decanal (15), THF, $0{ }^{\circ} \mathrm{C}$ to r.t., 20 h, $87 \%$; (d) $\mathrm{Pd} / \mathrm{C}, \mathrm{H}_{2}$ (g), EtOAc, r.t., $20 \mathrm{~h}, 82 \%$; (e) $\mathrm{LiAlH}_{4}, \mathrm{THF}, 0{ }^{\circ} \mathrm{C}, 45 \mathrm{~min}$, to give crude $\left[{ }^{13} \mathrm{C}_{3}\right]$-dodecanal, which was added to a solution of $\left(12, n \mathrm{BuLi}, \mathrm{THF}, 0{ }^{\circ} \mathrm{C}\right.$, $10 \mathrm{~min}$ ), $0{ }^{\circ} \mathrm{C}$ to r.t., $20 \mathrm{~h}, 77 \%$; (f) $\mathrm{Pd} / \mathrm{C}, \mathrm{H}_{2}$ (g), EtOAc, $93 \%$; (g) LiAlH $n \mathrm{BuLi}$, THF, $0{ }^{\circ} \mathrm{C}, 10 \mathrm{~min}$ ), $0{ }^{\circ} \mathrm{C}$ to r.t., $20 \mathrm{~h}, 93 \%$; (h) 21, Grubbs 2 nd generation catalyst, $\mathrm{AcOH}, \mathrm{CH}_{2} \mathrm{Cl}_{2}$, reflux, $48 \mathrm{~h}, 81 \%$; (i) $\mathrm{BzCl}$, DMAP [4-(dimethylamino)pyridine], $\mathrm{CH}_{2} \mathrm{Cl}_{2}$ /pyridine, room temp., 20 h, 92\%; (ii) MeOH/EtOH, $p$ TsOH, r.t., 20 h, $63 \%$. 

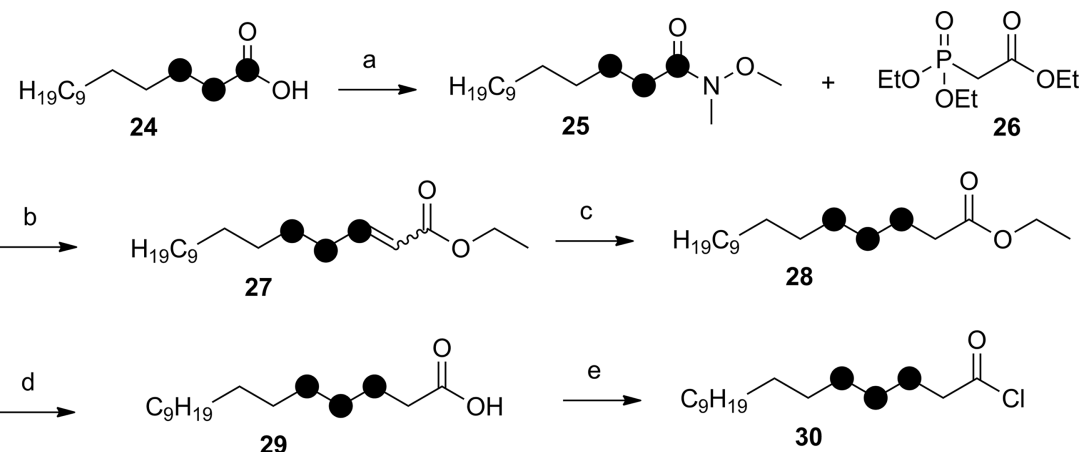

Scheme 3. Reagents and conditions: (a) (i) oxalyl chloride, $\mathrm{DMF}, \mathrm{CH}_{2} \mathrm{Cl}_{2}, 0^{\circ} \mathrm{C}$ to room temp., $2 \mathrm{~h}$; (ii) $\mathrm{N}, \mathrm{O}$-dimethylhydroxylamine, $-78^{\circ} \mathrm{C}$ to r.t., $2 \mathrm{~h}, 98 \%$; (b) DIBAL-H, THF, $-78{ }^{\circ} \mathrm{C}, 30 \mathrm{~min}$, to give crude $\left[{ }^{13} \mathrm{C}_{3}\right]$-tetradecanal, which was added to a solution of $(26$, $n$ BuLi, THF, $0{ }^{\circ} \mathrm{C}, 10 \mathrm{~min}$ ), $0{ }^{\circ} \mathrm{C}$ to r.t., 20 h, $81 \%$; (c) Pd-C, $\mathrm{H}_{2}$ (g), EtOAc, 20 h, 95\%; (d) LiOH, THF/EtOH/H 20 h, $95 \%$; (e) oxalyl chloride, $\mathrm{DMF}, \mathrm{CH}_{2} \mathrm{Cl}_{2}, 0{ }^{\circ} \mathrm{C}$ to r.t., $2 \mathrm{~h}, 100 \%$.

resulting aldehyde to HWE olefination with reagent $\mathbf{2 6}$. Reduction of the double bond in $\mathbf{2 7}$, saponification, and treatment with oxalyl chloride gave $\left[{ }^{13} \mathrm{C}_{3}\right]$-palmitoyl chloride (30).

The synthesis of sphingolipids and glycosphingolipids in various ${ }^{13} \mathrm{C}$-labelled forms based on $\mathbf{2 3}$ is shown in Scheme 4. Debenzoylation of 23b with sodium methoxide in methanol, followed by TFA (trifluoroacetic acid) mediated removal of the Boc group provided $\left[{ }^{13} \mathrm{C}_{5}\right]$-sphingosine $(\mathbf{3 1 b}$; $59 \%$ yield). Both $\left[{ }^{13} \mathrm{C}_{0}\right]-31 \mathrm{a}$ and $\left[{ }^{13} \mathrm{C}_{5}\right]-\mathbf{3 1 b}$ were condensed with either $\left[{ }^{13} \mathrm{C}_{0}\right]$-palmitoyl chloride or $\left[{ }^{13} \mathrm{C}_{3}\right]$-palmitoyl chloride (30) to give the panel of labelled ceramides 32a32d. Alternatively, debenzoylation of $23 \mathbf{a} / \mathbf{b}$, reduction of the alkene moiety with Adams catalyst, and TFA-mediated Boc removal gave stable-isotope sphinganine pair 33a and 33b, which were used as starting materials to produce dihydroceramides $\mathbf{3 4 a}-\mathbf{3 4 d}$.

The glycosylated sphingolipids were assembled by coupling the labelled sphingosine alcohols with the appropriate glycosyl donors. Thus, $N$-phenyltrifluoroacetimidate glucose donor 35 (see Experimental Section for its synthesis; Scheme 5) and sphingosine $\mathbf{2 3} \mathbf{a} / \mathbf{b}$ were condensed in a reaction promoted by boron trifluoride diethyl etherate to give fully protected glucosylsphingosines $\mathbf{3 6 a} / \mathbf{b}$. The moderate yield of the glycosylation reaction can be explained by the concomitant cleavage of the Boc group, which took place under the Lewis acidic reaction conditions. It is interesting to note that attempted glucosylation of $\mathbf{2 3 a} \mathbf{a} / \mathbf{b}$ using the cor-

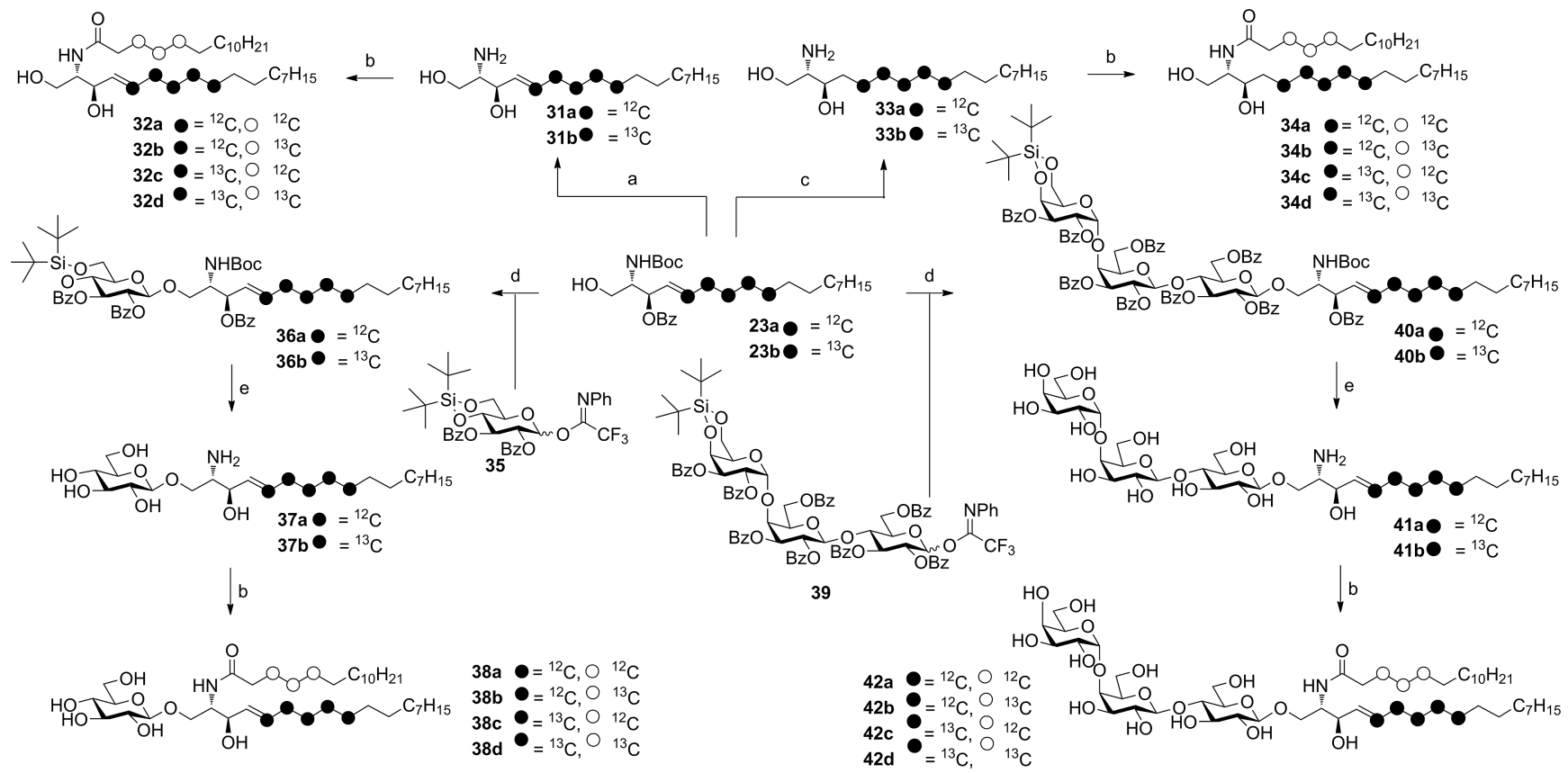

Scheme 4. Reagents and conditions: (a) (i) $\mathrm{NaOMe}, \mathrm{MeOH}$, room temp., 20 h; (ii) $\mathrm{KOH}, \mathrm{H}_{2} \mathrm{O}$, r.t., 20 h; (iii) $\mathrm{TFA}, \mathrm{H}_{2} \mathrm{O}, 0{ }^{\circ} \mathrm{C}, 30$ min, $59 \%$; (b) palmitoyl chloride, satd. aq. NaOAc, THF, r.t., 3 h, 50-70\%; (c) (i) $\mathrm{NaOMe}, \mathrm{MeOH}$, r.t., 20 h; (ii) $\mathrm{KOH}$, $\mathrm{H}_{2} \mathrm{O}$, r.t., 20 h; (iii) $\mathrm{PtO}_{2}, \mathrm{H}_{2}$ (g), EtOAc, r.t., 20 h; (iv) TFA, $\mathrm{H}_{2} \mathrm{O}, 0{ }^{\circ} \mathrm{C}, 30 \mathrm{~min}, 52 \%$; (d) Glucosyl donor $(35$ or 39$), \mathrm{BF}_{3} \cdot \mathrm{OEt}_{2}, \mathrm{CH}_{2} \mathrm{Cl}_{2}, 0{ }^{\circ} \mathrm{C}, 1 \mathrm{~h}, 49-$ $61 \%$; (e) (i) $\mathrm{HF} /$ pyridine, THF/pyridine, r.t., 2 h; (ii) $\mathrm{NaOMe}, \mathrm{MeOH}$, r.t., 20 h; (iii) $\mathrm{KOH}, \mathrm{H}_{2} \mathrm{O}$, r.t., 20 h; (iv) $\mathrm{TFA}, \mathrm{H}_{2} \mathrm{O}, 0{ }^{\circ} \mathrm{C}, 30 \mathrm{~min}$, $48-53 \%$. 
responding perbenzoylated $N$-phenyltrifluoroacetimidate donor and boron trifluoride diethyl etherate was unproductive, and led only to the isolation of the product of Boc removal from $\mathbf{2 3} \mathbf{a} / \mathbf{b}$. Global deprotection of $\mathbf{3 6}$ by treatment with $\mathrm{HF} /$ pyridine, sodium methoxide, and trifluoroacetic acid provided stable-isotope glucosylsphingosine pair 37a/ b in $53 \%$ yield. Both $\left[{ }^{13} \mathrm{C}_{0}\right]$-glucosylsphingosine (37a) and $\left[{ }^{13} \mathrm{C}_{5}\right]$-glucosylsphingosine (37b) were condensed with either $\left[{ }^{13} \mathrm{C}_{0}\right]$-palmitoyl chloride or $\left[{ }^{13} \mathrm{C}_{3}\right]$-palmitoyl chloride (30) to give the panel of labelled glucosylceramide derivatives 38a-38d.

Finally, the syntheses of globotriaosylsphingosines $\mathbf{4 1} \mathbf{a} / \mathbf{b}$ and globotriaosylceramides $\mathbf{4 2 a}-\mathbf{4 2 d}$ were undertaken. To this end, sphingosine $\mathbf{2 3}$ was condensed with trisaccharide donor $39^{[21]}$ in a reaction promoted by boron trifluoride diethyl etherate to give fully protected globotriaosylsphingosines $\mathbf{4 0 a} / \mathbf{b}$. Subsequent global deprotection by the same procedure described above gave $\mathbf{4 1} \mathbf{a} / \mathbf{b}$ in $48 \%$ yield. Standard palmitoylation with either $\left[{ }^{13} \mathrm{C}_{0}\right]$-palmitoyl chloride or $\left[{ }^{13} \mathrm{C}_{3}\right]$-palmitoyl chloride gave the panel of globotriaosylceramides $42 \mathbf{a}-\mathbf{4 2 d}$ in an average yield of $59 \%$ to complete the library of labelled (glyco)sphingosines.

The physical properties of all the labelled compounds matched those of their ${ }^{12} \mathrm{C}$ counterparts, apart from their

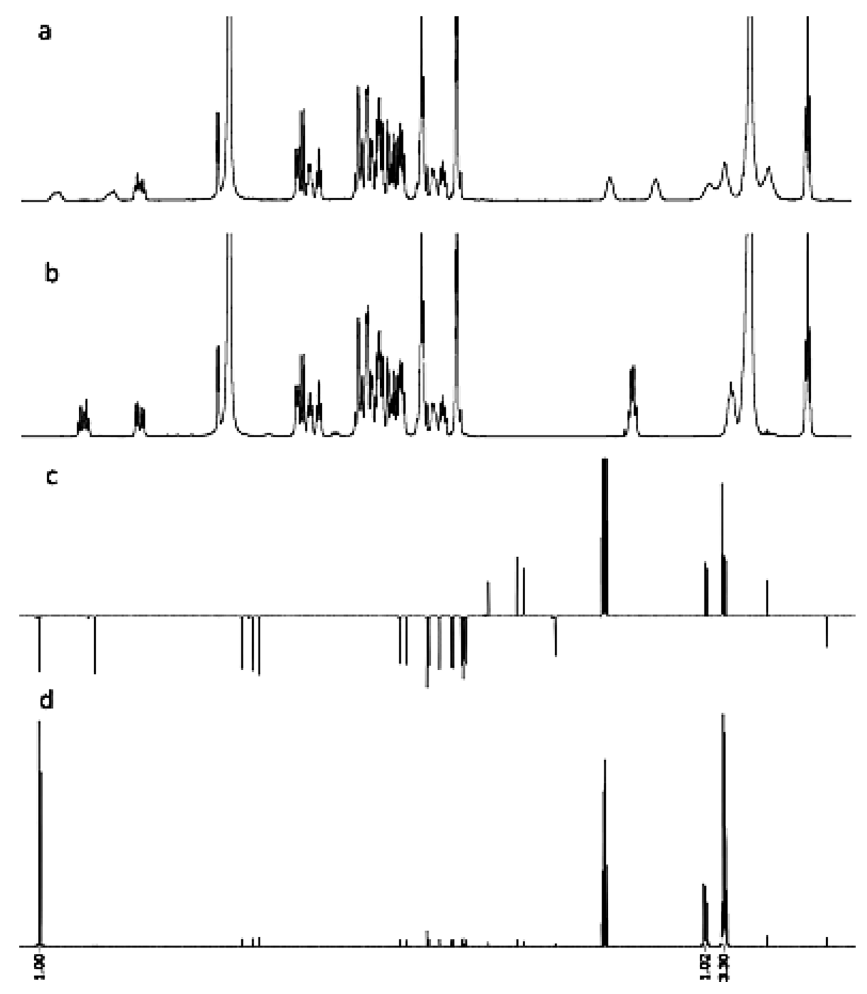

Figure 2. ${ }^{1} \mathrm{H}$ and ${ }^{13} \mathrm{C}$ NMR spectra of the synthesised labelled and unlabelled globotriaosylsphingsosine. (a) $400 \mathrm{MHz}{ }^{1} \mathrm{H}$ NMR spectrum ([D $\left.\mathrm{D}_{4}\right]$ methanol) of labelled globotriaosylsphingosine $41 \mathbf{b}$, in which the ${ }^{13} \mathrm{C},{ }^{1} \mathrm{H}$ coupling of the double-bond proton is apparent. (b) $400 \mathrm{MHz}{ }^{13} \mathrm{C}$-decoupled ${ }^{1} \mathrm{H}$ NMR spectrum ([D $\left.\mathrm{D}_{4}\right]$ methanol) of labelled globotriaosylsphingosine 41b. (c) $151.1 \mathrm{MHz}{ }^{13} \mathrm{C} \mathrm{NMR}$ spectrum ( $\left[\mathrm{D}_{4}\right]$ methanol) of unlabelled globotriaosylsphingosine 41a. (d) $151.1 \mathrm{MHz}{ }^{13} \mathrm{C}$ NMR spectrum ([ $\left.\mathrm{D}_{4}\right]$ methanol) of labelled globotriaosylsphingosine $\mathbf{4 1 b}$, with integration of the ${ }^{13} \mathrm{C}$ labels. mass spectra and their ${ }^{1} \mathrm{H}$ and ${ }^{13} \mathrm{C}$ NMR spectra. As a representative example, Figure 2 shows the ${ }^{1} \mathrm{H}$ and ${ }^{13} \mathrm{C}$ NMR spectra of ${ }^{13} \mathrm{C}$-labelled globotriasylsphingosine 41b (Figure $2 \mathrm{a}, \mathrm{b}$ and $\mathrm{d})$, and the ${ }^{13} \mathrm{C}$ NMR spectrum of its unlabelled counterpart 41a (Figure 2c). In Figure $2 b$, the ${ }^{13} \mathrm{C}$-decoupled ${ }^{1} \mathrm{H}$ NMR spectrum of ${ }^{13} \mathrm{C}$-labelled $41 \mathrm{~b}$ is shown, which is identical in all respects to the spectrum of unlabelled 41a. Integration of the peaks due to the ${ }^{13} \mathrm{C}$ labels in $41 \mathrm{~b}$ clearly shows the ratio of the incorporated atoms.

\section{Conclusions}

In conclusion, a comprehensive library of stable-isotopeenriched sphingolipids has been constructed by straightforward synthetic routes taking into consideration that the synthesis of ${ }^{13} \mathrm{C}$-enriched lipids with the carbons introduced at specific predetermined sites can be executed with only a limited number of reagents available from commercial sources. The key step in the assembly of the sphingosine backbone, the cross-metathesis reaction between the sphingosine head-group alkene and the long-chain alkene, was optimised to minimise truncation of the long-chain alkene before the cross-metathesis event. Elimination of one or two methylene units, leading to the loss of ${ }^{13} \mathrm{C}$ labels, was observed during this reaction under conditions previously described. The addition of acetic acid to the reaction mixture effectively prevented the truncation of the alkene chain. With this work we believe we have obtained a valuable set of molecular probes to study sphingolipid metabolism in healthy and disease states in a chemical metabolomics setting. The route is also flexible, and is thus amenable for the production of other sphingolipid metabolites, with respect to both the polar head group, such as for instance phosphate and phosphate diesters, and also the $N$-acyl-substituted fatty acid moiety.

\section{Experimental Section}

General Remarks: $\left[{ }^{13} \mathrm{C}_{2}\right]$-Acetic acid (99.95\% isotopically pure, product code CLM-105), potassium $\left[{ }^{13} \mathrm{C}\right]$-cyanide (99\% isotopically pure, product code CLM-297), and $\left[1,2,3-{ }^{13} \mathrm{C}_{3}\right]$-myristic acid ( $99 \%$ isotopically pure, product code CLM-3665) were purchased from Cambridge Isotope Laboratories, Inc., and were used as received. Commercially available reagents and solvents (Acros, Fluka, or Merck) were used as received, unless otherwise stated. $\mathrm{CH}_{2} \mathrm{Cl}_{2}$ and THF were freshly distilled before use, over $\mathrm{P}_{2} \mathrm{O}_{5}$ and $\mathrm{Na}$ /benzophenone, respectively. Triethylamine was distilled from calcium hydride and stored over potassium hydroxide. Traces of water were removed from starting compounds by coevaporation with toluene. All moisture-sensitive reactions were carried out under an argon atmosphere. Molecular sieves ( $3 \AA$ ) were flame-dried before use. Column chromatography was carried out using forced flow of the indicated solvent systems on Screening Devices Silica gel 60 (40-63 $\mu \mathrm{m}$ mesh). Size-exclusion chromatography was carried out on Sephadex LH20 $\left(\mathrm{MeOH} / \mathrm{CH}_{2} \mathrm{Cl}_{2}, 1: 1\right)$. Analytical TLC was carried out on aluminium sheets (Merck, silica gel 60, $\mathrm{F}_{254}$ ). Compounds were visualised by UV absorption $(254 \mathrm{~nm})$, or by spraying with ammonium molybdate/cerium sulphate solution $\left[\left(\mathrm{NH}_{4}\right)_{6} \mathrm{Mo}_{7} \mathrm{O}_{24} \cdot 4 \mathrm{H}_{2} \mathrm{O} \quad(25 \mathrm{~g} / \mathrm{L}),\left(\mathrm{NH}_{4}\right)_{4} \mathrm{Ce}\left(\mathrm{SO}_{4}\right)_{6} \cdot 2 \mathrm{H}_{2} \mathrm{O} \quad(10 \mathrm{~g} / \mathrm{L})\right.$, 
$10 \%$ sulphuric acid in ethanol] or phosphormolybdic acid in EtOH $(150 \mathrm{~g} / \mathrm{L})$, followed by charring (ca. $\left.150^{\circ} \mathrm{C}\right)$. IR spectra were recorded with a Shimadzu FTIR-8300 instrument and are reported in $\mathrm{cm}^{-1}$. Optical rotations were measured with a Propol automatic polarimeter (sodium D-line, $\lambda=589 \mathrm{~nm}$ ). ${ }^{1} \mathrm{H}$ and ${ }^{13} \mathrm{C}$ NMR spectra were recorded with a Bruker $\mathrm{AV} 400 \mathrm{MHz}$ spectrometer at 400.2 $\left({ }^{1} \mathrm{H}\right)$ and $100.6\left({ }^{13} \mathrm{C}\right) \mathrm{MHz}$, or with a Bruker AV $600 \mathrm{MHz}$ spectrometer at $600.0\left({ }^{1} \mathrm{H}\right)$ and $151.1\left({ }^{13} \mathrm{C}\right) \mathrm{MHz}$. Chemical shifts are reported as $\delta$ values (ppm), and were referenced to tetramethylsilane $(\delta=0.00 \mathrm{ppm})$ directly in $\mathrm{CDCl}_{3}$, or using the residual solvent peak $\left(\mathrm{D}_{2} \mathrm{O}\right)$. Coupling constants $(J)$ are given in $\mathrm{Hz}$, and all ${ }^{13} \mathrm{C}$ spectra were proton decoupled. NMR assignments were made using COSY and HSQC, and in some cases TOCSY experiments. LC-MS analysis was carried out with an LCQ Advantage Max (Thermo Finnigan) instrument equipped with a Gemini $\mathrm{C}_{18}$ column (Phenomenex, $50 \times 4.6 \mathrm{~mm}, 3 \mu \mathrm{m}$ ), using the following buffers: A: $\mathrm{H}_{2} \mathrm{O}, \mathrm{B}$ : acetonitrile, and C: aq. TFA (1.0\%). HPLCMS purifications were carried out with an Agilent Technologies 1200 Series automated HPLC system with a Quadrupole MS 6130, equipped with a semi-preparative Gemini $\mathrm{C}_{18}$ column (Phenomenex, $250 \times 10.00,5 \mu \mathrm{m})$. Products were eluted using the following buffers: A: aq. TFA (0.2\%), B: acetonitrile (HPLC-grade), $5 \mathrm{~mL} / \mathrm{min}$. Purified products were lyophilised with a CHRIST

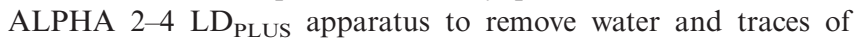
buffer salts.

General Procedure for the Synthesis of Ceramides from Sphingosine: Sphingosine $(0.1 \mathrm{mmol})$ was dissolved in THF $(12 \mathrm{~mL})$, and satd. aq. NaOAc $(10 \mathrm{~mL})$ was added. Palmitoyl chloride $(0.13 \mathrm{mmol}$, 1.3 equiv.) was added, and the reaction mixture was stirred vigorously at room temperature for $3 \mathrm{~h}$. The mixture was diluted with THF $(20 \mathrm{~mL})$, and washed with water $(10 \mathrm{~mL})$. The aqueous layer was extracted with THF $(3 \times 20 \mathrm{~mL})$, and the combined organic extracts were dried $\left(\mathrm{Na}_{2} \mathrm{SO}_{4}\right)$, filtered, and concentrated in vacuo. The ceramides were purified by column chromatography (chloroform/ $\mathrm{MeOH}$ ) and $\mathrm{HPLC}-\mathrm{MS}$, using a $\mathrm{C}_{4}$ column. Products were eluted using the following buffers: A: $\mathrm{NH}_{4} \mathrm{OAc}[25 \mathrm{nM}$ in $\mathrm{MeOH} /$ $\mathrm{H}_{2} \mathrm{O}(3: 1)$ ], B: acetonitrile (HPLC grade). Purified products were lyophilised to remove water and traces of buffer salts.

${ }^{[13} \mathbf{C}_{2}$ ]-2-Bromoacetic Acid (10): Trifluoroacetic anhydride $(67.3 \mathrm{~mL}$, $484 \mathrm{mmol}, 3.0$ equiv.) was slowly added to $\left[1,2-{ }^{13} \mathrm{C}_{2}\right]$-acetic acid (9; $10 \mathrm{~g}, 161 \mathrm{mmol}, 1.0$ equiv.) while stirring. Bromine $(8.30 \mathrm{~mL}$, $161 \mathrm{mmol}, 1.0$ equiv.) was added, and the reaction mixture was stirred at room temperature for $20 \mathrm{~h}$. The mixture was then cooled to $0{ }^{\circ} \mathrm{C}$, and water $(10.2 \mathrm{~mL}, 564 \mathrm{mmol}, 3.5$ equiv.) was added. The excess bromine was removed by a flow of argon. The crude mixture was then dissolved in toluene $(200 \mathrm{~mL})$, and the solution was concentrated in vacuo. This procedure was repeated twice to give $\left[{ }^{13} \mathrm{C}_{2}\right]$-2-bromoacetic acid $(\mathbf{1 0} ; 23.2 \mathrm{~g}, 142 \mathrm{mmol}, 88 \%)$ as an offwhite solid, which was used without further purification. ${ }^{[8]}$

$\left[1,2-{ }^{13} C_{2}\right]-2-B r o m o-N$-methoxy- $N$-methylacetamide and $\left[1,2-{ }^{13} C_{2}\right]-2-$ Chloro- $N$-methoxy- $N$-methylacetamide (11): $\left[{ }^{13} \mathrm{C}_{2}\right]-2$-Bromoacetic acid $(10 ; 8.46 \mathrm{~g}, 60 \mathrm{mmol}, 1.0$ equiv.) was dissolved in anhydrous $\mathrm{CH}_{2} \mathrm{Cl}_{2}(100 \mathrm{~mL})$, and the solution was put under an atmosphere of argon, and cooled to $0{ }^{\circ} \mathrm{C}$. Oxalyl chloride $(10.5 \mathrm{~mL}, 120 \mathrm{mmol}$, 2.0 equiv.) was added, followed by DMF (one drop). The reaction mixture was kept under a flow of argon and stirred at room temperature. When the evolution of gas stopped (ca. $2 \mathrm{~h}$ ), the mixture was concentrated in vacuo $\left(10-15^{\circ} \mathrm{C}, 180 \mathrm{mbar}\right)$.

The residue was dissolved in anhydrous $\mathrm{CH}_{2} \mathrm{Cl}_{2}(40 \mathrm{~mL})$, and the solution was cooled to $-70^{\circ} \mathrm{C}$. A solution of $N, O$-dimethylhydroxylamine (12.3 mL, $168 \mathrm{mmol}, 2.8$ equiv.) in anhydrous $\mathrm{CH}_{2} \mathrm{Cl}_{2}$ $(30 \mathrm{~mL})$ was slowly added to the acyl chloride solution at $-70^{\circ} \mathrm{C}$.
The stirred mixture was allowed to reach room temperature over $2 \mathrm{~h}$. The reaction mixture was then stirred at room temperature for $30 \mathrm{~min}$. The solids were removed by filtration through a Whatmann paper, and washed with $\mathrm{CH}_{2} \mathrm{Cl}_{2}$. The filtrate was concentrated in vacuo, and resulting residue was purified by column chromatography $(10-40 \%$ EtOAc in petroleum ether) to give a mixture of $\left[1,2-{ }^{13} \mathrm{C}_{2}\right]$-2-bromo- $N$-methoxy- $N$-methylacetamide and $\left[1,2-{ }^{13} \mathrm{C}_{2}\right]-$ 2-chloro- $N$-methoxy- $N$-methylacetamide (4:1 ratio, as determined by ${ }^{1} \mathrm{H}$ and ${ }^{13} \mathrm{C}$ NMR spectroscopy) (10.25 g, $\left.58.3 \mathrm{mmol}, 97 \%\right)$ as a colourless oil. $R_{\mathrm{f}}=0.35$ (30\% EtOAc in petroleum ether).

Data for $\left[1,2-{ }^{13} \mathrm{C}_{2}\right]$-2-Bromo- $N$-methoxy- $N$-methyl-acetamide: ${ }^{1} \mathrm{H}$ NMR (400 MHz, $\left.\mathrm{CDCl}_{3}\right): \delta=4.01(\mathrm{dd}, J=154.0,3.6 \mathrm{~Hz}, 2 \mathrm{H})$, $3.80(\mathrm{~s}, 3 \mathrm{H}), 3.24(\mathrm{~s}, 3 \mathrm{H}) \mathrm{ppm} .{ }^{13} \mathrm{C} \mathrm{NMR}\left(101 \mathrm{MHz}, \mathrm{CDCl}_{3}\right): \delta$ $=167.5(\mathrm{~d}, J=58.5 \mathrm{~Hz}), 61.6,32.5,25.1(\mathrm{~d}, J=58.4 \mathrm{~Hz}) \mathrm{ppm}$. HRMS: calcd for $\left[\mathrm{C}_{2}{ }^{13} \mathrm{C}_{2} \mathrm{H}_{8} \mathrm{NO}_{2} \mathrm{Br}+\mathrm{H}\right]^{+}$183.9878; found 183.9877 .

Data for $\left[1,2-{ }^{13} \mathrm{C}_{2}\right]$-2-Chloro- $N$-methoxy- $N$-methylacetamide: ${ }^{1} \mathrm{H}$ NMR (400 MHz, $\left.\mathrm{CDCl}_{3}\right): \delta=4.25(\mathrm{dd}, J=152.3,4.4 \mathrm{~Hz}, 2 \mathrm{H})$, $3.76(\mathrm{~s}, 3 \mathrm{H}), 3.24(\mathrm{~s}, 3 \mathrm{H}) \mathrm{ppm} .{ }^{13} \mathrm{C} \mathrm{NMR}\left(101 \mathrm{MHz}, \mathrm{CDCl}_{3}\right): \delta$ $=167.5(\mathrm{~d}, J=57.2 \mathrm{~Hz}), 61.6,40.7(\mathrm{~d}, J=57.7 \mathrm{~Hz}), 32.5 \mathrm{ppm}$. HRMS: calcd. for $\left[\mathrm{C}_{2}{ }^{13} \mathrm{C}_{2} \mathrm{H}_{8} \mathrm{NO}_{2} \mathrm{Cl}+\mathrm{H}\right]^{+}$140.0383; found 140.0381

Diethyl-([1,2- $\left.{ }^{13} \mathrm{C}_{2}\right]-\mathrm{N}$-methoxy- $\mathrm{N}$-methylcarbamoylmethyl) Phosphonate (12): $\left[1,2-{ }^{13} \mathrm{C}_{2}\right]-2$-Bromo/chloro- $N$-methoxy- $N$-methylacetamide (11; $10.25 \mathrm{~g}, 58.3 \mathrm{mmol}, 1.0$ equiv.) and triethylphosphite ( $10.5 \mathrm{~mL}, 60 \mathrm{mmol}, 1.05$ equiv.) were put in a round-bottomed flask equipped with a $15 \mathrm{~cm}$ air-cooled condenser, and the mixture was heated for $3 \mathrm{~h}$ at $150{ }^{\circ} \mathrm{C}$. The crude mixture was cooled down, and directly purified by column chromatography (30-50\% acetone in petroleum ether) to give compound $12(13.7 \mathrm{~g}, 56.8 \mathrm{mmol}, 95 \%)$ as a colourless oil. $R_{\mathrm{f}}=0.20(40 \%$ acetone in petroleum ether $) .{ }^{1} \mathrm{H}$ NMR (400 MHz, $\left.\mathrm{CDCl}_{3}\right): \delta=4.24-13(\mathrm{~m}, 4 \mathrm{H}), 3.79(\mathrm{~s}, 3 \mathrm{H})$, $3.22(\mathrm{~s}, 3 \mathrm{H}), 3.16(\mathrm{ddd}, J=129.8,21.9,6.6 \mathrm{~Hz}, 2 \mathrm{H}), 1.35(\mathrm{t}, J=$ $7.1 \mathrm{~Hz}, 6 \mathrm{H}) \mathrm{ppm} .{ }^{13} \mathrm{C} \mathrm{NMR}\left(101 \mathrm{MHz}, \mathrm{CDCl}_{3}\right): \delta=165.5(\mathrm{dd}, J$ $=53.1,4.5 \mathrm{~Hz}), 62.0,61.9,60.9,31.57,30.9(\mathrm{dd}, J=136.1$, 53.1 Hz), 15.82, $15.76 \mathrm{ppm}$. IR (neat): $\tilde{\mathrm{v}}=2984,1658,1423,1381$, 1253, 1018, 961, $789 \mathrm{~cm}^{-1}$. HRMS: calcd. for $\left[\mathrm{C}_{6}{ }^{13} \mathrm{C}_{2} \mathrm{H}_{18} \mathrm{NO}_{5} \mathrm{P}+\right.$ $\mathrm{H}]^{+}$242.1063; found 242.1064.

[1-13 $\mathbf{C}_{1}$-Decanitrile (14): $\quad\left[{ }^{13} \mathrm{C}_{1}\right]$-Potassium cyanide $\quad(5.00 \mathrm{~g}$, $76.0 \mathrm{mmol}, 1.0$ equiv.) was added to a solution of 1-bromononane (13; $16.5 \mathrm{~g}, 79.0 \mathrm{mmol}, 1.05$ equiv.) in a mixture of ethanol and water $(9: 1 ; 140 \mathrm{~mL})$, and the reaction mixture was heated overnight at $80^{\circ} \mathrm{C}$. The mixture was then cooled to room temperature, diluted with $\mathrm{Et}_{2} \mathrm{O}(500 \mathrm{~mL})$, and washed with water $(2 \times 500 \mathrm{~mL})$ and brine $(400 \mathrm{~mL})$. The aqueous layers were extracted with $\mathrm{Et}_{2} \mathrm{O}$ $(400 \mathrm{~mL})$, and the combined organic extracts were dried $\left(\mathrm{Na}_{2} \mathrm{SO}_{4}\right)$, filtered, and concentrated in vacuo. Purification by column chromatography (0-2\% EtOAc in petroleum ether) gave compound $14(11.1 \mathrm{~g}, 72.0 \mathrm{mmol}, 95 \%)$ as a colourless oil. $R_{\mathrm{f}}=0.23(3 \%$ EtOAc in petroleum ether). ${ }^{1} \mathrm{H} \mathrm{NMR}\left(400 \mathrm{MHz}, \mathrm{CDCl}_{3}\right): \delta=2.33$ (dt, $J=9.6,7.1 \mathrm{~Hz}, 2 \mathrm{H}), 1.65$ (m, $2 \mathrm{H}), 1.44$ (m, $2 \mathrm{H}), 1.35-1.22$ $(\mathrm{m}, 10 \mathrm{H}), 0.88(\mathrm{t}, J=6.9 \mathrm{~Hz}, 3 \mathrm{H}) \mathrm{ppm} .{ }^{13} \mathrm{C} \mathrm{NMR}(101 \mathrm{MHz}$, $\left.\mathrm{CDCl}_{3}\right): \delta=119.8,31.7,29.2,29.1,28.7,28.5(\mathrm{~d}, J=3.3 \mathrm{~Hz}), 25.3$ (d, $J=0.4 \mathrm{~Hz}), 22.5,17.0$ (d, $J=55.8 \mathrm{~Hz}), 14.0 \mathrm{ppm}$. IR (neat): $\tilde{v}$ =2925, 2856, 2194, 1467, 1425, 1378, $721 \mathrm{~cm}^{-1}$. HRMS: calcd. for $\left[\mathrm{C}_{9}{ }^{13} \mathrm{CH}_{19} \mathrm{~N}+\mathrm{H}\right]^{+}$155.2623; found 155.2624.

[1-13 $\mathbf{C}_{1}$--Decanal (15): $\left[1-{ }^{13} \mathrm{C}_{1}\right]$-Decanitrile $(\mathbf{1 4} ; 11.1 \mathrm{~g}, 72.0 \mathrm{mmol}$, 1.0 equiv.) was dissolved in anhydrous THF $(250 \mathrm{~mL})$, and the solution was cooled to $0{ }^{\circ} \mathrm{C}$. Then DIBAL-H $(1.5 \mathrm{M}$ in hexanes; $52.9 \mathrm{~mL}, 79.0 \mathrm{mmol}, 1.1$ equiv.) was added, and the reaction mixture was stirred at ambient temperature for $2.5 \mathrm{~h}$. The mixture was then transferred to an extraction funnel, diluted with $\mathrm{Et}_{2} \mathrm{O}$ 
(200 mL), and washed with $\mathrm{HCl}(1 \mathrm{~m}$ aq.; $2 \times 400 \mathrm{~mL})$, and satd. aq. $\mathrm{NaHCO}_{3}(400 \mathrm{~mL})$. The aqueous layers were extracted with $\mathrm{Et}_{2} \mathrm{O}(2 \times 400 \mathrm{~mL})$, and the combined organic extracts were dried $\left(\mathrm{MgSO}_{4}\right)$, filtered through Celite, and concentrated in vacuo. Purification by column chromatography $\left(0-10 \% \mathrm{CH}_{2} \mathrm{Cl}_{2}\right.$ in petroleum ether) gave compound $15(10.4 \mathrm{~g}, 66.1 \mathrm{mmol}, 92 \%)$ as a colourless oil. $R_{\mathrm{f}}=0.22\left(20 \% \mathrm{CH}_{2} \mathrm{Cl}_{2}\right.$ in petroleum ether $) .{ }^{1} \mathrm{H} \mathrm{NMR}$ $\left(400 \mathrm{MHz}, \mathrm{CDCl}_{3}\right): \delta=9.76(\mathrm{dt}, J=169.8,1.9 \mathrm{~Hz}, 1 \mathrm{H}), 2.42(\mathrm{dtd}$, $J=7.4,6.2,1.8 \mathrm{~Hz}, 2 \mathrm{H}), 1.62(\mathrm{~m}, 2 \mathrm{H}), 1.36-1.23(\mathrm{~m}, 12 \mathrm{H}), 0.88$ (t, $J=6.9 \mathrm{~Hz}, 3 \mathrm{H}) \mathrm{ppm} .{ }^{13} \mathrm{C} \mathrm{NMR}\left(101 \mathrm{MHz}, \mathrm{CDCl}_{3}\right): \delta=203.0$, 43.9 (d, $J=38.8 \mathrm{~Hz}), 31.8,29.35,29.32,29.2,29.1$ (d, $J=3.4 \mathrm{~Hz})$, 22.6, 22.0 (d, $J=1.6 \mathrm{~Hz}$ ), $14.0 \mathrm{ppm}$. IR (neat): $\tilde{v}=2922,2855$, $1728,1466,719 \mathrm{~cm}^{-1}$.

[1,2,3-13 $\left.\mathrm{C}_{3}\right]-(E / Z)-N$-Methoxy- $N$-methyldodec-2-enamide (16): Diethyl $\left(\left[1,2-{ }^{13} \mathrm{C}_{2}\right]-N\right.$-methoxy- $N$-methylcarbamoylmethyl)phosphonate $(12 ; 10.4 \mathrm{~g}, 43.1 \mathrm{mmol}, 1.1$ equiv.) was dissolved in dry THF $(200 \mathrm{~mL})$, and the solution was cooled to $0{ }^{\circ} \mathrm{C}$. Then $n$-butyllithium ( $1.6 \mathrm{~m}$ in hexanes; $26.5 \mathrm{~mL}, 42.3 \mathrm{mmol}, 1.08$ equiv.) was added, and the reaction mixture was stirred for $10 \mathrm{~min}$ at $0{ }^{\circ} \mathrm{C}$. A solution of [1- $\left.{ }^{13} \mathrm{C}_{1}\right]$-decanal $(\mathbf{1 5} ; 6.16 \mathrm{~g}, 39.2 \mathrm{mmol}, 1.0$ equiv.) in anhydrous THF $(40 \mathrm{~mL})$ was then added to the phosphonate carbanion solution, and the reaction mixture was stirred at room temperature overnight. The mixture was then transferred to an extraction funnel with $\mathrm{Et}_{2} \mathrm{O}(50 \mathrm{~mL})$, and washed with water $(250 \mathrm{~mL})$ and brine $(200 \mathrm{~mL})$. The aqueous layers were extracted with $\mathrm{Et}_{2} \mathrm{O}(2 \times$ $250 \mathrm{~mL})$, and the combined organic extracts were dried $\left(\mathrm{Na}_{2} \mathrm{SO}_{4}\right)$, filtered, and concentrated in vacuo. Purification by column chromatography $(0-15 \%$ EtOAc in petroleum ether) gave [1,2,3$\left.{ }^{13} \mathrm{C}_{3}\right]$ - $(E)$ - $N$-methoxy- $N$-methyldodec-2-enamide $\quad(\mathbf{1 6 E} ; \quad 7.52 \mathrm{~g}$, $30.8 \mathrm{mmol}, 79 \%)$ and $\left[1,2,3-{ }^{13} \mathrm{C}_{3}\right]-(Z)-N$-methoxy- $N$-methyldodec2-enamide (16Z; $0.75 \mathrm{mg}, 3.07 \mathrm{mmol}, 8 \%)$ as a colourless oil (combined yield $87 \%$ ).

Data for $E$ isomer 16E: $R_{\mathrm{f}}=0.42(20 \%$ EtOAc in petroleum ether). ${ }^{1} \mathrm{H}$ NMR $\left(400 \mathrm{MHz}, \mathrm{CDCl}_{3}\right): \delta=6.98(\mathrm{dm}, J=153.8 \mathrm{~Hz}, 1 \mathrm{H})$, 6.38 (ddd, $J=160.8,15.4,4.1 \mathrm{~Hz}, 1 \mathrm{H}), 3.70(\mathrm{~s}, 3 \mathrm{H}), 3.24$ (s, 3 H), 2.23 (m, 2 H), 1.46 (m, 2 H), 1.35-1.23 (m, $12 \mathrm{H}), 0.88$ (t, $J=$ $6.8 \mathrm{~Hz}, 3 \mathrm{H}) \mathrm{ppm} .{ }^{13} \mathrm{C} \mathrm{NMR}\left(101 \mathrm{MHz}, \mathrm{CDCl}_{3}\right): \delta=167.1(\mathrm{~d}, J$ $=67.1 \mathrm{~Hz}), 148.0(\mathrm{~d}, J=71.6 \mathrm{~Hz}), 118.5(\mathrm{dd}, J=71.6,67.1 \mathrm{~Hz})$, 61.6, $32.5(\mathrm{~m}), 32.3(\mathrm{~m}), 31.9,29.5,29.4,29.3,29.2(\mathrm{~d}, J=3.6 \mathrm{~Hz})$, $28.3(\mathrm{~m}), 22.7,14.1 \mathrm{ppm}$. IR (neat): $\tilde{v}=2926,5856,1622,1584$, 1462, 1368, 1175, $993 \mathrm{~cm}^{-1}$. HRMS: calcd for $\left[\mathrm{C}_{11}{ }^{13} \mathrm{C}_{3} \mathrm{H}_{27} \mathrm{NO}_{2} \mathrm{H}\right]^{+}$ 245.2215; found 245.2216 .

Data for $Z$ isomer 16Z: $R_{\mathrm{f}}=0.64$ (20\% EtOAc in petroleum ether). ${ }^{1} \mathrm{H}$ NMR $\left(400 \mathrm{MHz}, \mathrm{CDCl}_{3}\right): \delta=6.22(\mathrm{dd}, J=161.8,11.5 \mathrm{~Hz}, 1$ $\mathrm{H}), 6.11(\mathrm{dm}, J=152.0 \mathrm{~Hz}, 1 \mathrm{H}), 3.68(\mathrm{~s}, 3 \mathrm{H}), 3.21(\mathrm{~s}, 3 \mathrm{H}), 2.61$ $(\mathrm{m}, 2 \mathrm{H}), 1.43(\mathrm{~m}, 2 \mathrm{H}), 1.35-1.22(\mathrm{~m}, 12 \mathrm{H}), 0.88(\mathrm{t}, J=6.9 \mathrm{~Hz}$, $3 \mathrm{H}) \mathrm{ppm} .{ }^{13} \mathrm{C}$ NMR $\left(101 \mathrm{MHz}, \mathrm{CDCl}_{3}\right): \delta=167.6(\mathrm{~d}, J=$ $63.6 \mathrm{~Hz}), 147.8(\mathrm{~d}, J=67.1 \mathrm{~Hz}), 117.9(\mathrm{dd}, J=67.1,63.6 \mathrm{~Hz}), 61.5$, $31.9,31.6,29.6,29.5,29.38(\mathrm{~d}, J=4.0 \mathrm{~Hz}), 29.35-29.29(\mathrm{~m}), 29.1$ (m), 22.7, $14.1 \mathrm{ppm}$. IR (neat): $\tilde{\mathrm{v}}=2925,2855,1618,1459,1334$, 1178, 996, $776 \mathrm{~cm}^{-1}$. HRMS: calcd. for $\left[\mathrm{C}_{11}{ }^{13} \mathrm{C}_{3} \mathrm{H}_{27} \mathrm{NO}_{2}+\mathrm{H}\right]^{+}$ 245.2215; found 245.2216 .

[1,2,3- $\left.{ }^{13} \mathrm{C}_{3}\right]-N$-Methoxy- $N$-methyldodecanamide (17): $\left[1,2,3-{ }^{13} \mathrm{C}_{3}\right]-$ (E/Z)- $N$-Methoxy- $N$-methyldodec-2-enamide $\quad(\mathbf{1 6 E} / Z ; \quad 8.25 \mathrm{~g}$, $33.8 \mathrm{mmol}, 1.0$ equiv.) was dissolved in EtOAc $(200 \mathrm{~mL})$. The solution was bubbled with argon while stirring, and palladium $(10 \%$ on charcoal; $0.72 \mathrm{~g}, 0.67 \mathrm{mmol}, 0.02$ equiv.) was added. The reaction mixture was then stirred under a flow of hydrogen gas for $30 \mathrm{~min}$, and left overnight under a hydrogen atmosphere. The palladium was removed by filtration through a Whatmann paper, and rinsed with EtOAc $(100 \mathrm{~mL})$. The solvent was removed from the filtrate in vacuo. Purification by column chromatography (5-20\% EtOAc in petroleum ether) gave compound 17 (6.85 g, $27.8 \mathrm{mmol}, 82 \%)$ as a colourless oil. $R_{\mathrm{f}}=0.38(20 \%$ EtOAc in petroleum ether $) .{ }^{1} \mathrm{H}$ NMR (400 MHz, $\mathrm{CDCl}_{3}$ ): $\delta=3.68$ (s, $\left.3 \mathrm{H}\right), 3.18$ (s, $\left.3 \mathrm{H}\right), 2.41(\mathrm{dm}$, $J=127.3 \mathrm{~Hz}, 2 \mathrm{H}), 1.62(\mathrm{dm}, J=127.9 \mathrm{~Hz}, 2 \mathrm{H}), 1.35-1.23(\mathrm{~m}$, $16 \mathrm{H}), 0.88(\mathrm{t}, J=6.8 \mathrm{~Hz}, 3 \mathrm{H}) \mathrm{ppm} .{ }^{13} \mathrm{C} \mathrm{NMR}\left(101 \mathrm{MHz}, \mathrm{CDCl}_{3}\right)$ : $\delta=174.6$ (br. d, $J=51.5 \mathrm{~Hz}), 61.1,31.9,31.8(\mathrm{dd}, J=51.5$, $37.5 \mathrm{~Hz}), 29.7-29.1(\mathrm{~m}), 24.6$ (dd, $J=34.9,1.3 \mathrm{~Hz}), 22.6,14.1 \mathrm{ppm}$. IR (neat): $\tilde{v}=2923,2854,1627,1464,1369,1174,1119,998,722$, $436 \mathrm{~cm}^{-1}$. HRMS: calcd. for $\left[\mathrm{C}_{11}{ }^{13} \mathrm{C}_{3} \mathrm{H}_{29} \mathrm{NO}_{2}+\mathrm{H}\right]^{+}$247.2372; found 247.2373 .

$\left[1,2,3,4,5-{ }^{13} C_{5}\right]-(E / Z)-N$-Methoxy- $N$-methyltetradec-2-enamide (18): $\left[1,2,3-{ }^{13} \mathrm{C}_{3}\right]-N$-Methoxy- $N$-methyldodecanamide $(17 ; 3.91 \mathrm{~g}$, $15.9 \mathrm{mmol}, 1.0$ equiv.) was dissolved in anhydrous THF $(120 \mathrm{~mL})$, and the solution was cooled to $0{ }^{\circ} \mathrm{C}$. Then lithium aluminium hydride ( $4.0 \mathrm{M}$ in THF; $2.38 \mathrm{~mL}, 9.52 \mathrm{mmol}, 0.6$ equiv.) was added. The reaction mixture was stirred for $45 \mathrm{~min}$, and then it was cooled to $-15^{\circ} \mathrm{C}$. Sat. aq. $\mathrm{KHSO}_{4}(100 \mathrm{~mL})$ and $\mathrm{Et}_{2} \mathrm{O}(300 \mathrm{~mL})$ were added. The two-phase system was stirred vigorously for $30 \mathrm{~min}$, then the phases were separated, and the organic phase was then dried with $\mathrm{MgSO}_{4}$, followed by $\mathrm{Na}_{2} \mathrm{SO}_{4}$. The solids were filtered and washed with $\mathrm{Et}_{2} \mathrm{O}(200 \mathrm{~mL})$. The filtrate was concentrated in vacuo to give crude $\left[1,2,3-{ }^{13} \mathrm{C}_{3}\right]$-dodecanal $(2.96 \mathrm{~g}, 15.8 \mathrm{mmol})$ as a colourless oil, which was used without further purification.

Diethyl ( $N$-methoxy- $N$-methylcarbamoylmethyl)phosphonate (12; $4.20 \mathrm{~g}, 17.4 \mathrm{mmol}, 1.1$ equiv.) was dissolved in anhydrous THF $(80 \mathrm{~mL})$, and the solution was cooled to $0{ }^{\circ} \mathrm{C}$. $n$-Butyllithium $(1.6 \mathrm{M}$ in hexanes; $10.4 \mathrm{~mL}, 16.6 \mathrm{mmol}, 1.05$ equiv.) was added, and the reaction mixture was stirred for $10 \mathrm{~min}$ at $0{ }^{\circ} \mathrm{C}$. The crude $[1,2,3-$ ${ }^{13} \mathrm{C}_{3}$ ]-dodecanal was dissolved in anhydrous THF $(20 \mathrm{~mL})$, and the resulting solution was added to the Horner-Wadsworth-Emmons reagent at $0{ }^{\circ} \mathrm{C}$. The reaction mixture was then stirred at room temperature overnight. The mixture was transferred to an extraction funnel with $\mathrm{Et}_{2} \mathrm{O}(50 \mathrm{~mL})$, and washed with water $(100 \mathrm{~mL})$ and brine $(100 \mathrm{~mL})$. The aqueous layers were extracted with $\mathrm{Et}_{2} \mathrm{O}(2 \times$ $100 \mathrm{~mL})$ and the combined organic extracts were dried $\left(\mathrm{Na}_{2} \mathrm{SO}_{4}\right)$, filtered, and concentrated in vacuo. Purification by column chromatography $(5-15 \%$ EtOAc in petroleum ether) gave $[1,2,3,4,5-$ $\left.{ }^{13} \mathrm{C}_{5}\right]$ - $(E)$ - $N$-methoxy- $N$-methyl-tetradec-2-enamide $(\mathbf{1 8 E} E ; 3.05 \mathrm{~g}$, $11.1 \mathrm{mmol}, 70 \%)$ and $\left[1,2,3,4,5-{ }^{13} \mathrm{C}_{5}\right]-(Z)-N$-methoxy- $N$-methyltetradec-2-enamide $(\mathbf{1 8 Z} ; 310 \mathrm{mg}, 1.13 \mathrm{mmol}, \mathbf{7} \%)$ as colourless oils (combined yield $77 \%$ ).

Data for $E$ isomer 18E: $R_{\mathrm{f}}=0.39(15 \%$ EtOAc in petroleum ether). ${ }^{1} \mathrm{H}$ NMR $\left(600 \mathrm{MHz}, \mathrm{CDCl}_{3}\right): \delta=6.98(\mathrm{dm}, J=153.8 \mathrm{~Hz}, 1 \mathrm{H})$, 6.39 (ddm, $J=161.1,15.4 \mathrm{~Hz}, 1 \mathrm{H}), 3.70(\mathrm{~s}, 3 \mathrm{H}), 3.24(\mathrm{~s}, 3 \mathrm{H})$, 2.23 (ddt, $J=126.2,7.0,6.1 \mathrm{~Hz}, 2 \mathrm{H}), 1.60-1.20$ (m, $18 \mathrm{H}), 0.88$ (t, $J=7.0 \mathrm{~Hz}, 3 \mathrm{H}) \mathrm{ppm} .{ }^{13} \mathrm{C} \mathrm{NMR}\left(151 \mathrm{MHz}, \mathrm{CDCl}_{3}\right): \delta=167.1$ $(\mathrm{dd}, J=67.1,6.1 \mathrm{~Hz}), 148.0(\mathrm{ddd}, J=71.6,41.8,2.1 \mathrm{~Hz}), 118.6$ (dddd, $J=71.6,67.1,3.6,1.5 \mathrm{~Hz}), 61.6,32.5$ (dddd, $J=41.8,33.7$, 6.1, $1.5 \mathrm{~Hz}$ ), 32.3, 31.9, 29.6-29.0 (m), 28.3 (ddd, $J=33.7,3.6$, $2.1 \mathrm{~Hz}), 22.7,14.1 \mathrm{ppm}$. IR (neat): $\tilde{v}=2924,2854,1618,1583$, 1464, 1368, $991 \mathrm{~cm}^{-1}$. HRMS: calcd for $\left[\mathrm{C}_{11}{ }^{13} \mathrm{C}_{5} \mathrm{H}_{31} \mathrm{NO}_{2}+\mathrm{H}\right]^{+}$ 275.2595; found 275.2595 .

Data for $Z$ isomer 18Z: $R_{\mathrm{f}}=0.58(15 \%$ EtOAc in petroleum ether). ${ }^{1} \mathrm{H} \mathrm{NMR}\left(600 \mathrm{MHz}, \mathrm{CDCl}_{3}\right): \delta=6.23(\mathrm{dm}, J=160.7 \mathrm{~Hz}, 1 \mathrm{H})$, $6.12(\mathrm{dm}, J=152.0 \mathrm{~Hz}, 1 \mathrm{H}), 3.68(\mathrm{~s}, 3 \mathrm{H}), 3.21(\mathrm{~s}, 3 \mathrm{H}), 2.62(\mathrm{dm}$, $J=125.3 \mathrm{~Hz}, 2 \mathrm{H}), 1.59-1.20(\mathrm{~m}, 18 \mathrm{H}), 0.88(\mathrm{t}, J=7.1 \mathrm{~Hz}, 3 \mathrm{H})$ ppm. ${ }^{13} \mathrm{C} \mathrm{NMR}\left(151 \mathrm{MHz}, \mathrm{CDCl}_{3}\right): \delta=167.6(\mathrm{dm}, J=67.1 \mathrm{~Hz})$, 147.8 (dd, $J=69.9,35.2 \mathrm{~Hz}), 117.9$ (dd, $J=69.9,67.1 \mathrm{~Hz}), 61.4$, $32.0,31.9,30.2-28.4$ (m), 22.7, 14.1 ppm. IR (neat): $\tilde{v}=2923,2854$, 1618, 1464, 1331, 1176, 1086, 999, $775 \mathrm{~cm}^{-1}$. HRMS: calcd. for $\left[\mathrm{C}_{11}{ }^{13} \mathrm{C}_{5} \mathrm{H}_{31} \mathrm{NO}_{2}+\mathrm{H}\right]^{+}$275.2595; found 275.2595. 
$\left[1,2,3,4,5-{ }^{13} \mathrm{C}_{5}\right]-N$-Methoxy- $N$-methyltetradecanamide (19): $\left[1,2,3,4,5-{ }^{13} \mathrm{C}_{5}\right]-(E / Z)-N$-Methoxy- $N$-methyl-tetradec-2-enamide $(\mathbf{1 8 E} / Z ; 3.20 \mathrm{~g}, 11.66 \mathrm{mmol}, 1.0$ equiv.) was dissolved in EtOAc $(100 \mathrm{~mL})$. The solution was bubbled with argon while stirring, and then palladium ( $10 \%$ on charcoal; $0.62 \mathrm{~g}, 0.58 \mathrm{mmol}, 0.05$ equiv.) was added. The reaction mixture was then stirred under a flow of hydrogen gas for $30 \mathrm{~min}$, and was then left overnight under a hydrogen atmosphere. The palladium residue was removed by filtration through a Whatmann paper, and rinsed with EtOAc $(100 \mathrm{~mL})$. The solvent was removed from the filtrate in vacuo. Purification by column chromatography $(5-15 \%$ EtOAc in petroleum ether) gave compound $19(3.00 \mathrm{~g}, 10.85 \mathrm{mmol}, 93 \%)$ as a colourless oil. $R_{\mathrm{f}}=0.38(15 \%$ EtOAc in petroleum ether $) .{ }^{1} \mathrm{H}$ NMR $\left(600 \mathrm{MHz}, \mathrm{CDCl}_{3}\right): \delta=3.68(\mathrm{~s}, 3 \mathrm{H}), 3.18(\mathrm{~s}, 3 \mathrm{H}), 2.41(\mathrm{dm}, J=$ $128.4 \mathrm{~Hz}, 2 \mathrm{H}), 1.62(\mathrm{dm}, J=127.1 \mathrm{~Hz}, 2 \mathrm{H}), 1.46-1.12(\mathrm{~m}, 20 \mathrm{H})$, $0.88(\mathrm{t}, J=7.1 \mathrm{~Hz}, 3 \mathrm{H}) \mathrm{ppm} .{ }^{13} \mathrm{C} \mathrm{NMR}\left(151 \mathrm{MHz}, \mathrm{CDCl}_{3}\right): \delta=$ $174.8(\mathrm{dm}, J=51.5 \mathrm{~Hz}), 61.1,32.1,31.9(\mathrm{dd}, J=51.5,35.6 \mathrm{~Hz})$, 29.7-29.1 (m), $24.6(\mathrm{~m}), 22.6,14.1 \mathrm{ppm}$. IR (neat): $\tilde{v}=2922,2853$, $1628,1458,1370,1175,996,721 \mathrm{~cm}^{-1}$. HRMS: calcd. for $\left[\mathrm{C}_{11}{ }^{13} \mathrm{C}_{5} \mathrm{H}_{33} \mathrm{NO}_{2}+\mathrm{H}\right]^{+}$277.2751; found 277.2752.

[2,3,4,5,6- ${ }^{13} \mathbf{C}_{5}$-Pentadec-1-ene (20): $\left[1,2,3,4,5-{ }^{13} \mathrm{C}_{5}\right]-N$-Methoxy- $N$ methyltetradecanamide $(\mathbf{1 9} ; 1.57 \mathrm{~g}, 5.72 \mathrm{mmol}, 1.0$ equiv. $)$ was dissolved in anhydrous THF ( $55 \mathrm{~mL})$, and $\mathrm{LiAlH}_{4}$ (4 $\mathrm{M}$ in THF; $0.86 \mathrm{~mL}, 3.43 \mathrm{mmol}, 0.6$ equiv.) was added at $0{ }^{\circ} \mathrm{C}$. The reaction mixture was stirred for $45 \mathrm{~min}$, and then it was cooled to ca. $-15^{\circ} \mathrm{C}$, and satd. aq. $\mathrm{KHSO}_{4}(40 \mathrm{~mL})$ and $\mathrm{Et}_{2} \mathrm{O}(100 \mathrm{~mL})$ were added. The resulting two-phase mixture was stirred vigorously for $30 \mathrm{~min}$, then the phases were separated, and the organic phase dried with $\mathrm{MgSO}_{4}$, and then $\mathrm{Na}_{2} \mathrm{SO}_{4}$. The solids were removed by filtration, and washed with $\mathrm{Et}_{2} \mathrm{O}(100 \mathrm{~mL})$. The filtrate was concentrated in vacuo to give crude $\left[1,2,3,4,5-{ }^{13} \mathrm{C}_{5}\right]$-tetradecanal $(1.24 \mathrm{~g}$, $5.72 \mathrm{mmol}$ ) as a colourless oil, which was used without further purification.

Methyltriphenylphosphonium bromide $(3.06 \mathrm{~g}, 8.58 \mathrm{mmol}$, 1.5 equiv.) was suspended in anhydrous THF $(150 \mathrm{~mL})$, and $n$-butyllithium (1.6 $\mathrm{m}$ in hexanes; $4.65 \mathrm{~mL}, 7.44 \mathrm{mmol}, 1.3$ equiv.) was added at $0{ }^{\circ} \mathrm{C}$. The reaction mixture was then stirred for $10 \mathrm{~min}$ at $0{ }^{\circ} \mathrm{C}$. The crude $\left[1,2,3,4,5-{ }^{13} \mathrm{C}_{5}\right]$-tetradecanal was dissolved in anhydrous THF $(20 \mathrm{~mL})$, and this solution was then added to the phosphorylide at $0{ }^{\circ} \mathrm{C}$. The reaction mixture was stirred overnight at room temperature, and then transferred to an extraction funnel using $\mathrm{Et}_{2} \mathrm{O}(100 \mathrm{~mL})$. The reaction mixture was washed with water $(2 \times 200 \mathrm{~mL})$ and brine $(200 \mathrm{~mL})$. The aqueous phases were extracted with $\mathrm{Et}_{2} \mathrm{O}(200 \mathrm{~mL})$, and the combined organic extracts were dried $\left(\mathrm{Na}_{2} \mathrm{SO}_{4}\right)$, filtered, and concentrated in vacuo. Purification by column chromatography ( $100 \%$ petroleum ether) gave compound $20(1.15 \mathrm{~g}, 5.34 \mathrm{mmol}, 93 \%)$ as a colourless oil. $R_{\mathrm{f}}=0.98$ (100\% petroleum ether). ${ }^{1} \mathrm{H}$ NMR $\left(400 \mathrm{MHz}, \mathrm{CDCl}_{3}\right): \delta=5.81$ $(\mathrm{dm}, J=150.3 \mathrm{~Hz}, 1 \mathrm{H}), 4.99(\mathrm{dd}, J=17.1,6.5 \mathrm{~Hz}, 1 \mathrm{H}), 4.92(\mathrm{t}$, $J=10.8 \mathrm{~Hz}, 1 \mathrm{H}), 2.03(\mathrm{dm}, J=125.4 \mathrm{~Hz}, 2 \mathrm{H}), 1.57-1.11(\mathrm{~m}, 22$ $\mathrm{H}), 0.88(\mathrm{t}, J=6.8 \mathrm{~Hz}, 3 \mathrm{H}) \mathrm{ppm} .{ }^{13} \mathrm{C}$ NMR $\left(101 \mathrm{MHz}, \mathrm{CDCl}_{3}\right)$ : $\delta=139.2(\mathrm{dm}, J=42.1 \mathrm{~Hz}), 114.0(\mathrm{dd}, J=69.1,3.1 \mathrm{~Hz}), 33.9(\mathrm{~m})$, $32.0,29.9-28.6(\mathrm{~m}), 22.7,14.1 \mathrm{ppm}$. IR (neat): $\tilde{v}=2922,2853$, $1628,1458,1370,1175,1117,996,721 \mathrm{~cm}^{-1}$.

(E)-1,2-O, $N$-Isopropylidene- $N$-(tert-butoxycarbonyl)-D-erythrosphingosine (22a): (2S,3R)-2-Amino- $N$-(tert-butyloxycarbonyl)-1,3dihydroxy-1,2- $O, N$-isopropylidene-4-pentene $(21 ; 1 \mathrm{~g}, 4.0 \mathrm{mmol}$, 1.0 equiv.) and pentadec- 1 -ene $(1.70 \mathrm{~g}, 8.0 \mathrm{mmol}, 2.0$ equiv.) were dissolved in anhydrous $\mathrm{CH}_{2} \mathrm{Cl}_{2}(4 \mathrm{~mL})$, and the flask was flushed with argon. Grubbs $2^{\text {nd }}$ generation catalyst $(67 \mathrm{mg}, 79 \mu \mathrm{mol}$, 0.02 equiv.) and acetic acid $(45 \mu \mathrm{L}, 0.79 \mathrm{mmol}, 0.2$ equiv. $)$ were added. The reaction mixture was heated at reflux under a flow of argon for $36 \mathrm{~h}$. The reaction mixture was concentrated in vacuo, and the residue was purified by column chromatography $(0-10 \%$ EtOAc in petroleum ether) to give compound 22a $(1.30 \mathrm{~g}$, $2.96 \mathrm{mmol}, 74 \%)$ as a viscous oil. $R_{\mathrm{f}}=0.19(10 \%$ EtOAc in petroleum ether $) .[\alpha]_{\mathrm{D}}^{22}=-26\left(c=0.25, \mathrm{CHCl}_{3}\right) .{ }^{1} \mathrm{H}$ NMR $(400 \mathrm{MHz}$, [D $\left.\left.\mathrm{D}_{6}\right] \mathrm{DMSO}, 363 \mathrm{~K}\right): \delta=5.56(\mathrm{dt}, J=15.8,6.5 \mathrm{~Hz}, 1 \mathrm{H}), 5.45$ (ddd, $J=15.8,6.6,1.1 \mathrm{~Hz}, 1 \mathrm{H}), 4.61$ (br. s, $1 \mathrm{H}), 4.03(\mathrm{~m}, 1 \mathrm{H}), 3.93$ (br. d, $J=8.5 \mathrm{~Hz}, 1 \mathrm{H}), 3.83$ (br. t, $J=7.3 \mathrm{~Hz}, 1 \mathrm{H}), 3.75$ (m, 1 H), 1.98 (m, $2 \mathrm{H}), 1.48(\mathrm{~s}, 3 \mathrm{H}), 1.43(\mathrm{~m}, 12 \mathrm{H}), 1.39-1.20$ (m, 22 $\mathrm{H}), 0.87$ (t, $J=6.6 \mathrm{~Hz}, 3 \mathrm{H}) \mathrm{ppm} .{ }^{13} \mathrm{C} \mathrm{NMR}\left(100 \mathrm{MHz},\left[\mathrm{D}_{6}\right]-\right.$ DMSO, $363 \mathrm{~K}): \delta=151.3,130.8,130.4,92.8$, 78.7, 71.4, 63.7, 61.0, $31.2,30.8,28.5,28.4,28.2,28.12,28.06,27.7,26.2,21.5,13.2 \mathrm{ppm}$. IR (neat): $\tilde{v}=3436,2924,2854,1702,1381,1365,1255,1173,1097$, 848, $766 \mathrm{~cm}^{-1}$. HRMS: calcd. for $\left[\mathrm{C}_{26} \mathrm{H}_{49} \mathrm{NO}_{4}+\mathrm{H}\right]^{+} 440.3734$; found 440.3733 .

(E)-[5,6,7,8,9- $\left.{ }^{13} \mathrm{C}_{5}\right]-1,2-O, N$-Isopropylidene- $N$-(tert-butoxycarbonyl)-D-erythro-sphingosine (22b): $(2 S, 3 R)$-2-Amino- $N$-(tert-butyloxycarbonyl)-1,3-dihydroxy-1,2-O,N-isopropylidene-4-pentene (21; $3.58 \mathrm{~g}, 13.9 \mathrm{mmol}, 3.0$ equiv.) and $\left[2,3,4,5,6-{ }^{13} \mathrm{C}_{5}\right]$-pentadec-1-ene (20; $1.00 \mathrm{~g}, 4.64 \mathrm{mmol}, 1.0$ equiv.) were dissolved in anhydrous $\mathrm{CH}_{2} \mathrm{Cl}_{2}(4 \mathrm{~mL})$, and the flask was flushed with argon. Grubbs $2^{\text {nd }}$ generation catalyst $(79 \mathrm{mg}, 93 \mu \mathrm{mol}, 0.02$ equiv.) and acetic acid ( $53 \mu \mathrm{L}, 0.93 \mathrm{mmol}, 0.2$ equiv.) were added. The reaction mixture was heated at reflux under a flow of argon for $36 \mathrm{~h}$. The reaction mixture was concentrated in vacuo, and the residue was purified by column chromatography $(0-10 \%$ EtOAc in petroleum ether) to give compound 22b $(1.68 \mathrm{~g}, 3.29 \mathrm{mmol}, 81 \%)$ as a viscous oil. $R_{\mathrm{f}}$ $=0.19(10 \%$ EtOAc in petroleum ether $) .[\alpha]_{\mathrm{D}}^{22}=-19(c=0.5$, $\left.\mathrm{CHCl}_{3}\right) .{ }^{1} \mathrm{H}$ NMR (400 MHz, [D 6 DMSO, $\left.363 \mathrm{~K}\right): \delta=5.55(\mathrm{dm}, J$ $=152.0 \mathrm{~Hz}, 1 \mathrm{H}), 5.44(\mathrm{~m}, 1 \mathrm{H}), 4.60($ br. $\mathrm{d}, J=5.4 \mathrm{~Hz}, 1 \mathrm{H}), 4.05$ $(\mathrm{m}, 1 \mathrm{H}), 3.94(\mathrm{dd}, J=8.6,2.0 \mathrm{~Hz}, 1 \mathrm{H}), 3.82(\mathrm{dd}, J=8.6,6.1 \mathrm{~Hz}$, $1 \mathrm{H}), 3.75(\mathrm{td}, J=6.1,2.0 \mathrm{~Hz}, 1 \mathrm{H}), 1.98(\mathrm{dm}, J=124.2 \mathrm{~Hz}, 2 \mathrm{H})$, $1.56-1.06(\mathrm{~m}, 37 \mathrm{H}), 0.87(\mathrm{t}, J=6.9 \mathrm{~Hz}, 3 \mathrm{H}) \mathrm{ppm} .{ }^{1} \mathrm{H} \mathrm{NMR}$ $\left(400 \mathrm{MHz}, \mathrm{CDCl}_{3}\right): \delta=5.74(\mathrm{dm}, J=149.4 \mathrm{~Hz}, 1 \mathrm{H}), 5.45(\mathrm{dd}, J$ $=15.4,6.0 \mathrm{~Hz}, 1 \mathrm{H}), 4.39-3.74(\mathrm{~m}, 5 \mathrm{H}), 2.04(\mathrm{dm}, J=125.2 \mathrm{~Hz}$, $2 \mathrm{H}), 1.72-1.01(\mathrm{~m}, 37 \mathrm{H}), 0.88(\mathrm{t}, J=6.8 \mathrm{~Hz}, 3 \mathrm{H}) \mathrm{ppm} .{ }^{1} \mathrm{H}$ NMR (400 MHz, $\mathrm{CDCl}_{3},{ }^{13} \mathrm{C}$-decoupled): $\delta=5.74(\mathrm{dt}, J=15.4,6.6 \mathrm{~Hz}$, $1 \mathrm{H}), 5.45(\mathrm{dd}, J=15.4,6.4 \mathrm{~Hz}, 1 \mathrm{H}), 4.39-3.74(\mathrm{~m}, 5 \mathrm{H}), 2.04$ (q, $J=7.0 \mathrm{~Hz}, 2 \mathrm{H}), 1.71-1.16(\mathrm{~m}, 37 \mathrm{H}), 0.88(\mathrm{t}, J=6.8 \mathrm{~Hz}, 3 \mathrm{H})$ ppm. ${ }^{13} \mathrm{C}$ NMR $\left(100 \mathrm{MHz},\left[\mathrm{D}_{6}\right.\right.$ ]DMSO, $\left.363 \mathrm{~K}\right): \delta=151.3,130.8$ $(\mathrm{d}, J=42.3 \mathrm{~Hz}), 130.4(\mathrm{~d}, J=73.4 \mathrm{~Hz}), 92.8,78.4,71.4$ (d, $J=$ $5.2 \mathrm{~Hz}), 63.7,61.0(\mathrm{~d}, J=2.7 \mathrm{~Hz}), 31.9-30.5(\mathrm{~m}), 29.7-26.1(\mathrm{~m})$, 21.5, 13.2 ppm. IR (neat): $\tilde{v}=3436,2922,2853,1698,1458,1386$, 1365, 1256, 1173, 1098, 965, 848, $766 \mathrm{~cm}^{-1}$. HRMS: calcd. for $\left[\mathrm{C}_{21}{ }^{13} \mathrm{C}_{5} \mathrm{H}_{49} \mathrm{NO}_{4}+\mathrm{H}\right]^{+}$445.3902; found 445.3902.

3-O-Benzoyl- $N$-(tert-butoxycarbonyl)-D-erythro-sphingosine (23a): (E)-1,2-O, $N$-Isopropylidene- $N$-(tert-butoxycarbonyl)-D-erythrosphingosine (22a; $0.59 \mathrm{~g}, 1.3 \mathrm{mmol}, 1.0$ equiv.) was dissolved in a mixture of pyridine and $\mathrm{CH}_{2} \mathrm{Cl}_{2}(2: 1 ; 10 \mathrm{~mL})$. DMAP $(16 \mathrm{mg}$, $0.13 \mathrm{mmol}, 0.1$ equiv.) was added, followed by benzoyl chloride $(0.23 \mathrm{~mL}, 2.0 \mathrm{mmol}, 1.5$ equiv. $)$. The reaction mixture was stirred overnight, and was then quenched with methanol $(0.5 \mathrm{~mL})$. The mixture was concentrated in vacuo, and the residue was dissolved in EtOAc $(50 \mathrm{~mL})$. The organic phase was washed with $\mathrm{HCl}(1 \mathrm{M}$ aq.; $50 \mathrm{~mL})$, satd. aq. $\mathrm{NaHCO}_{3}(50 \mathrm{~mL})$, and brine $(50 \mathrm{~mL})$. The aqueous layers were extracted with EtOAc $(50 \mathrm{~mL})$, and the combined organic layers were dried $\left(\mathrm{Na}_{2} \mathrm{SO}_{4}\right)$, filtered, and concentrated in vacuo. Purification by column chromatography $(1.5 \%$ EtOAc in petroleum ether) gave 1,2- $O, N$-isopropylidene-3- $O$ benzoyl- $N$-(tert-butyloxycarbonyl)-D-erythro-sphingosine $(0.61 \mathrm{~g}$, $1.1 \mathrm{mmol}, 84 \%)$ as a colourless oil. $R_{\mathrm{f}}=0.82(10 \%$ EtOAc in petroleum ether $) .[a]_{\mathrm{D}}^{22}=-29\left(c=0.66, \mathrm{CHCl}_{3}\right) .{ }^{1} \mathrm{H} \mathrm{NMR}(400 \mathrm{MHz}$, [D $]$ DMSO, $363 \mathrm{~K}): \delta=8.00(\mathrm{dm}, J=7.9 \mathrm{~Hz}, 1 \mathrm{H}), 7.63(\mathrm{~m}, 1 \mathrm{H})$, 
7.55-7.47 (m, $2 \mathrm{H}), 5.82$ (br. s, $1 \mathrm{H}), 5.75$ (dt, $J=15.4,6.5 \mathrm{~Hz}, 1$ H), 5.53 (ddd, $J=15.4,6.2,1.4 \mathrm{~Hz}, 1 \mathrm{H}), 4.09$ (m, 1 H), 4.06-3.97 (m, $2 \mathrm{H}), 2.01(\mathrm{~m}, 2 \mathrm{H}), 1.43(\mathrm{~s}, 9 \mathrm{H}), 1.40$ (s, $3 \mathrm{H}), 1.36-1.17$ (m, $25 \mathrm{H}), 0.86(\mathrm{t}, J=6.3 \mathrm{~Hz}, 3 \mathrm{H}) \mathrm{ppm} .{ }^{13} \mathrm{C} \mathrm{NMR}\left(100 \mathrm{MHz},\left[\mathrm{D}_{6}\right]\right.$ DMSO, $363 \mathrm{~K}): \delta=164.5,134.4,132.7,129.7,128.9,128.1,125.4$, 93.2, 79.1, 73.4, 62.9, 59.1, 31.1, 30.8, $28.5(\times 2), 28.4(\times 2), 28.4$, $28.2,27.8(\times 2), 27.6(\times 2), 21.5(\mathrm{~m}), 13.3 \mathrm{ppm}$. IR (neat): $\tilde{v}=2924$, 2854, 1724, 1701, 1365, 1268, 1097, 1070, 855, $709 \mathrm{~cm}^{-1}$. HRMS: calcd. for $\left[\mathrm{C}_{33} \mathrm{H}_{53} \mathrm{NO}_{5}+\mathrm{Na}\right]^{+}$566.3816; found 566.3814 .

1,2-O,N-Isopropylidene-3-O-benzoyl- $N$-(tert-butyloxycarbonyl)-Derythro-sphingosine $(0.5 \mathrm{~g}, 0.92 \mathrm{mmol}, 1.0$ equiv.) was dissolved in methanol/ethanol $(1: 1 ; 15 \mathrm{~mL})$, and $p$-toluenesulfonic acid (monohydrate; $87 \mathrm{mg}, 0.46 \mathrm{mmol}, 0.5$ equiv.) was added. The reaction mixture was stirred at ambient temperature overnight, and then the reaction was quenched with triethylamine $(0.32 \mathrm{~mL}, 2.3 \mathrm{mmol}$, 2.5 equiv.). The mixture was diluted with toluene $(10 \mathrm{~mL})$, and then concentrated in vacuo. The residue was dissolved in EtOAc $(60 \mathrm{~mL})$, and this solution was washed with satd. aq. $\mathrm{Na}_{2} \mathrm{HCO}_{3}$ $(60 \mathrm{~mL})$ and brine $(50 \mathrm{~mL})$. The aqueous layers were back-extracted with EtOAc $(60 \mathrm{~mL})$. The combined organic extracts were dried $\left(\mathrm{Na}_{2} \mathrm{SO}_{4}\right)$, filtered, and concentrated in vacuo. Purification by column chromatography ( $10 \%$ EtOAc in petroleum ether) gave compound 23a $(0.25 \mathrm{~g}, 0.50 \mathrm{mmol}, 54 \% ; 88 \%$ based on recovered starting material) as a colourless waxy solid. $R_{\mathrm{f}}=0.07(10 \%$ EtOAc in petroleum ether). $[\alpha]_{\mathrm{D}}^{22}=+15\left(c=1.0, \mathrm{CHCl}_{3}\right) .{ }^{1} \mathrm{H} \mathrm{NMR}$ $\left(400 \mathrm{MHz}, \mathrm{CDCl}_{3}\right): \delta=8.04(\mathrm{dm}, J=7.5 \mathrm{~Hz}, 2 \mathrm{H}), 7.57(\mathrm{t}, J=$ $7.4 \mathrm{~Hz}, 1 \mathrm{H}), 7.44(\mathrm{t}, J=7.7 \mathrm{~Hz}, 2 \mathrm{H}), 5.87(\mathrm{dt}, J=14.9,6.6 \mathrm{~Hz}$, $1 \mathrm{H}), 5.60(\mathrm{dd}, J=14.9,7.7 \mathrm{~Hz}, 1 \mathrm{H}), 5.53(\mathrm{t}, J=7.3 \mathrm{~Hz}, 1 \mathrm{H})$, $5.12(\mathrm{~d}, J=8.9 \mathrm{~Hz}, 1 \mathrm{H}), 3.95(\mathrm{~m}, 1 \mathrm{H}), 3.76-3.67(\mathrm{~m}, 2 \mathrm{H}), 2.82$ (br. s, $1 \mathrm{H}), 2.05(\mathrm{~m}, 2 \mathrm{H}), 1.43$ (s, $9 \mathrm{H}), 1.40-1.20$ (m, $22 \mathrm{H}), 0.88$ $(\mathrm{t}, J=6.8 \mathrm{~Hz}, 3 \mathrm{H}) \mathrm{ppm} .{ }^{13} \mathrm{C} \mathrm{NMR}\left(100 \mathrm{MHz}, \mathrm{CDCl}_{3}\right): \delta=166.2$, 155.8, 137.3, 133.2, 129.8, 129.7, $128.4(\times 2), 124.6,79.6,74.8,61.7$, $54.5,32.2,31.9,29.62(\times 3), 29.60,29.5,29.4,29.3,29.2,28.9,28.3$, 22.6, 14.1 ppm. IR (neat): $\tilde{v}=3372,2924,2854,1715,1268,1171$, 1111, 1070, 969, $710 \mathrm{~cm}^{-1}$. HRMS: calcd. for $\left[\mathrm{C}_{30} \mathrm{H}_{49} \mathrm{NO}_{5}+\mathrm{Na}\right]^{+}$ 526.3503; found 526.3500 .

$\left[\mathbf{5 , 6 , 7 , 8 , 9 - 1 3} \mathrm{C}_{5}\right]-3-O$-Benzoyl- $\mathrm{N}$-(tert-butoxycarbonyl)-D-erythrosphingosine (23b): $\left[5,6,7,8,9-{ }^{13} \mathrm{C}_{5}\right]-1,2-O, N$-Isopropylidene- $N$ - $($ tertbutyloxycarbonyl)-D-erythro-sphingosine (22b; $1.14 \mathrm{~g}, 2.56 \mathrm{mmol}$, 1.0 equiv.) was dissolved in a mixture of pyridine and $\mathrm{CH}_{2} \mathrm{Cl}_{2}(2: 1$; $20 \mathrm{~mL}$ ). DMAP (16 mg, $0.13 \mathrm{mmol}, 0.05$ equiv.) was added, followed by benzoyl chloride $(0.45 \mathrm{~mL}, 3.85 \mathrm{mmol}, 1.5$ equiv.). The reaction mixture was stirred overnight, and then the reaction was quenched with methanol $(0.5 \mathrm{~mL})$. The solvent was removed in vacuo, and the resulting residue was dissolved in EtOAc $(50 \mathrm{~mL})$. This solution was washed with $\mathrm{HCl}(1 \mathrm{M} ; 50 \mathrm{~mL})$, satd. aq. $\mathrm{NaHCO}_{3}(50 \mathrm{~mL})$, and brine $(40 \mathrm{~mL})$. The aqueous layers were extracted with EtOAc $(50 \mathrm{~mL})$, and the combined organic extracts were dried $\left(\mathrm{Na}_{2} \mathrm{SO}_{4}\right)$, filtered, and concentrated in vacuo. Purification by column chromatography $(1.5 \%$ EtOAc in petroleum ether) gave $\left[5,6,7,8,9-{ }^{13} \mathrm{C}_{5}\right]-1,2-O, N$-isopropylidene-3-O-benzoyl- $N$-(tertbutoxycarbonyl)-D-erythro-sphingosine (1.13 g, $2.37 \mathrm{mmol}, 92 \%)$ as a colourless oil. $R_{\mathrm{f}}=0.29$ ( $5 \%$ EtOAc in petroleum ether). $[a]_{\mathrm{D}}^{22}=-30\left(c=0.5, \mathrm{CHCl}_{3}\right) .{ }^{1} \mathrm{H}$ NMR $\left(400 \mathrm{MHz},\left[\mathrm{D}_{6}\right] \mathrm{DMSO}\right.$, $363 \mathrm{~K}): \delta=8.00(\mathrm{~d}, J=7.6 \mathrm{~Hz}, 2 \mathrm{H}), 7.64(\mathrm{t}, J=7.4 \mathrm{~Hz}, 1 \mathrm{H})$, 7.52 (t, $J=7.6 \mathrm{~Hz}, 2 \mathrm{H}), 5.82$ (br. s, $1 \mathrm{H}), 5.75(\mathrm{dm}, J=149.2 \mathrm{~Hz}$, $1 \mathrm{H}), 5.53(\mathrm{~m}, 1 \mathrm{H}), 4.15-3.97(\mathrm{~m}, 3 \mathrm{H}, 2-\mathrm{H}), 2.04(\mathrm{dm}, J=$ $126.1 \mathrm{~Hz}, 2 \mathrm{H}), 1.54-1.01(\mathrm{~m}, 37 \mathrm{H}), 0.86(\mathrm{t}, J=6.3 \mathrm{~Hz}, 3 \mathrm{H}) \mathrm{ppm}$. ${ }^{13} \mathrm{C}$ NMR (100 MHz, [D 6 ]DMSO, $\left.363 \mathrm{~K}\right): \delta=164.5,151.1,134.4$ $(\mathrm{d}, J=42.6 \mathrm{~Hz}), 132.8,129.7,128.9,128.2(\times 2), 125.2(\mathrm{~d}, J=$ $72.2 \mathrm{~Hz}), 93.2,79.2,73.4(\mathrm{~d}, J=5.6 \mathrm{~Hz}), 62.9,59.1,31.8-30.4(\mathrm{~m})$, $28.8-27.3(\mathrm{~m}), 21.6,13.4 \mathrm{ppm}$. The same sample in $\mathrm{CDCl}_{3}$ at room temperature showed two rotamers: ${ }^{1} \mathrm{H}$ NMR $\left(400 \mathrm{MHz}, \mathrm{CDCl}_{3}\right)$ : $\delta=8.10(\mathrm{~d}, J=7.4 \mathrm{~Hz}, 2 \mathrm{H}), 7.55(\mathrm{t}, J=7.4 \mathrm{~Hz}, 1 \mathrm{H}), 7.44(\mathrm{t}, J$ $=7.6 \mathrm{~Hz}, 2 \mathrm{H}), 5.93-5.82(\mathrm{~m}, 1 \mathrm{H}), 5.82(\mathrm{dm}, J=149.8 \mathrm{~Hz}, 1 \mathrm{H})$, $5.46(\mathrm{~m}, 1 \mathrm{H}), 4.25-4.10(\mathrm{~m}, 1.5 \mathrm{H}), 4.07-3.96(\mathrm{~m}, 1.5 \mathrm{H}), 2.03$ $(\mathrm{dm}, J=125.7 \mathrm{~Hz}, 2 \mathrm{H}), 1.58-1.00(\mathrm{~m}, 37 \mathrm{H}), 0.88(\mathrm{t}, J=6.9 \mathrm{~Hz}$, $3 \mathrm{H}) \mathrm{ppm} .{ }^{13} \mathrm{C}$ NMR $\left(100 \mathrm{MHz}, \mathrm{CDCl}_{3}\right): \delta=165.5,165.4,152.5$, $151.7,135.8(\mathrm{~d}, J=42.6 \mathrm{~Hz}) 135.7(\mathrm{~d}, J=42.6 \mathrm{~Hz}), 132.9,132.8$, $130.5,130.3,129.8,128.3,125.0(\mathrm{~d}, J=72.8 \mathrm{~Hz}), 94.6,94.0,80.4$, $80.2,74.4(\mathrm{~d}, J=5.6 \mathrm{~Hz}), 74.2(\mathrm{~d}, J=5.6 \mathrm{~Hz}), 63.70,63.66,60.00$, 59.97, 32.8-31.7 (m), 29.8-28.2 (m), $22.7\left(\mathrm{CH}_{2}\right), 14.1$ ppm. HRMS: calcd. for $\left[\mathrm{C}_{28}{ }^{13} \mathrm{C}_{5} \mathrm{H}_{53} \mathrm{NO}_{5}+\mathrm{Na}\right]^{+}$571.3984; found 571.3982 .

$\left[5,6,7,8,9-{ }^{13} \mathrm{C}_{5}\right]-1,2-O, N$-Isopropylidene-3-O-benzoyl- $N$-(tert-butoxycarbonyl)-D-erythro-sphingosine $(120 \mathrm{mg}, 0.22 \mathrm{mmol}$, 1.0 equiv.) was dissolved in methanol/ethanol $(1: 1 ; 10 \mathrm{~mL})$, and $p$ toluenesulphonic acid (monohydrate; $8.3 \mathrm{mg}, 44 \mu \mathrm{mol}, 0.2$ equiv.) was added. The reaction mixture was stirred overnight at room temperature. The mixture was then transferred to an extraction funnel using EtOAc $(60 \mathrm{~mL})$, and washed with satd. aq. $\mathrm{NaHCO}_{3} /$ water $(2: 1 ; 60 \mathrm{~mL})$, and brine $(50 \mathrm{~mL})$. The aqueous layer was extracted with EtOAc $(60 \mathrm{~mL})$. The combined organic extracts were dried $\left(\mathrm{Na}_{2} \mathrm{SO}_{4}\right)$, filtered, and concentrated in vacuo. Purification by column chromatography $(5-10 \%$ EtOAc in petroleum ether) gave compound 23b (70 mg, $0.14 \mathrm{mmol}, 63 \% ; 83 \%$ based on recovered starting material) as an amorphous solid. $R_{\mathrm{f}}=0.07(10 \%$ EtOAc in petroleum ether). $[\alpha]_{\mathrm{D}}^{22}=+16\left(c=0.5, \mathrm{CHCl}_{3}\right) .{ }^{1} \mathrm{H} \mathrm{NMR}$ $\left(400 \mathrm{MHz}, \mathrm{CDCl}_{3}\right): \delta=8.03(\mathrm{dm}, J=7.8 \mathrm{~Hz}, 2 \mathrm{H}), 7.57(\mathrm{tt}, J=$ $7.0,1.5 \mathrm{~Hz}, 1 \mathrm{H}), 7.45(\mathrm{t}, J=7.8 \mathrm{~Hz}, 2 \mathrm{H}), 5.88(\mathrm{dm}, J=149.8 \mathrm{~Hz}$, $1 \mathrm{H}), 5.60(\mathrm{~m}, 1 \mathrm{H}), 5.52(\mathrm{~m}, 1 \mathrm{H}), 5.08(\mathrm{~d}, J=8.9 \mathrm{~Hz}, 1 \mathrm{H}), 3.93$ (m, $1 \mathrm{H}), 3.76-3.67(\mathrm{~m}, 2 \mathrm{H}), 2.66$ (br. s, $1 \mathrm{H}), 2.08$ (dm, $J=$ $125.5 \mathrm{~Hz}, 2 \mathrm{H}), 1.58-1.01(\mathrm{~m}, 31 \mathrm{H}), 0.88(\mathrm{t}, J=6.8 \mathrm{~Hz}, 3 \mathrm{H})$ ppm. ${ }^{13} \mathrm{C}$ NMR (101 MHz, $\left.\mathrm{CDCl}_{3}\right): \delta=166.3,155.8,137.4$ (d, $J$ $=42.5 \mathrm{~Hz}), 133.3,129.80,129.75,128.4,124.6(\mathrm{~d}, J=71.5 \mathrm{~Hz})$, $79.7,74.9(\mathrm{~d}, J=5.4 \mathrm{~Hz}), 61.9,54.6,33.0-31.6(\mathrm{~m}), 29.8-28.1(\mathrm{~m})$, $22.7,14.1 \mathrm{ppm}$. IR (neat): $\tilde{v}=3372,2922,2853,1696,1505,1452$, 1267, 1169, 1111, 1070, 1026, 966, $710 \mathrm{~cm}^{-1}$. HRMS: calcd. for $\left[\mathrm{C}_{25}{ }^{13} \mathrm{C}_{5} \mathrm{H}_{49} \mathrm{NO}_{5}+\mathrm{Na}\right]^{+}$531.3671; found 531.3667.

[1,2,3- $\left.{ }^{13} \mathrm{C}_{3}\right]-N$-Methoxy- $N$-(methyl)-tetradecanamide (25): [1,2,3$\left.{ }^{13} \mathrm{C}_{3}\right]$-Myristic acid (24; $3.00 \mathrm{~g}, 13.0 \mathrm{mmol}, 1.0$ equiv.) was dissolved in anhydrous $\mathrm{CH}_{2} \mathrm{Cl}_{2}(26 \mathrm{~mL})$, and the solution was put under an atmosphere of argon and cooled to $0{ }^{\circ} \mathrm{C}$. Oxalyl chloride $(2.28 \mathrm{~mL}$, $26.0 \mathrm{mmol}, 2.0$ equiv.) was added, followed by a drop of DMF. The reaction mixture was then stirred under a flow of argon at room temperature. When the evolution of gas stopped (ca. $2 \mathrm{~h}$ ), the mixture was concentrated in vacuo.

The residue was dissolved in anhydrous $\mathrm{CH}_{2} \mathrm{Cl}_{2}(13 \mathrm{~mL})$, and the solution was cooled to $-78^{\circ} \mathrm{C}$. A solution of $N, O$-dimethylhydroxylamine (2.30 mL, $32.5 \mathrm{mmol}, 2.5$ equiv.) in anhydrous $\mathrm{CH}_{2} \mathrm{Cl}_{2}$ $(13 \mathrm{~mL})$ was slowly added to the myristoyl chloride solution at $-78^{\circ} \mathrm{C}$. Then the stirred reaction mixture was allowed to reach room temperature over $2 \mathrm{~h}$. The reaction mixture was stirred at room temperature for $30 \mathrm{~min}$. The solids were removed by filtration through a Whatmann paper, and washed with $\mathrm{CH}_{2} \mathrm{Cl}_{2}$. The filtrate was concentrated in vacuo, and the residue was purified by column chromatography (5-20\% EtOAc in pentane) to give compound $\mathbf{2 5}$ $(3.45 \mathrm{~g}, 12.7 \mathrm{mmol}, 98 \%)$ as a colourless oil. $R_{\mathrm{f}}=0.42(20 \%$ EtOAc in pentane). ${ }^{1} \mathrm{H}$ NMR $\left(400 \mathrm{MHz}, \mathrm{CDCl}_{3}\right): \delta=3.68(\mathrm{~s}, 3 \mathrm{H}), 3.13$ $(\mathrm{d}, J=2.0 \mathrm{~Hz}, 3 \mathrm{H}), 2.41(\mathrm{dm}, J=127.2 \mathrm{~Hz}, 2 \mathrm{H}), 1.62(\mathrm{dm}, J=$ $128.8 \mathrm{~Hz}, 2 \mathrm{H}), 1.35-1.22(\mathrm{~m}, 20 \mathrm{H}), 0.88(\mathrm{t}, J=6.8 \mathrm{~Hz}, 3 \mathrm{H}) \mathrm{ppm}$. ${ }^{13} \mathrm{C}$ NMR (100 MHz, $\left.\mathrm{CDCl}_{3}\right): \delta=175.0(\mathrm{~d}, J=51.0 \mathrm{~Hz}), 61.4$, $32.04,31.99(\mathrm{dd}, J=51.0,34.0 \mathrm{~Hz}), 29.8-29.3(\mathrm{~m}), 24.77(\mathrm{dd}, J=$ 35.0, 2.0 Hz), 22.8, 14.2 ppm. IR (neat): $\tilde{v}=2924,2855,1616,1462$, 1375, 1176, 908, $729 \mathrm{~cm}^{-1}$. HRMS: calcd. for $\left[\mathrm{C}_{13}{ }^{13} \mathrm{C}_{3} \mathrm{H}_{33} \mathrm{NO}_{2}+\right.$ $\mathrm{H}]^{+}$275.2612; found 275.2683. 
Ethyl (E)-[3,4,5-13 $\left.\mathbf{C}_{3}\right]$-Hexadec-2-enoate (27): [1,2,3-1 $\left.{ }^{13} \mathrm{C}_{3}\right]-N$-(Methoxy)- $N$-methyl-tetradecanamide (25; 2.74 g, $10.0 \mathrm{mmol}, 1.0$ equiv.) was dissolved in dry THF $(20 \mathrm{~mL})$. The solution was cooled to $-78^{\circ} \mathrm{C}$, and then DIBAL-H $(1.5 \mathrm{M}$ in toluene; $8.0 \mathrm{~mL}, 12.0 \mathrm{mmol}$, 1.2 equiv.) was added. The reaction mixture was stirred for $30 \mathrm{~min}$, then it was quenched with satd. aq. Rochelle salt $(12 \mathrm{~mL})$. The mixture was then transferred to an extraction funnel with EtOAc $(50 \mathrm{~mL})$, and washed with water $(40 \mathrm{~mL})$ and brine $(40 \mathrm{~mL})$. The aqueous layers were extracted with EtOAc $(50 \mathrm{~mL})$. The combined organic extracts were dried $\left(\mathrm{Na}_{2} \mathrm{SO}_{2}\right)$, filtered, and concentrated in vacuo to give crude $\left[1,2,3-{ }^{13} \mathrm{C}_{3}\right]$-tetradecanal $(2.15 \mathrm{~g}, 10.0 \mathrm{mmol})$ as a colourless oil, which was used without further purification.

Triethyl phosphonoacetate (26; $3.14 \mathrm{~g}, 14.0 \mathrm{mmol}, 1.4$ equiv.) was dissolved in dry THF $(50 \mathrm{~mL})$, and the solution was cooled to $0{ }^{\circ} \mathrm{C}$. n-Butyllithium (1.6 $\mathrm{M}$ in hexanes; $7.8 \mathrm{~mL}, 12.5 \mathrm{~mL}, 1.25$ equiv.) was added, and the reaction mixture was stirred for $10 \mathrm{~min}$ at $0{ }^{\circ} \mathrm{C}$. The crude $\left[1,2,3-{ }^{13} \mathrm{C}_{3}\right]$-tetradecanal was dissolved in anhydrous in THF $(10 \mathrm{~mL})$, and this solution was added to the Horner-WadsworthEmmons reagent at $0{ }^{\circ} \mathrm{C}$. The mixture was then stirred overnight at room temperature. The mixture was transferred to an extraction funnel with $\mathrm{Et}_{2} \mathrm{O}(50 \mathrm{~mL})$, and washed with water $(50 \mathrm{~mL})$ and brine $(50 \mathrm{~mL})$. The aqueous layers were extracted with $\mathrm{Et}_{2} \mathrm{O}$ $(50 \mathrm{~mL})$, and the combined organic extracts were dried with $\left(\mathrm{Na}_{2} \mathrm{SO}_{4}\right)$, filtered, and concentrated in vacuo. Purification by column chromatography (0-2\% EtOAc in pentane) gave compound $27(2.3 \mathrm{~g}, 8.1 \mathrm{mmol}, 81 \%)$ as a colourless oil. $R_{\mathrm{f}}=0.58(2 \%$ EtOAc in pentane). ${ }^{1} \mathrm{H}$ NMR $\left(400 \mathrm{MHz}, \mathrm{CDCl}_{3}\right): \delta=6.96(\mathrm{dm}, J=$ $152.0 \mathrm{~Hz}, 1 \mathrm{H}), 5.81(\mathrm{dd}, J=15.6,5.2 \mathrm{~Hz}, 1 \mathrm{H}), 4.18(\mathrm{q}, J=7.2 \mathrm{~Hz}$, $2 \mathrm{H}), 2.19(\mathrm{dm}, J=126.0 \mathrm{~Hz}, 2 \mathrm{H}), 1.62-1.22(\mathrm{~m}, 25 \mathrm{H}), 0.88(\mathrm{t}, J$ $=6.8 \mathrm{~Hz}, 3 \mathrm{H}) \mathrm{ppm} .{ }^{13} \mathrm{C} \mathrm{NMR}\left(100 \mathrm{MHz}, \mathrm{CDCl}_{3}\right): \delta=166.9(\mathrm{~d}$, $J=6.0 \mathrm{~Hz}), 150.84(\mathrm{dt}, J=39.0,17.0 \mathrm{~Hz}), 149.65(\mathrm{dd}, J=41.0$, $2.0 \mathrm{~Hz}$ ), 60.24, 32.33 (dd, $J=41.0,34.0 \mathrm{~Hz}), 29.8-29.0$ (m), 28.1 (dd, $J=34.0,2.0 \mathrm{~Hz}), 22.8,14.4,14.3 \mathrm{ppm}$. IR (neat): $\tilde{v}=2922$, 2852, 1720, 1626, 1466, 1365, 1301, 1263, 1175, 1034, 977, $721 \mathrm{~cm}^{-1}$. HRMS: calcd. for $\left[\mathrm{C}_{15}{ }^{13} \mathrm{C}_{3} \mathrm{H}_{34} \mathrm{O}_{2}+\mathrm{H}\right]^{+}$286.2738; found 286.2733 .

Ethyl $\left[3,4,5-{ }^{13} \mathbf{C}_{3}\right]$-hexadecanoate (28): Ethyl $(E)-\left[3,4,5-{ }^{13} \mathrm{C}_{3}\right]$-hexadec-2-enoate $(\mathbf{2 7} ; 2.20 \mathrm{~g}, 7.71 \mathrm{mmol}, 1.0$ equiv.) was dissolved in EtOAc $(40 \mathrm{~mL})$. The solution was purged with argon while stirring, and then palladium $(10 \%$ on charcoal; $0.41 \mathrm{~g}, 0.38 \mathrm{mmol}$, 0.05 equiv.) was added. The reaction mixture was then stirred under a flow of hydrogen gas for $30 \mathrm{~min}$, and then it was left under a hydrogen atmosphere overnight. The palladium residue was removed by filtration through a Whatmann paper, and rinsed with EtOAc $(50 \mathrm{~mL})$. The solvent was removed from the filtrate in vacuo. Purification by column chromatography (1\% EtOAc in pentane) gave compound $28(2.21 \mathrm{~g}, 7.32 \mathrm{mmol}, 95 \%)$ as a colourless oil. $R_{\mathrm{f}}=0.58\left(2 \%\right.$ EtOAc in pentane). ${ }^{1} \mathrm{H}$ NMR $(400 \mathrm{MHz}$, $\left.\mathrm{CDCl}_{3}\right): \delta=4.12(\mathrm{q}, J=7.2 \mathrm{~Hz}, 2 \mathrm{H}), 2.28(\mathrm{~m}, 2 \mathrm{H}), 1.61(\mathrm{dm}, J$ $=130.8 \mathrm{~Hz}, 2 \mathrm{H}), 1.46-1.08(\mathrm{~m}, 27 \mathrm{H}), 0.88(\mathrm{t}, J=6.8 \mathrm{~Hz}, 3 \mathrm{H})$ ppm. ${ }^{13} \mathrm{C}$ NMR $\left(100 \mathrm{MHz}, \mathrm{CDCl}_{3}\right): \delta=174.0,62.0,32.1,29.8-$ $28.8(\mathrm{~m}), 25.4-24.7(\mathrm{~m}), 22.8,14.3,14.2 \mathrm{ppm}$. IR (neat): $\tilde{v}=2920$, 2851, 1738, 1463, 1238, 1174, 1035, $733 \mathrm{~cm}^{-1}$. HRMS: calcd. for $\left[\mathrm{C}_{15}{ }^{13} \mathrm{C}_{3} \mathrm{H}_{36} \mathrm{O}_{2}+\mathrm{H}\right]^{+}$288.2894; found 288.2889.

[3,4,5- $\left.{ }^{13} \mathbf{C}_{3}\right]$-Palmitic Acid (29): Ethyl $\left[3,4,5-{ }^{13} \mathrm{C}_{3}\right]$-hexadecanoate (28; $2.10 \mathrm{~g}, 7.30 \mathrm{mmol}, 1.0$ equiv.) was dissolved in THF/EtOH/ $\mathrm{H}_{2} \mathrm{O}(1: 1: 1 ; 35 \mathrm{~mL})$, and lithium hydroxide $(0.52 \mathrm{~g}, 21.9 \mathrm{mmol}$, 3.0 equiv.) was added. The reaction mixture was stirred at room temperature overnight. The mixture was then transferred to an extraction funnel with EtOAc $(50 \mathrm{~mL})$, and washed with $\mathrm{HCl}(1 \mathrm{M}$ aq.; $50 \mathrm{~mL})$, water $(50 \mathrm{~mL})$, and brine $(50 \mathrm{~mL})$. The aqueous layers were extracted with EtOAc $(50 \mathrm{~mL})$, and the combined organic ex- tracts were dried $\left(\mathrm{Na}_{2} \mathrm{SO}_{4}\right)$, filtered, and concentrated in vacuo. Purification by column chromatography $(5 \%$ EtOAc, $1 \% \mathrm{AcOH}$ in pentane) gave $29(1.89 \mathrm{~g}, 6.94 \mathrm{mmol}, 95 \%)$ as a white solid. $R_{\mathrm{f}}=$ $0.6\left(10 \%\right.$ EtOAc, $1 \% \mathrm{AcOH}$ in pentane). ${ }^{1} \mathrm{H}$ NMR $(400 \mathrm{MHz}$, $\left.\mathrm{CDCl}_{3}\right): \delta=11.40$ (br. s, $\left.1 \mathrm{H}\right), 2.35(\mathrm{~m}, 2 \mathrm{H}), 1.61(\mathrm{dm}, J=$ $130.0 \mathrm{~Hz}, 2 \mathrm{H}), 1.52-1.06(\mathrm{~m}, 24 \mathrm{H}), 0.88(\mathrm{t}, J=6.8 \mathrm{~Hz}, 3 \mathrm{H}) \mathrm{ppm}$. ${ }^{13} \mathrm{C}$ NMR $\left(100 \mathrm{MHz}, \mathrm{CDCl}_{3}\right): \delta=180.1,32.1,29.9-28.7(\mathrm{~m}), 25.2-$ $24.4(\mathrm{~m}), 22.8,14.3 \mathrm{ppm}$. IR (neat): $\tilde{v}=2912,2847,1694,1470$, 1430, 1308, 1288, 941, 718, $679 \mathrm{~cm}^{-1}$.

[3,4,5- ${ }^{13} \mathbf{C}_{3}$ ]-Palmitoyl Chloride (30): $\left[3,4,5-{ }^{13} \mathrm{C}_{3}\right]$-Palmitic acid ( $1.80 \mathrm{~g}, 6.93 \mathrm{mmol}, 1.0$ equiv.) was dissolved in dry $\mathrm{CH}_{2} \mathrm{Cl}_{2}$ $(72 \mathrm{~mL})$, and the solution was put under an atmosphere of argon, and cooled to $0{ }^{\circ} \mathrm{C}$. Oxalyl chloride $(1.2 \mathrm{~mL}, 14 \mathrm{mmol}, 2$ equiv.) was added, followed by DMF (one drop). The reaction mixture was then kept under a flow of argon at room temperature. When the evolution of gas stopped (ca. $2 \mathrm{~h}$ ), the mixture was concentrated in vacuo to give compound $30(1.90 \mathrm{~g}, 6.93 \mathrm{mmol}, 100 \%) .{ }^{1} \mathrm{H}$ NMR $\left(400 \mathrm{MHz}, \mathrm{CDCl}_{3}\right): \delta=2.88(\mathrm{~m}, 2 \mathrm{H}), 1.70(\mathrm{dm}, J=$ $130.5 \mathrm{~Hz}, 2 \mathrm{H}), 1.56-1.05(\mathrm{~m}, 24 \mathrm{H}), 0.88(\mathrm{t}, J=6.8 \mathrm{~Hz}, 3 \mathrm{H}) \mathrm{ppm}$. ${ }^{13} \mathrm{C} \mathrm{NMR}\left(100 \mathrm{MHz}, \mathrm{CDCl}_{3}\right): \delta=166.4,32.0,29.8-28.0(\mathrm{~m})$, $25.15,24.14$ (dd, $J=32.0,1.5 \mathrm{~Hz}), 22.8,14.2 \mathrm{ppm}$. IR (neat): $\tilde{v}=$ ; 2918, 2848, 2747, 1800, 1660, 1384, 1305, 1161, 1033, 908, $802 \mathrm{~cm}^{-1}$.

D-erythro-Sphingosine (31a): 3-O-Benzoyl- $N$-(tert-butyloxycarbonyl)-D-erythro-sphingosine (23a; $90 \mathrm{mg}, 0.30 \mathrm{mmol}, 1.0$ equiv.) was dissolved in methanol $(10 \mathrm{~mL})$, and sodium methoxide $(30 \%$ in methanol; $20 \mu \mathrm{L}, 0.15 \mathrm{mmol}, 0.5$ equiv.) was added. The reaction mixture was stirred at room temperature until TLC showed full conversion into a lower-running spot. Potassium hydroxide $(0.5 \mathrm{M}$ in water; $1.2 \mathrm{~mL}, 0.60 \mathrm{mmol}, 2.0$ equiv.) was added, and the reaction mixture was stirred overnight at ambient temperature. The reaction was quenched with acetic acid $(0.09 \mathrm{~mL}, 1.5 \mathrm{mmol}, 5$ equiv.), and then the mixture was concentrated in vacuo.

The residue was cooled to $0{ }^{\circ} \mathrm{C}$, and then water $(1.0 \mathrm{~mL})$ and TFA $(3 \mathrm{~mL})$ were added. The reaction mixture was stirred for $2 \mathrm{~min}$ at $0{ }^{\circ} \mathrm{C}$, then it was diluted with toluene $(40 \mathrm{~mL})$, and concentrated in vacuo. Purification by HPLC-MS $(52-62 \% \mathrm{~B}$, following the general procedure for HPLC-MS purifications) gave compound 31a $(41 \mathrm{mg}, 0.1 \mathrm{mmol}, 54 \%)$ as a TFA adduct. $[a]_{\mathrm{D}}^{22}=-2.0(c=0.5$, $\mathrm{MeOH}) .{ }^{1} \mathrm{H}$ NMR (600 MHz, $\left[\mathrm{D}_{4}\right]$ methanol): $\delta=5.85(\mathrm{~m}, 1 \mathrm{H})$, $5.47(\mathrm{~m}, 1 \mathrm{H}), 4.28(\mathrm{~m}, 1 \mathrm{H}), 3.79(\mathrm{dd}, J=11.6,4.0 \mathrm{~Hz}, 1 \mathrm{H}), 3.66$ $(\mathrm{dd}, J=11.6,8.4 \mathrm{~Hz}, 1 \mathrm{H}), 3.19(\mathrm{dt}, J=8.6,4.4 \mathrm{~Hz}, 1 \mathrm{H}), 2.10$ (q, $J=7.1 \mathrm{~Hz}, 2 \mathrm{H}), 1.45-1.32(\mathrm{~m}, 2 \mathrm{H}), 1.35-1.26(\mathrm{~m}, 20 \mathrm{H}), 0.90(\mathrm{t}$, $J=7.0 \mathrm{~Hz}, 3 \mathrm{H}) \mathrm{ppm} .{ }^{13} \mathrm{C} \mathrm{NMR}\left(150 \mathrm{MHz},\left[\mathrm{D}_{4}\right]\right.$ methanol): $\delta=$ $136.6,128.5,71.0,59.4,58.5,33.4,33.1,30.81,30.80(2 \times), 30.77$, $30.75,30.65,30.5,30.4,30.2,23.8,14.4 \mathrm{ppm}$. IR (neat): $\tilde{v}=3289$, 2918, 2850, 1668, 1520, 1470, 1192, 1134, 986, $720 \mathrm{~cm}^{-1}$. HRMS: calcd. for $\left[\mathrm{C}_{18} \mathrm{H}_{37} \mathrm{NO}_{2}+\mathrm{H}\right]^{+} 300.2897$; found 300.2899 .

[5,6,7,8,9- $\left.{ }^{13} \mathrm{C}_{5}\right]$-D-erythro-Sphingosine (31b): $\left[5,6,7,8,9-{ }^{13} \mathrm{C}_{5}\right]-3-O-$ Benzoyl- $N$-(tert-butoxycarbonyl)-D-erythro-sphingosine 23b (90 mg, $0.29 \mathrm{mmol}, 1$ equiv.) was dissolved in methanol $(10 \mathrm{~mL})$, and sodium methoxide $(30 \%$ in methanol; $19 \mu \mathrm{L}, 0.14 \mathrm{mmol}$, 0.5 equiv.) was added. The reaction mixture was stirred at room temperature until TLC showed full conversion into a lower-running spot. Potassium hydroxide $(0.5 \mathrm{~m}$ in water; $1.2 \mathrm{~mL}, 0.59 \mathrm{mmol}$, 2 equiv.) was added, and the reaction mixture was stirred overnight at ambient temperature. The reaction was quenched with acetic acid $(0.08 \mathrm{~mL}, 1.45 \mathrm{mmol}, 5$ equiv.), and then the mixture was concentrated in vacuo.

The residue was cooled to $0{ }^{\circ} \mathrm{C}$, then water $(1 \mathrm{~mL})$ and TFA $(3 \mathrm{~mL})$ were added. The reaction mixture was stirred for $2 \mathrm{~min}$ at $0{ }^{\circ} \mathrm{C}$, then it was diluted with toluene $(40 \mathrm{~mL})$ and concentrated in vacuo. 
Purification by HPLC-MS (52-62\% B, following the general procedure for HPLC-MS purifications) gave compound $\mathbf{3 1 b}(52 \mathrm{mg}$, $0.17 \mathrm{mmol}, 59 \%)$ as a TFA adduct. $[\alpha]_{\mathrm{D}}^{22}=-2.0(c=0.5, \mathrm{MeOH})$. ${ }^{1} \mathrm{H}$ NMR (600 MHz, [D $\left.\mathrm{D}_{4}\right]$ methanol): $\delta=5.85(\mathrm{dm}, J=150 \mathrm{~Hz}, 1$ $\mathrm{H}), 5.47(\mathrm{dt}, J=15.6,6.0 \mathrm{~Hz}, 1 \mathrm{H}), 4.28(\mathrm{dd}, J=11.4,4.8 \mathrm{~Hz}, 1$ $\mathrm{H}), 3.79(\mathrm{dd}, J=11.6,4.0 \mathrm{~Hz}, 1 \mathrm{H}), 3.66(\mathrm{dd}, J=11.6,8.3 \mathrm{~Hz}, 1$ $\mathrm{H}), 3.19(\mathrm{dt}, J=8.5,4.3 \mathrm{~Hz}, 1 \mathrm{H}), 2.1(\mathrm{dm}, J=126.0 \mathrm{~Hz}, 2 \mathrm{H})$, $1.56-1.20(\mathrm{~m}, 22 \mathrm{H}), 0.90(\mathrm{t}, J=7.0 \mathrm{~Hz}, 3 \mathrm{H}) \mathrm{ppm} .{ }^{13} \mathrm{C} \mathrm{NMR}$ (151 MHz, [D $\left.\mathrm{D}_{4}\right]$ methanol): $\delta=135.6(\mathrm{dd}, J=42.0,3.0 \mathrm{~Hz}), 128.5$ $(\mathrm{dd}, J=72.0,3.0 \mathrm{~Hz}), 71.0(\mathrm{dd}, J=5.5,1.3 \mathrm{~Hz}), 59.5,58.5(\mathrm{~d}, J=$ $3.0 \mathrm{~Hz}$ ), 33.8-32.9 (m), 30.9-29.8 (m), 23.7, $14.5 \mathrm{ppm}$. IR (neat): $\tilde{v}$ = 3287, 2914, 2847, 1661, 1526, 1470, 1198, 1136, 966, $721 \mathrm{~cm}^{-1}$. HRMS: calcd. for $\left[\mathrm{C}_{13}{ }^{13} \mathrm{C}_{5} \mathrm{H}_{37} \mathrm{NO}_{2}+\mathrm{H}\right]^{+} 305.2897$; found 305.3065 .

Ceramide (32a): See the general procedure for the synthesis of ceramides from sphingosine, yield $(20 \mathrm{mg}, 37 \mu \mathrm{mol}, 79 \%) . R_{\mathrm{f}}=$ 0.48 (EtOAc/pentane, 1:1). $[\alpha]_{\mathrm{D}}^{22}=-7.6\left(c=1.0, \mathrm{MeO} / \mathrm{CHCl}_{3}, 1: 1\right)$. ${ }^{1} \mathrm{H}$ NMR $\left(600 \mathrm{MHz}, \mathrm{CDCl}_{3}\right): \delta=6.26(\mathrm{~d}, J=7.8 \mathrm{~Hz}, 1 \mathrm{H}), 5.78$ $(\mathrm{dt}, J=15.4,7.0 \mathrm{~Hz}, 1 \mathrm{H}), 5.53(\mathrm{dd}, J=15.4,6.5 \mathrm{~Hz}, 1 \mathrm{H}), 4.31$ (t, $J=4.7 \mathrm{~Hz}, 1 \mathrm{H}), 3.95(\mathrm{dd}, J=11.2,3.8 \mathrm{~Hz}, 1 \mathrm{H}), 3.90(\mathrm{~m}, 1$ H), 3.70 (dd, $J=11.4,3.6 \mathrm{~Hz}, 1 \mathrm{H}), 3.00-2.60$ (br. s, $2 \mathrm{H}), 2.23$ (t, $J=7.7 \mathrm{~Hz}, 2 \mathrm{H}), 2.05(\mathrm{q}, J=7.2 \mathrm{~Hz}, 2 \mathrm{H}), 1.63(\mathrm{~m}, 2 \mathrm{H}), 140$ $1.21(\mathrm{~m}, 46 \mathrm{H}), 0.88(\mathrm{t}, J=7.0 \mathrm{~Hz}, 6 \mathrm{H}) \mathrm{ppm} .{ }^{13} \mathrm{C} \mathrm{NMR}(150 \mathrm{MHz}$, $\left.\mathrm{CDCl}_{3}\right): \delta=174.1,134.4,128.9,74.5,62.4,54.7,37.0,32.4,32.08$, $29.86(4 \times), 29.85(4 \times), 29.82(3 \times), 29.80,29.78,29.67,29.65$, $29.53,29.52 \times 2,29.45,29.39,29.28,25.92,22.84,14.3(2 \times) \mathrm{ppm}$. IR (neat): $\tilde{v}=3308,2914,2865,1645,1548,1464,1049,959$, $719 \mathrm{~cm}^{-1}$. HRMS: calcd. for $\left[\mathrm{C}_{34} \mathrm{H}_{67} \mathrm{NO}_{3}+\mathrm{H}\right]^{+} 538.5121$; found 538.5192 .

2- $\mathrm{N}-\left(\left[3,4,5-{ }^{13} \mathrm{C}_{3}\right]-\right.$ Hexadecanoyl)-sphingosine (32b): See the general procedure for the synthesis of ceramides from sphingosine, yield (14 mg, $25 \mu \mathrm{mmol}, 71 \%) . R_{\mathrm{f}}=0.48$ (EtOAc/pentane, $\left.1: 1\right) .[\alpha]_{\mathrm{D}}^{22}=$ $-8.0\left(c=0.1, \mathrm{MeOH} / \mathrm{CHCl}_{3}, 1: 1\right) .{ }^{1} \mathrm{H} \mathrm{NMR}\left(600 \mathrm{MHz}, \mathrm{CDCl}_{3} /\right.$ [D $\left.\mathrm{D}_{4}\right]$ methanol): $\delta=6.26(\mathrm{~d}, J=7.8 \mathrm{~Hz}, 1 \mathrm{H}), 5.78(\mathrm{dt}, J=15.4$, $7.0 \mathrm{~Hz}, 1 \mathrm{H}), 5.53(\mathrm{dd}, J=15.4,6.5 \mathrm{~Hz}, 1 \mathrm{H}), 4.31(\mathrm{t}, J=4.7 \mathrm{~Hz}$, $1 \mathrm{H}), 3.95$ (dd, $J=11.2,3.8 \mathrm{~Hz}, 1 \mathrm{H}), 3.90(\mathrm{~m}, 1 \mathrm{H}), 3.70$ (dd, $J=$ 11.4, 3.6 Hz, $1 \mathrm{H}$ ), 3.00-2.60 (br. s, $2 \mathrm{H}$ ), 2.23 (m, $2 \mathrm{H}$ ), 2.05 (q, $J$ $=7.2 \mathrm{~Hz}, 2 \mathrm{H}), 1.63(\mathrm{dm}, J=130 \mathrm{~Hz}, 2 \mathrm{H}), 1.45-1.15(\mathrm{~m}, 46 \mathrm{H})$, $0.88(\mathrm{t}, J=7.0 \mathrm{~Hz}, 6 \mathrm{H}) \mathrm{ppm} .{ }^{13} \mathrm{C} \mathrm{NMR}\left(151 \mathrm{MHz}, \mathrm{CDCl}_{3} /\left[\mathrm{D}_{4}\right]\right.$ methanol): $\delta=174.1,134.4,128.9,74.8,62.6,54.7,37.0(\mathrm{~d}, J=$ $35.0 \mathrm{~Hz}), 32.4,32.0,29.91,29.85-29.38(\mathrm{~m}), 26.15-25.79(\mathrm{~m})$, 22.84, $14.3(2 \times)$ ppm. IR (neat): $\tilde{v}=3293,2914,2847,1636,1547$, 1465, 1038, 972, $721 \mathrm{~cm}^{-1}$. HRMS: calcd. for $\left[\mathrm{C}_{31}{ }^{13} \mathrm{C}_{3} \mathrm{H}_{67} \mathrm{NO}_{3}+\right.$ $\mathrm{H}]^{+}$541.5121; found 541.5293.

2- $N$-(Hexadecanoyl)-[5,6,7,8,9-13 $\left.\mathrm{C}_{5}\right]$-sphingosine (32c): See the general procedure for the synthesis of ceramides from sphingosine, yield (12 mg, $22 \mu \mathrm{mol}, 73 \%) . R_{\mathrm{f}}=0.48($ EtOAc/pentane, 1:1). $[\alpha]_{\mathrm{D}}^{22}=-7.2\left(c=0.25, \mathrm{MeOH} / \mathrm{CHCl}_{3}, 1: 1\right) .{ }^{1} \mathrm{H} \mathrm{NMR}(600 \mathrm{MHz}$, $\left.\mathrm{CDCl}_{3}\right): \delta=6.31(\mathrm{~d}, J=7.8 \mathrm{~Hz}, 1 \mathrm{H}), 5.76(\mathrm{dm}, J=150.0 \mathrm{~Hz}, 1$ $\mathrm{H}), 5.53(\mathrm{~m}, 1 \mathrm{H}), 4.30(\mathrm{~m}, 1 \mathrm{H}), 3.95(\mathrm{~m}, 1 \mathrm{H}), 3.90(\mathrm{~m}, 1 \mathrm{H}), 3.70$ (m, $1 \mathrm{H}), 3.00-2.60$ (br. s, $2 \mathrm{H}), 2.22$ (t, $J=7.9 \mathrm{~Hz}, 2 \mathrm{H}), 2.05$ (dm, $J=124.0 \mathrm{~Hz}, 2 \mathrm{H}), 1.63(\mathrm{~m}, 2 \mathrm{H}), 1.52-1.13(\mathrm{~m}, 46 \mathrm{H}), 0.88(\mathrm{t}, J$ $=7.0 \mathrm{~Hz}, 6 \mathrm{H}) \mathrm{ppm} .{ }^{13} \mathrm{C} \mathrm{NMR}\left(151 \mathrm{~Hz}, \mathrm{CDCl}_{3}\right): \delta=174.2,133.0$ (d, $J=43.0 \mathrm{~Hz}), 129.1(\mathrm{~d}, J=72.0 \mathrm{~Hz}), 74.7(\mathrm{~d}, J=20.8 \mathrm{~Hz}), 62.6$, $54.6(\mathrm{~d}, J=2.6 \mathrm{~Hz}), 37.0,32.8-32.0(\mathrm{~m}), 29.9-29.0(\mathrm{~m}), 28.25-$ $27.74(\mathrm{~m}), 25.92(\mathrm{~m}), 22.84,14.3(2 \times)$ ppm. IR (neat): $\tilde{v}=3300$, 2914, 2847, 1701, 1635, 1547, 1464, 1124, 970, $719 \mathrm{~cm}^{-1}$. HRMS: calcd. for $\left[\mathrm{C}_{29}{ }^{13} \mathrm{C}_{5} \mathrm{H}_{67} \mathrm{NO}_{3}+\mathrm{H}\right]^{+}$543.5121; found 543.5358 .

2- $N$-([3,4,5-13 $\left.\mathrm{C}_{3}\right]-$ Hexadecanoyl)-[5,6,7,8,9-13 $\left.\mathrm{C}_{5}\right]$-sphingosine (32d): See the general procedure for the synthesis of ceramides from sphingosine, yield $(18 \mathrm{mg}, 33 \mu \mathrm{mol}, 81 \%) . R_{\mathrm{f}}=0.48$ (EtOAc/pentane, 1:1). $[\alpha]_{\mathrm{D}}^{22}=-7.0\left(c=0.33, \mathrm{MeOH} / \mathrm{CHCl}_{3}, 1: 1\right) .{ }^{1} \mathrm{H} \mathrm{NMR}$ $\left(600 \mathrm{MHz}, \mathrm{CDCl}_{3}\right): \delta=6.26(\mathrm{~d}, J=7.8 \mathrm{~Hz}, 1 \mathrm{H}), 5.76(\mathrm{dm}, J=$ $150.0 \mathrm{~Hz}, 1 \mathrm{H}), 5.53(\mathrm{~m}, 1 \mathrm{H}), 4.31(\mathrm{~m}, 1 \mathrm{H}), 3.95$ (dd, $J=11.2$, $4.0 \mathrm{~Hz}, 1 \mathrm{H}), 3.90$ (m, $2 \mathrm{H}), 3.70$ (dd, $J=11.4,3.2 \mathrm{~Hz}, 1 \mathrm{H}), 3.00$ 2.60 (br. s, $2 \mathrm{H}), 2.23$ (m, $2 \mathrm{H}), 2.05$ (dm, $J=124.0 \mathrm{~Hz}, 2 \mathrm{H}), 1.63$ $(\mathrm{dm}, J=130 \mathrm{~Hz}, 2 \mathrm{H}), 1.50-1.15(\mathrm{~m}, 46 \mathrm{H}), 0.88(\mathrm{t}, J=7.0 \mathrm{~Hz}, 6$ H) ppm. ${ }^{13} \mathrm{C}$ NMR $\left(151 \mathrm{MHz}, \mathrm{CDCl}_{3}\right): \delta=174.1,134.4$ (d, $J=$ $43.0 \mathrm{~Hz}), 128.8(\mathrm{~d}, J=72.0 \mathrm{~Hz}), 74.5(\mathrm{~d}, J=20.8 \mathrm{~Hz}), 62.6,54.6$ $(\mathrm{d}, J=2.6 \mathrm{~Hz}), 37.0(\mathrm{~d}, J=35.0 \mathrm{~Hz}), 32.8-32.0(\mathrm{~m}), 29.9-29.0(\mathrm{~m})$, 28.2-27.7 (m), 26.2-25.6 (m), 21.7, $14.3(2 \times)$ ppm. IR (neat): $\tilde{v}=$ 3294, 2914, 2847, 1699, 1636, 1547, 1464, 1040, 970, $719 \mathrm{~cm}^{-1}$. HRMS: calcd. for $\left[\mathrm{C}_{26}{ }^{13} \mathrm{C}_{8} \mathrm{H}_{67} \mathrm{NO}_{3}+\mathrm{H}\right]^{+} 546.5121$; found 546.5461 .

Sphinganine (33a): 3-O-Benzoyl- $N$-(tert-butyloxycarbonyl)-Derythro-sphingosine (23a; $36.8 \mathrm{mg}, 0.07 \mathrm{mmol}, 1.0$ equiv.) was dissolved in methanol $(2.4 \mathrm{~mL})$, and sodium methoxide (30\% in methanol; $4.6 \mu \mathrm{L}, 0.035 \mathrm{mmol}, 0.5$ equiv.) was added. The reaction mixture was stirred at room temperature until TLC showed full conversion into a lower-running spot. Potassium hydroxide $(0.5 \mathrm{M}$ in water; $0.28 \mathrm{~mL}, 0.14 \mathrm{mmol}, 2.0$ equiv.)was added, and the reaction mixture was stirred overnight at ambient temperature. The reaction was quenched with acetic acid $(0.019 \mathrm{~mL}, 0.35 \mathrm{mmol}, 5.0$ equiv.), and then the mixture was concentrated in vacuo. The residue was coevaporated once with toluene $(4.0 \mathrm{~mL})$.

The residue was dissolved in EtOAc $(1 \mathrm{~mL})$. The solution was purged with argon, and then platinum dioxide $(1.5 \mathrm{mg}$, $0.007 \mathrm{mmol}, 0.1$ equiv.) was added. The reaction mixture was stirred under a flow of hydrogen gas for $30 \mathrm{~min}$, and then it was left under a hydrogen atmosphere overnight. The platinum dioxide residue was removed by filtration through a plug of Celite, and then rinsed with EtOAc. The filtrate was concentrated in vacuo.

The resulting residue was cooled to $0{ }^{\circ} \mathrm{C}$, and then water $(1 \mathrm{~mL})$ and TFA $(2 \mathrm{~mL})$ were added. The reaction mixture was stirred for $2 \mathrm{~min}$ at $0{ }^{\circ} \mathrm{C}$, then it was diluted with toluene $(4 \mathrm{~mL})$, and concentrated in vacuo. Purification by HPLC-MS (52-62\% B, following the general procedure for HPLC-MS purifications) gave compound 33a $(10 \mathrm{mg}, 33 \mu \mathrm{mol}, 47 \%)$ as a TFA adduct. $[\alpha]_{\mathrm{D}}^{22}=-7.0(c=0.1$, $\mathrm{MeOH}) .{ }^{1} \mathrm{H}$ NMR $\left(600 \mathrm{MHz},\left[\mathrm{D}_{4}\right]\right.$ methanol): $\delta=3.83$ (dd, $J=$ 11.6, $4.0 \mathrm{~Hz}, 1 \mathrm{H}), 3.77$ (dt, $J=8.4,4.2 \mathrm{~Hz}, 1 \mathrm{H}), 3.70(\mathrm{dd}, J=$ $11.5,8.7 \mathrm{~Hz}, 1 \mathrm{H}), 3.19(\mathrm{dt}, J=8.3,3.9 \mathrm{~Hz}, 1 \mathrm{H}), 1.55-1.22(\mathrm{~m}, \mathrm{H}$ 28), 0.90 (t, $J=7.0 \mathrm{~Hz}, 3 \mathrm{H}) \mathrm{ppm} .{ }^{13} \mathrm{C}$ NMR $(151 \mathrm{MHz}$, [D 4 methanol): $\delta=70.3,58.8,58.4,34.2,33.1,30.84(4 \times), 30.78,30.77$, $30.74,30.70,30.57,30.49,27.0,23.8,14.5$ ppm. IR (neat): $\tilde{v}=3150$, 2914, 2849, 1676, 1207, 1186, 1153, 1126, 1053, 840, 800, $721 \mathrm{~cm}^{-1}$. HRMS: calcd. for $\left[\mathrm{C}_{18} \mathrm{H}_{39} \mathrm{NO}_{2}+\mathrm{H}\right]^{+} 302.2981$; found 302.3054 .

[5,6,7,8,9- $\left.{ }^{13} \mathbf{C}_{5}\right]-$ Sphinganine (33b): $\left[5,6,7,8,9-{ }^{13} \mathrm{C}_{5}\right]-3-O$-Benzoyl- $N$ (tert-butoxycarbonyl)-D-erythro-sphingosine $(\mathbf{2 3 b} ; 81.4 \mathrm{mg}$, $0.16 \mathrm{mmol}, 1.0$ equiv.) was dissolved in methanol $(5.5 \mathrm{~mL})$, and sodium methoxide ( $30 \%$ in methanol; $10 \mu \mathrm{L}, 0.08 \mathrm{mmol}, 0.5$ equiv.) was added. The reaction mixture was stirred at room temperature until TLC showed full conversion into a lower-running spot. Potassium hydroxide ( $0.5 \mathrm{~m}$ in water; $0.64 \mathrm{~mL}, 0.32 \mathrm{mmol}, 2.0$ equiv.)was added, and the reaction mixture was stirred overnight at ambient temperature. The reaction was quenched with acetic acid $(4.4 \mu \mathrm{L}$, $0.8 \mathrm{mmol}, 5.0$ equiv.), then the mixture was concentrated in vacuo. The residue was coevaporated once with toluene $(10 \mathrm{~mL})$.

The residue was dissolved in EtOAc $(2 \mathrm{~mL})$. The solution was purged with argon, then platinum dioxide $(3.6 \mathrm{mg}, 0.016 \mathrm{mmol}$, 0.1 equiv.) was added. The reaction mixture was stirred under a flow of hydrogen gas for $30 \mathrm{~min}$, and then it was left under a hydrogen atmosphere overnight. The platinum dioxide residue was removed by filtration through a plug of Celite, and then rinsed with EtOAc. The filtrate was concentrated in vacuo. 
The residue was cooled to $0{ }^{\circ} \mathrm{C}$, then water $(0.5 \mathrm{~mL})$ and TFA $(1.5 \mathrm{~mL})$ were added. The reaction mixture was stirred for $2 \mathrm{~min}$ at $0{ }^{\circ} \mathrm{C}$, then it was diluted with toluene $(10 \mathrm{~mL})$ and concentrated in vacuo. Purification by HPLC-MS $(52-62 \% \mathrm{~B}$, following the general procedure for HPLC-MS purifications) gave compound 33b $(25 \mathrm{mg}, 83 \mu \mathrm{mol}, 52 \%)$ as a TFA adduct. $[\alpha]_{\mathrm{D}}^{22}=-7.5(c=0.1$, $\mathrm{MeOH}) .{ }^{1} \mathrm{H}$ NMR $\left(600 \mathrm{MHz},\left[\mathrm{D}_{4}\right]\right.$ methanol): $\delta=3.83$ (dd, $J=$ $11.5,4.0 \mathrm{~Hz}, 1 \mathrm{H}), 3.76(\mathrm{dt}, J=8.3,4.3 \mathrm{~Hz}, 1 \mathrm{H}), 3.69(\mathrm{dd}, J=$ $11.5,8.8 \mathrm{~Hz}, 1 \mathrm{H}), 3.18(\mathrm{dt}, J=8.9,4.0 \mathrm{~Hz}, 1 \mathrm{H}), 1.65-1.15(\mathrm{~m}, 28$ $\mathrm{H}), 0.90(\mathrm{t}, J=7.0 \mathrm{~Hz}, 3 \mathrm{H}) \mathrm{ppm} .{ }^{13} \mathrm{C}$ NMR $\left(151 \mathrm{MHz},\left[\mathrm{D}_{4}\right]\right.$ methanol): $\delta=70.3,58.6,58.4,34.1(\mathrm{~d}, J=34.7 \mathrm{~Hz}), 33.1,31.1-30.2$ (m), 27.3-26.7 (m), 23.8, 14.5 (C-18) ppm. IR (neat): $\tilde{v}=3120$, 2914, 2847, 1676, 1206, 1186, 1153, 1130, 840, 800, $723 \mathrm{~cm}^{-1}$. HRMS: calcd. for $\left[\mathrm{C}_{18} \mathrm{H}_{39} \mathrm{NO}_{2}+\mathrm{H}\right]^{+} 307.2981$; found 307.3222 .

Dihydroceramide (34a): See the general procedure for the synthesis of ceramides from sphingosine, yield $(12 \mathrm{mg}, 22 \mu \mathrm{mol}, 68 \%) . R_{\mathrm{f}}=$ 0.50 (EtOAc/pentane, 1:1). $[a]_{\mathrm{D}}^{22}=+4.5\left(c=0.15, \mathrm{MeOH} / \mathrm{CHCl}_{3}\right.$, 1:1). ${ }^{1} \mathrm{H}$ NMR $\left(600 \mathrm{MHz}, \mathrm{CDCl}_{3}, 318 \mathrm{~K}\right): \delta=6.36(\mathrm{~d}, J=7.6 \mathrm{~Hz}$, $1 \mathrm{H}), 4.01(\mathrm{~d}, J=11.3 \mathrm{~Hz}, 1 \mathrm{H}), 3.83(\mathrm{~m}, 1 \mathrm{H}), 3.80-3.72(\mathrm{~m}, 2$ H), 2.90-2.50 (br. s, $2 \mathrm{H}), 2.23$ (t, $J=7.4 \mathrm{~Hz}, 2 \mathrm{H}), 1.68-1.59$ (m, $4 \mathrm{H}), 1.59-1.45$ (m, $2 \mathrm{H}), 1.38-1.19(\mathrm{~m}, 46 \mathrm{H}), 0.88$ (t, $J=7.2 \mathrm{~Hz}$, $6 \mathrm{H}) \mathrm{ppm} .{ }^{13} \mathrm{C}$ NMR $\left(151 \mathrm{MHz}, \mathrm{CDCl}_{3}, 318 \mathrm{~K}\right): \delta=173.7,74.4$, $62.7,54.2,37.1,34.7,32.10,29.86(4 \times), 29.84(3 \times), 29.82(3 \times)$, $29.79(2 \times), 29.75(3 \times), 29.72,29.71,29.67,29.66,29.52,29.51$ $(2 \times), 29.48,22.84,14.2(2 \times) \mathrm{ppm}$. IR (neat): $\tilde{v}=3395,2914,2849$, $1738,1630,1570,1470,1047,719 \mathrm{~cm}^{-1}$. HRMS: calcd. for $\left[\mathrm{C}_{34} \mathrm{H}_{67} \mathrm{NO}_{3}+\mathrm{H}\right]^{+}$540.5121; found 540.5347 .

2- $N$-([3,4,5-13 $\left.\mathrm{C}_{3}\right]$-Hexadecanoyl)-sphinganine (34b): See the general procedure for the synthesis of ceramides from sphingosine $(15 \mathrm{mg}$, $27 \mu \mathrm{mol}, 74 \%) . R_{\mathrm{f}}=0.50($ EtOAc/pentane, $1: 1) \cdot[\alpha]_{\mathrm{D}}^{22}=+4.8(c=$ $\left.0.1, \mathrm{MeOH} / \mathrm{CHCl}_{3}, 1: 1\right) .{ }^{1} \mathrm{H}$ NMR $\left(600 \mathrm{MHz}, \mathrm{CDCl}_{3}, 318 \mathrm{~K}\right): \delta=$ $6.26(\mathrm{~d}, J=7.6 \mathrm{~Hz}, 1 \mathrm{H}), 4.01(\mathrm{~d}, J=11.3 \mathrm{~Hz}, 1 \mathrm{H}), 3.83(\mathrm{~m}, 1$ H), 3.80-3.72 (m, 2 H), 2.80-2.40 (br. s, 2 H), 2.23 (m, 2 H), 1.80$1.10(\mathrm{~m}, 54 \mathrm{H}), 0.88(\mathrm{t}, J=7.2 \mathrm{~Hz}, 6 \mathrm{H}) \mathrm{ppm} .{ }^{13} \mathrm{C} \mathrm{NMR}(151 \mathrm{MHz}$, $\left.\mathrm{CDCl}_{3}, 318 \mathrm{~K}\right): \delta=173.7,74.5,62.7,54.1,37.1(\mathrm{~d}, J=34.0 \mathrm{~Hz})$, $34.8,32.09,29.9-29.3$ (m), 29.18, 26.2-25.8 (m), 25.67, 22.83, 14.2 $(2 \times)$ ppm. IR (neat): $\tilde{v}=3394,2914,2849,1738,1630,1570,1470$, 1049, $719 \mathrm{~cm}^{-1}$. HRMS: calcd. for $\left[\mathrm{C}_{31}{ }^{13} \mathrm{C}_{3} \mathrm{H}_{67} \mathrm{NO}_{3}+\mathrm{H}\right]^{+}$ 543.5121; found 543.5442 .

2- $\mathrm{N}$-(Hexadecanoyl)-[5,6,7,8,9-13 $\left.\mathrm{C}_{5}\right]$-sphinganine (34c): See the general procedure for the synthesis of ceramides from sphingosine, yield (14 mg, $25 \mu \mathrm{mol}, 65 \%) . R_{\mathrm{f}}=0.50($ EtOAc/pentane, $1: 1)$. $[\alpha]_{\mathrm{D}}^{22}=+5.2\left(c=0.25, \mathrm{MeOH} / \mathrm{CHCl}_{3}, 1: 1\right) .{ }^{1} \mathrm{H} \mathrm{NMR}(600 \mathrm{MHz}$, $\left.\mathrm{CDCl}_{3}, 318 \mathrm{~K}\right): \delta=6.26(\mathrm{~d}, J=7.6 \mathrm{~Hz}, 1 \mathrm{H}), 4.01(\mathrm{~d}, J=11.3 \mathrm{~Hz}$, $1 \mathrm{H}), 3.83(\mathrm{~m}, 1 \mathrm{H}), 3.80-3.72(\mathrm{~m}, 2 \mathrm{H}), 2.70-2.40$ (br. s, $2 \mathrm{H}) 2.22$ $(\mathrm{t}, J=7.9 \mathrm{~Hz}, 2 \mathrm{H}), 1.65-1.15(\mathrm{~m}, 54 \mathrm{H}), 0.89(\mathrm{t}, J=7.2 \mathrm{~Hz}, 6 \mathrm{H})$ ppm. ${ }^{13} \mathrm{C}$ NMR $\left(151 \mathrm{MHz}, \mathrm{CDCl}_{3}, 318 \mathrm{~K}\right): \delta=173.7,74.4,62.7$, $54.1(\mathrm{~d}, J=2.6 \mathrm{~Hz}), 37.1,34.8(\mathrm{~d}, J=35.0 \mathrm{~Hz}), 34.0,32.1029 .9-$ $29.5(\mathrm{~m}), 26.4-25.8(\mathrm{~m}), 22.8,14.2(2 \times) \mathrm{ppm}$. IR (neat): $\tilde{v}=3399$, 2914, 2849, 1630, 1568, 1470, 1047, $717 \mathrm{~cm}^{-1}$. HRMS: calcd. for $\left[\mathrm{C}_{29}{ }^{13} \mathrm{C}_{5} \mathrm{H}_{67} \mathrm{NO}_{3}+\mathrm{H}\right]^{+}$545.5121; found 545.5515.

2- $\mathrm{N}$-([3,4,5-13 $\left.\mathrm{C}_{3}\right]$-Hexadecanoyl)-[5,6,7,8,9-13 $\left.\mathrm{C}_{5}\right]$-sphinganine (34d): See the general procedure for the synthesis of ceramides from sphingosine, yield $(18 \mathrm{mg}, 33 \mu \mathrm{mol}, 66 \%) . R_{\mathrm{f}}=0.50$ (EtOAc/pentane, 1:1). $[a]_{\mathrm{D}}^{22}=+5.0\left(c=0.25, \mathrm{MeOH} / \mathrm{CHCl}_{3}, 1: 1\right) .{ }^{1} \mathrm{H} \mathrm{NMR}$ $\left(600 \mathrm{MHz}, \mathrm{CDCl}_{3}, 318 \mathrm{~K}\right): \delta=6.26(\mathrm{~d}, J=7.6 \mathrm{~Hz}, 1 \mathrm{H}), 4.01(\mathrm{~d}$, $J=11.3 \mathrm{~Hz}, 1 \mathrm{H}), 3.83(\mathrm{~m}, 1 \mathrm{H}), 3.80-3.72$ (m, $2 \mathrm{H}), 2.55$ (br. s, 1 H), 2.45 (br. s, $1 \mathrm{H}), 2.23$ (m, $2 \mathrm{H}), 1.72-1.12(\mathrm{~m}, 54 \mathrm{H}), 0.88$ (t, $J$ $=7.2 \mathrm{~Hz}, 6 \mathrm{H}) \mathrm{ppm} \cdot{ }^{13} \mathrm{C} \mathrm{NMR}\left(151 \mathrm{MHz}, \mathrm{CDCl}_{3}, 318 \mathrm{~K}\right): \delta=\delta$ $=173.7,74.4,62.7,54.1(\mathrm{~d}, J=2.6 \mathrm{~Hz}), 37.1(\mathrm{~d}, J=35.0 \mathrm{~Hz}), 34.8$ (d, $J=35.0 \mathrm{~Hz}), 34.0(\mathrm{~m}), 32.1,30.0-29.3(\mathrm{~m}), 29.18,26.4-25.7$ (m), 25.67, 22.8, $14.2(2 \times)$ ppm. IR (neat): $\tilde{v}=3390,2914,2849$,
1726, 1630, 1572, 1470, 1047, $716 \mathrm{~cm}^{-1}$. HRMS: calcd. for $\left[\mathrm{C}_{26}{ }^{13} \mathrm{C}_{8} \mathrm{H}_{67} \mathrm{NO}_{3}+\mathrm{H}\right]^{+}$548.5121; found 548.5611.

Phenyl 4,6-O-(Di-tert-butylsilanediyl)-1-thio- $\beta$-D-glucosylpyranoside (35b): Phenyl 1-thio- $\boldsymbol{\beta}$-D-glucoside (35a; Scheme 5; $1.85 \mathrm{~g}$, $6.8 \mathrm{mmol}, 1.05$ equiv.) was dissolved in dry DMF (27 mmol) under an argon atmosphere. This solution was cooled down to $-40{ }^{\circ} \mathrm{C}$, and then di-tert-butylsilylbis(trifluoromethanesulfonate) $(2.1 \mathrm{~mL}$, $6.5 \mathrm{mmol}, 1$ equiv.) was added dropwise. The resulting reaction mixture was stirred at $-40{ }^{\circ} \mathrm{C}$ for $30 \mathrm{~min}$, and then pyridine (1.58 mL, $19.5 \mathrm{mmol}, 3$ equiv.) was added. The reaction mixture was stirred for a further $15 \mathrm{~min}$, and then it was transferred to an extraction funnel with $\mathrm{Et}_{2} \mathrm{O}(50 \mathrm{~mL})$. The organic phase was washed with water $(2 \times 100 \mathrm{~mL})$ and brine $(100 \mathrm{~mL})$. The aqueous layers were extracted with $\mathrm{Et}_{2} \mathrm{O}(50 \mathrm{~mL})$, and the combined organic extracts were dried $\left(\mathrm{Na}_{2} \mathrm{SO}_{4}\right)$, filtered, and concentrated in vacuo. Purification by silica column chromatography $\left(10 \% \mathrm{Et}_{2} \mathrm{O}\right.$ in petroleum ether) gave compound $35 \mathrm{~b}(2.16 \mathrm{~g}, 5.2 \mathrm{mmol}, 77 \%) . R_{\mathrm{f}}=0.8$ $\left(50 \%\right.$ EtOAc in petroleum ether). $[\alpha]_{\mathrm{D}}^{22}=-37\left(c=1.0, \mathrm{CHCl}_{3}\right),{ }^{1} \mathrm{H}$ NMR (400 MHz, $\left.\mathrm{CDCl}_{3}\right): \delta=7.53-7.50(\mathrm{~m}, 2 \mathrm{H}), 7.33-7.28(\mathrm{~m}, 3$ $\mathrm{H}), 4.61(\mathrm{~d}, J=10.0 \mathrm{~Hz}, 1 \mathrm{H}), 4.21(\mathrm{dd}, J=10.3,5.2 \mathrm{~Hz}, 1 \mathrm{H})$, $3.90(\mathrm{t}, J=10.2 \mathrm{~Hz}, 1 \mathrm{H}), 3.69(\mathrm{t}, J=9.2 \mathrm{~Hz}, 1 \mathrm{H}), 3.61(\mathrm{t}, J=$ $8.7 \mathrm{~Hz}, 1 \mathrm{H}), 3.49$ (m, $2 \mathrm{H}), 3.25$ (br. s, $2 \mathrm{H}), 1.05$ (s, $3 \mathrm{H}), 0.98$ (s, $3 \mathrm{H}) \mathrm{ppm} .{ }^{13} \mathrm{C}$ NMR $\left(101 \mathrm{MHz}, \mathrm{CDCl}_{3}\right): \delta=132.9,131.9,129.1$, 128.3, 88.6, 77.9, 76.5, 74.6, 71.9, 66.2, 27.5, 27.1, 22.8, $20.0 \mathrm{ppm}$. IR (neat): $\tilde{v}=3380,2931,2858,1472,1055,823,731,651 \mathrm{~cm}^{-1}$. HRMS: calcd. for $\left[\mathrm{C}_{20} \mathrm{H}_{32} \mathrm{O}_{5} \mathrm{SSi}+\mathrm{H}\right]^{+}$413.1740; found 413.1801 .

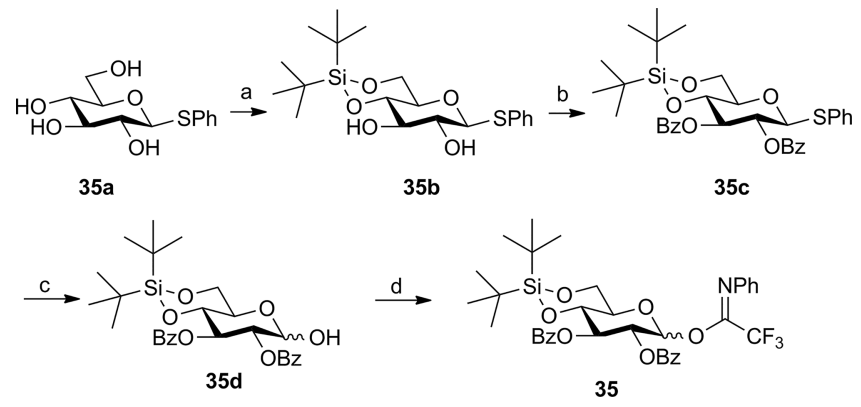

Scheme 5. Reagents and conditions: (a) $t \mathrm{Bu}_{2} \mathrm{SiOTf}_{2}$, pyridine, $\mathrm{DMF},-40{ }^{\circ} \mathrm{C}, 30 \mathrm{~min}, 77 \%$; (b) $\mathrm{BzCl}$, pyridine, room temp., $3 \mathrm{~h}$, $98 \%$; (c) NIS ( $N$-iodosuccinimide), TFA, $\mathrm{CH}_{2} \mathrm{Cl}_{2}, 0{ }^{\circ} \mathrm{C}, 3 \mathrm{~h}, 98 \%$; (d) $\mathrm{ClC}(\mathrm{NPh}) \mathrm{CF}_{3}, \mathrm{CsCO}_{3}$, acetone, $0{ }^{\circ} \mathrm{C}, 2 \mathrm{~h}, 80 \%$.

Phenyl 2,3-Di- $O$-benzoyl-4,6- $O$-(di-tert-butylsilanediyl)-1-thio- $\beta$-Dglucopyranoside (35c): Phenyl 4,6-O-(di-tert-butylsilanediyl)-1-thio$\beta$-D-glucosylpyranoside (35b; $2.16 \mathrm{~g}, 5.2 \mathrm{mmol}, 1.0$ equiv.) was dissolved in dry pyridine $(13 \mathrm{~mL})$, and benzoyl chloride $(3.25 \mathrm{~mL}$, $28.0 \mathrm{mmol}, 2.4$ equiv.) was added. The reaction mixture was stirred until TLC showed full conversion into a higher-running product. Then the reaction was quenched with methanol $(1 \mathrm{~mL})$, and the mixture was concentrated in vacuo. The residue was dissolved in EtOAc $(50 \mathrm{~mL})$, and this solution was washed with $\mathrm{HCl}(1 \mathrm{~N}$ aq.; $50 \mathrm{~mL})$, satd. aq. $\mathrm{NaHCO}_{3}(50 \mathrm{~mL})$, and brine $(50 \mathrm{~mL})$. The aqueous layers were extracted with EtOAc $(50 \mathrm{~mL})$, and the combined organic extracts were dried $\left(\mathrm{Na}_{2} \mathrm{SO}_{4}\right)$, filtered, and concentrated in vacuo. Purification by silica gel column chromatography $(10 \%$ $\mathrm{Et}_{2} \mathrm{O}$ in petroleum ether) gave compound 35c (3.18 g, $5.12 \mathrm{mmol}$, $98 \%) \cdot[a]_{\mathrm{D}}^{22}=+47.2\left(c=1.0, \mathrm{CHCl}_{3}\right) ; R_{\mathrm{f}}=0.7(15 \%$ EtOAc in petroleum ether). ${ }^{1} \mathrm{H} \mathrm{NMR}\left(400 \mathrm{MHz}, \mathrm{CDCl}_{3}\right): \delta=8.00-7.92(\mathrm{~m}$, $4 \mathrm{H}), 7.55-7.26(\mathrm{~m}, 11 \mathrm{H}), 5.59(\mathrm{t}, J=9.5 \mathrm{~Hz}, 1 \mathrm{H}), 5.39(\mathrm{t}, J=$ $9.8 \mathrm{~Hz}, 1 \mathrm{H}), 4.99(\mathrm{~d}, J=10.0 \mathrm{~Hz}, 1 \mathrm{H}), 4.31(\mathrm{dd}, J=10.0,5.1 \mathrm{~Hz}$, $1 \mathrm{H}), 4.10(\mathrm{t}, J=9.2 \mathrm{~Hz}, 1 \mathrm{H}), 4.01(\mathrm{t}, J=10.0 \mathrm{~Hz}, 1 \mathrm{H}), 3.69(\mathrm{td}$, 
$J=10.0,5.2 \mathrm{~Hz}, 1 \mathrm{H}), 0.973(\mathrm{~s}, 9 \mathrm{H}), 0.967(\mathrm{~s}, 9 \mathrm{H}) \mathrm{ppm} .{ }^{13} \mathrm{C}$ NMR $\left(101 \mathrm{MHz}, \mathrm{CDCl}_{3}\right): \delta=165.8,165.1,134.5,133.2,132.9$, $132.1,130.5,129.8,129.7,129.6,128.3,129.0,128.8,128.3,128.2$, 87.0, 76.2, 75.1, $74.970 .6,66.1,27.3,26.9,22.5,19.9$ ppm. IR (neat): $\tilde{v}=2959,2932,2883,2858,1732,1271,1177,1126,827$, $708 \mathrm{~cm}^{-1}$. HRMS: calcd. for $\left[\mathrm{C}_{34} \mathrm{H}_{40} \mathrm{O}_{7} \mathrm{SSi}+\mathrm{H}\right]^{+}$621.2344; found 621.2337

2,3-Di-O-benzoyl-4,6-O-(di-tert-butylsilanediyl)- $\alpha / \beta$-D-glucopyranose (35d): Phenyl 2,3-di-O-benzoyl-4,6-O-(di-tert-butylsilanediyl)1-thio- $\beta$-D-glucopyranoside (35c; Scheme 5; $6.27 \mathrm{~g}, 10.7 \mathrm{mmol}$, 1.0 equiv.) was dissolved in $\mathrm{CH}_{2} \mathrm{Cl}_{2}(100 \mathrm{~mL})$, and the solution was cooled to $0{ }^{\circ} \mathrm{C}$. $\mathrm{N}$-Iodosuccinimide $(4.81 \mathrm{~g}, 21.4 \mathrm{mmol}, 2.0$ equiv.) was added, followed by trifluoroacetic acid $(0.82 \mathrm{~mL}, 10.7 \mathrm{mmol}$, 1.0 equiv.). The reaction mixture was stirred under air until TLC showed full conversion. The mixture was transferred to an extraction funnel with EtOAc $(200 \mathrm{~mL})$, and it was washed with sodium thiosulfate $(20 \%$ aq.; $200 \mathrm{~mL})$, satd. aq. $\mathrm{NaHCO}_{3}(200 \mathrm{~mL})$, and brine $(200 \mathrm{~mL})$. The aqueous layers were extracted with EtOAc $(100 \mathrm{~mL})$, and the combined organic extracts were dried $\left(\mathrm{Na}_{2} \mathrm{SO}_{4}\right)$, filtered, and concentrated in vacuo. Purification by silica gel column chromatography ( $5 \%$ EtOAc in petroleum ether) gave compound 35d $(6.63 \mathrm{~g}, 10.5 \mathrm{mmol}, 98 \%, 5: 3 \alpha / \beta) . R_{\mathrm{f}}=0.1(10 \% \mathrm{EtOAc}$ in petroleum ether). ${ }^{1} \mathrm{H}$ NMR $\left(400 \mathrm{MHz}, \mathrm{CDCl}_{3}\right): \delta=8.10(\mathrm{~m}, 1$ H), 8.03-7.94 (m, 6 H), 7.60 (m, 0.6 H), 7.55-7.43 (m, 4.5 H), 7.41$7.32(\mathrm{~m}, 6.3 \mathrm{H}), 5.92(\mathrm{t}, J=9.1 \mathrm{~Hz}, 1 \mathrm{H}), 5.66-5.61(\mathrm{~m}, 1.6 \mathrm{H})$, $5.22(\mathrm{dd}, J=9.5,7.8 \mathrm{~Hz}, 0.6 \mathrm{H}), 5.18(\mathrm{dd}, J=10.3,3.9 \mathrm{~Hz}, 1 \mathrm{H})$, $4.97(\mathrm{~d}, J=8.1 \mathrm{~Hz}, 0.6 \mathrm{H}), 4.31-4.13(\mathrm{~m}, 3.2 \mathrm{H}), 4.12-4.06(\mathrm{~m}, 2$ H), 4.03-3.91 (m, $2 \mathrm{H}), 3.67(\mathrm{td}, J=10.4,5.2 \mathrm{~Hz}, 0.6 \mathrm{H}), 1.00$ $0.97(\mathrm{~m}, 25.2 \mathrm{H}) \mathrm{ppm} .{ }^{13} \mathrm{C} \mathrm{NMR}\left(101 \mathrm{MHz}, \mathrm{CDCl}_{3}\right): \delta=167.1$, $166.2,166.15,166.0,133.73,133.69,133.50,133.20,133.00,130.27$, $130.11,130.09,130.02,129.72,129.69,129.16,128.95,128.54$, 128.46, 128.40, 96.4, 90.9, 75.6, 75.3, 74.51, 74.47, 72.4, 74.3, 71.2, $66.73,66.52,66.32,27.44,27.41,27.00,26.96,22.75,22.72,20.08$, 20.05 ppm. IR (neat): $\tilde{v}=3431,2934,2859,1728,1277,1177,1070$, 827, $708 \mathrm{~cm}^{-1}$. HRMS: calcd. for $\left[\mathrm{C}_{26} \mathrm{H}_{38} \mathrm{O}_{8} \mathrm{Si}+\mathrm{H}\right]^{+}$529.2259; found 529.2256

2,3-Di- $O$-benzoyl-4,6- $O$-(di-tert-butylsilanediyl)-1- $O$-( $N$-[phenyl]-trifluoroacetimidoyl)- $\boldsymbol{\alpha} / \boldsymbol{\beta}$-D-glucopyranose (35): 2,3-Di- $O$-benzoyl-4,6$O$-(di-tert-butylsilanediyl)- $\alpha / \beta$-D-glucopyranose $(35 \mathrm{~d} ; 1.71 \mathrm{~g}$, $3.45 \mathrm{mmol}, 1.0$ equiv.) was dissolved in acetone $(20 \mathrm{~mL})$, and the solution was cooled to $0^{\circ} \mathrm{C}$. Cesium carbonate $(1.69 \mathrm{~g}, 5.18 \mathrm{mmol}$, 1.5 equiv.) was added, followed by chloro- $N$-phenyl-trifluoroimidiate $(0.78 \mathrm{~mL}, 5.18 \mathrm{mmol}, 1.5$ equiv. $)$, and the reaction mixture was stirred at $0{ }^{\circ} \mathrm{C}$ for $2 \mathrm{~h}$. The mixture was filtered, and the filtrate was concentrated in vacuo. Purifiaction by silica gel column chromatography (using silica gel that was neutralised by running an eluent of $3 \% \mathrm{Et}_{3} \mathrm{~N}$ in petroleum ether $(100 \mathrm{~mL})$ through the column; 0-5\% EtOAc, $20 \% \mathrm{CH}_{2} \mathrm{Cl}_{2}$ in petroleum ether) gave compound $35(1.93 \mathrm{~g}, 2.76 \mathrm{mmol}, 80 \%) . R_{\mathrm{f}}=0.1(10 \%$ EtOAc in petroleum ether). ${ }^{1} \mathrm{H}$ NMR $\left(400 \mathrm{MHz}, \mathrm{CDCl}_{3}\right): \delta=8.05-8.00(\mathrm{~m}, 4 \mathrm{H})$, 7.54-7.44 (m, $2 \mathrm{H}), 7.41-7.31(\mathrm{~m}, 4 \mathrm{H}), 7.28(\mathrm{~m}, 1 \mathrm{H}), 7.11(\mathrm{t}, J=$ $8.0 \mathrm{~Hz}, 2 \mathrm{H}), 7.00(\mathrm{t}, J=8.0 \mathrm{~Hz}, 1 \mathrm{H}), 6.74(\mathrm{~m}, 1 \mathrm{H}), 6.45(\mathrm{~m}, 1$ H), $5.98(\mathrm{~m}, 1 \mathrm{H}), 5.50(\mathrm{~m}, 1 \mathrm{H}), 4.32-4.20(\mathrm{~m}, 2 \mathrm{H}), 4.00(\mathrm{~m}, 1$ $\mathrm{H}), 1.05-0.97(\mathrm{~m}, 18 \mathrm{H}) \mathrm{ppm} .{ }^{13} \mathrm{C}$ NMR $\left(101 \mathrm{MHz}, \mathrm{CDCl}_{3}\right): \delta=$ $165.55,165.49,142.96,133.68,133.10,130.00,129.86,129.70$, $129.65,128.82,128.67,128.63,128.49,128.40,119.21,75.00,72.08$, $70.53,69.27,66.29,27.31,26.83,22.65,20.00 \mathrm{ppm}$. IR (neat): $\tilde{v}=$ 2959, 2936, 2860, 1728, 1273, 1211, 995, 766, $710 \mathrm{~cm}^{-1}$. HRMS: calcd. for $\left[\mathrm{C}_{36} \mathrm{H}_{40} \mathrm{~F}_{3} \mathrm{NO}_{8} \mathrm{Si}+\mathrm{H}\right]^{+}$700.2555; found 700.2549.

Glucosylsphingosine (36a): 2,3-di- $O$-Benzoyl-4,6-O-(di-tert-butylsilanediyl)-1- $O$-( $N$-[phenyl]-trifluoracetimidoyl)- $\alpha / \beta$-D-glucopyranose 35 ( $0.325 \mathrm{~g}, 0.465 \mathrm{mmol}, 1.3$ equiv.) and sphingosine acceptor 23a
(180 mg, $0.357 \mathrm{mmol}, 1.0$ equiv.) were coevaporated twice with toluene $(10 \mathrm{~mL})$, and then dissolved in anhydrous $\mathrm{CH}_{2} \mathrm{Cl}_{2}(4 \mathrm{~mL})$. Activated molecular sieves ( $3 \AA$ ) were added, and the mixture was stirred for $1 \mathrm{~h}$ at ambient temperature. The mixture was then cooled to $0{ }^{\circ} \mathrm{C}$, and $\mathrm{BF}_{3} \cdot \mathrm{OEt}_{2}(44 \mu \mathrm{L}, 0.36 \mathrm{mmol}, 1.0$ equiv.) was added. The reaction mixture was stirred until TLC showed a lower-running spot (removal of the Boc group from the sphingosine acceptor) (ca. $1 \mathrm{~h}$ ). The reaction mixture was transferred to an extraction funnel with EtOAc $(50 \mathrm{~mL})$, and washed with satd. aq. $\mathrm{NaHCO}_{3}(50 \mathrm{~mL})$ and brine $(50 \mathrm{~mL})$. The aqueous layers were extracted with EtOAc $(50 \mathrm{~mL})$, and the combined organic extracts were dried $\left(\mathrm{Na}_{2} \mathrm{SO}_{4}\right)$, filtered, and concentrated in vacuo. Purification by column chromatography $\left(2-5 \% \mathrm{Et}_{2} \mathrm{O}, 20 \% \mathrm{CH}_{2} \mathrm{Cl}_{2}\right.$ in petroleum ether) gave compound 36a (177 $\mathrm{mg}, 0.17 \mathrm{mmol}, 49 \%)$ as an amorphous solid. $R_{\mathrm{f}}=0.45\left(10 \% \mathrm{Et}_{2} \mathrm{O}, 20 \% \mathrm{CH}_{2} \mathrm{Cl}_{2}\right.$ in petroleum ether $) .[\alpha]_{\mathrm{D}}^{22}=+6.8\left(c=0.1, \mathrm{CHCl}_{3}\right) \cdot{ }^{1} \mathrm{H} \mathrm{NMR}(400 \mathrm{MHz}$, $\left.\mathrm{CDCl}_{3}\right): \delta=8.03-7.95(\mathrm{~m}, 6 \mathrm{H}), 7.56-7.48(\mathrm{~m}, 3 \mathrm{H}) 7.45-7.35(\mathrm{~m}$, $6 \mathrm{H}), 5.79(\mathrm{~m}, 1 \mathrm{H}), 5.56(\mathrm{t}, J=9.4 \mathrm{~Hz}, 1 \mathrm{H}), 5.50-5.41(\mathrm{~m}, 2 \mathrm{H})$, $5.35(\mathrm{dd}, J=10.4,7.8 \mathrm{~Hz}, 1 \mathrm{H}), 4.80(\mathrm{~d}, J=9.5 \mathrm{~Hz}, 1 \mathrm{H}), 4.68(\mathrm{~d}$, $J=7.8 \mathrm{~Hz}, 1 \mathrm{H}), 4.11-4.02(\mathrm{~m}, 3 \mathrm{H}), 3.97(\mathrm{dd}, J=10.2,4.5 \mathrm{~Hz}, 1$ $\mathrm{H}), 3.74(\mathrm{t}, J=10.2 \mathrm{~Hz}, 1 \mathrm{H}), 3.62(\mathrm{~m}, 1 \mathrm{H}), 3.55(\mathrm{~m}, 1 \mathrm{H}), 1.96$ $(\mathrm{q}, J=6.8 \mathrm{~Hz}, 2 \mathrm{H}), 1.34(\mathrm{~s}, 9 \mathrm{H}), 1.32-1.18(\mathrm{~m}, 22 \mathrm{H}), 0.95(\mathrm{~s}, 18$ $\mathrm{H}), 0.88(\mathrm{t}, J=6.8 \mathrm{~Hz}, 3 \mathrm{H}) \mathrm{ppm} .{ }^{13} \mathrm{C} \mathrm{NMR}\left(100 \mathrm{MHz}, \mathrm{CDCl}_{3}\right)$ : $\delta=165.9,165.4,165.1,155.4,137.6,133.3,133.1,133.0,130.6$, $129.9,129.8,129.7,129.5,128.5,128.4,124.7,101.4,79.5,75.1$, $74.8,74.4,72.1,70.8,67.9,66.0,52.4,32.4,32.0,29.80(4 \times), 29.71$, $29.59,29.48,29.35,28.92,28.4,27.4,26.922 .8,22.6,20.0$, 14.3 ppm. IR (neat): $\tilde{v}=3070,2958,2924,2854,1728,1271,1174$, 1103, 1070, $709 \mathrm{~cm}^{-1}$. HRMS: calcd. for $\left[\mathrm{C}_{58} \mathrm{H}_{83} \mathrm{NO}_{12} \mathrm{Si}+\mathrm{Na}\right]^{+}$ 1036.5685; found 1036.5584 .

$\mathbf{5 , 6 , 7 , 8 , 9 - 1 3} \mathrm{C}_{5}$ l-Glucosylsphingosine (36b): 2,3-di- $O$-Benzoyl-4,6- $O$ (di-tert-butylsilanediyl)-1-O-(N-[phenyl]-trifluoracetimidoyl)- $\alpha / \beta$ D-glucopyranose $(35 ; 0.27 \mathrm{~g}, 0.4 \mathrm{mmol}, 1.5$ equiv.) and sphingosine acceptor 23b (137 mg, $0.27 \mathrm{mmol}, 1.0$ equiv.) were coevaporated twice with toluene $(10 \mathrm{~mL})$, and then dissolved in anhydrous $\mathrm{CH}_{2} \mathrm{Cl}_{2}(3 \mathrm{~mL})$. Activated molecular sieves $(3 \AA)$ were added, and the mixture was stirred for $1 \mathrm{~h}$ at ambient temperature. Then the mixture was cooled to $0{ }^{\circ} \mathrm{C}$, and $\mathrm{BF}_{3} \cdot \mathrm{OEt}_{2}(35 \mu \mathrm{L}, 0.27 \mathrm{mmol}$, 1.0 equiv.) was added. The reaction mixture was stirred until TLC showed a lower-running spot (removal of the Boc group from the sphingosine acceptor) (ca. $1 \mathrm{~h}$ ). The mixture was transferred to an extraction funnel with EtOAc $(40 \mathrm{~mL})$, and it was washed with satd. aq. $\mathrm{NaHCO}_{3}(40 \mathrm{~mL})$ and brine $(40 \mathrm{~mL})$. The aqueous layers were extracted with EtOAc $(40 \mathrm{~mL})$, and the combined organic extracts were dried $\left(\mathrm{Na}_{2} \mathrm{SO}_{4}\right)$, filtered, and concentrated in vacuo. Purification by column chromatography $\left(2-5 \% \mathrm{Et}_{2} \mathrm{O}, 20 \% \mathrm{CH}_{2} \mathrm{Cl}_{2}\right.$ in petroleum ether) gave compound $\mathbf{3 6} \mathbf{b}(147 \mathrm{mg}, 0.145 \mathrm{mmol}$, $54 \%)$ as an amorphous solid. $R_{\mathrm{f}}=0.45\left(10 \% \mathrm{Et}_{2} \mathrm{O}, 20 \% \mathrm{CH}_{2} \mathrm{Cl}_{2}\right.$ in petroleum ether). $[a]_{\mathrm{D}}^{22}=+6.0\left(c=0.1, \mathrm{CHCl}_{3}\right) .{ }^{1} \mathrm{H} \mathrm{NMR}$ $\left(400 \mathrm{MHz}, \mathrm{CDCl}_{3}\right): \delta=8.03-7.95(\mathrm{~m}, 6 \mathrm{H}), 7.57-7.48(\mathrm{~m}, 3 \mathrm{H})$ $7.45-7.34(\mathrm{~m}, 6 \mathrm{H}), 5.79(\mathrm{dm}, J=151.2 \mathrm{~Hz}, 1 \mathrm{H}), 5.55(\mathrm{t}, J=$ $9.4 \mathrm{~Hz}, 1 \mathrm{H}), 5.50-5.41(\mathrm{~m}, 2 \mathrm{H}), 5.35(\mathrm{dd}, J=10.4,7.8 \mathrm{~Hz}, 1 \mathrm{H})$, $4.79(\mathrm{~d}, J=8.9 \mathrm{~Hz}, 1 \mathrm{H}), 4.67(\mathrm{~d}, J=7.8 \mathrm{~Hz}, 1 \mathrm{H}), 4.11-4.02(\mathrm{~m}$, $3 \mathrm{H}, 4-\mathrm{H}), 3.98(\mathrm{dd}, J=10.2,4.5 \mathrm{~Hz}, 1 \mathrm{H}), 3.74(\mathrm{t}, J=10.2 \mathrm{~Hz}, 1$ $\mathrm{H}), 3.62(\mathrm{~m}, 1 \mathrm{H}), 3.55(\mathrm{~m}, 1 \mathrm{H}), 1.96(\mathrm{dm}, J=126.2 \mathrm{~Hz}, 2 \mathrm{H})$, $1.34-1.10(\mathrm{~m}, 31 \mathrm{H}), 0.95(\mathrm{~s}, 18 \mathrm{H}), 0.88(\mathrm{t}, J=6.8 \mathrm{~Hz}, 3 \mathrm{H}) \mathrm{ppm}$. ${ }^{13} \mathrm{C} \mathrm{NMR}\left(100 \mathrm{MHz}, \mathrm{CDCl}_{3}\right): \delta=166.0,165.4,165.1,155.4,137.6$ $(\mathrm{d}, J=42.6 \mathrm{~Hz}), 133.3,133.1,133.0,130.6,129.9,129.8,129.7$, 129.5, 128.5, 128.4, 124.7 (d, $J=71.2 \mathrm{~Hz}), 101.4,79.5,75.1,74.8$, $74.4(\mathrm{~d}, J=5.2 \mathrm{~Hz}), 72.1,70.8,67.9,66.0,52.4,32.4(\mathrm{~m}), 32.0$, 29.80-28.4 (m), 27.4, 26.9, 22.8, 22.6, 20.0, 14.3 ppm. IR (neat): $\tilde{v}$ = 3070, 2922, 2854, 1724, 1267, 1172, 1069, 827, $708 \mathrm{~cm}^{-1}$. HRMS: calcd. for $\left[\mathrm{C}_{53}{ }^{13} \mathrm{C}_{5} \mathrm{H}_{83} \mathrm{NO}_{12} \mathrm{Si}+\mathrm{H}\right]^{+}$1041.5748; found 1041.5748. 
Glucosylsphingosine (37a): Protected glucosyl sphingosine 36a (130 mg, $0.128 \mathrm{mmol}, 1.0$ equiv.) was dissolved in THF/pyridine (4:1) $(15 \mathrm{~mL})$, and hydrogen fluoride $(70 \%$ in pyridine; $53 \mu \mathrm{L}$, $0.256 \mathrm{mmol}, 2.0$ equiv.) was added. The reaction mixture was stirred at room temperature until TLC showed full conversion [ca. $2 \mathrm{~h}$; product $R_{\mathrm{f}}=0.75\left(40 \%\right.$ EtOAc in $\mathrm{CH}_{2} \mathrm{Cl}_{2}$ ]. The mixture was concentrated in vacuo, the residue was redissolved in EtOAc $(30 \mathrm{~mL})$, and this solution was washed with $\mathrm{HCl}(1 \mathrm{M} \mathrm{aq}$.; $30 \mathrm{~mL})$, satd. aq. $\mathrm{NaHCO}_{3}(30 \mathrm{~mL})$, and brine $(30 \mathrm{~mL})$. The aqueous layers were extracted with EtOAc $(30 \mathrm{~mL})$, and the combined organic extracts were dried $\left(\mathrm{Na}_{2} \mathrm{SO}_{4}\right)$, filtered, and concentrated in vacuo.

The crude mixture was dissolved in $\mathrm{MeOH}(13 \mathrm{~mL})$, and sodium methoxide ( $30 \%$ in methanol; $18 \mu \mathrm{L}, 0.128 \mathrm{mmol}, 1.0$ equiv.) was added. The reaction mixture was stirred overnight at room temperature, and the progress of the reaction was monitored by HPLC-MS. Aqueous potassium hydroxide $(0.5 \mathrm{~m} ; 3.8 \mathrm{~mL}$, $1.9 \mathrm{mmol}, 15$ equiv.) was added, and the reaction mixture was stirred overnight at ambient temperature. The reaction was then quenched with $\mathrm{AcOH}(0.73 \mathrm{~mL}, 13 \mathrm{mmol}, 100$ equiv.), and the mixture was concentrated in vacuo. The crude reaction product was coevaporated in toluene.

The residue was cooled in an ice-bath, and then water $(1 \mathrm{~mL})$ and TFA ( $3 \mathrm{~mL}$ ) were added. The reaction mixture was stirred for $2 \mathrm{~min}$ at $0{ }^{\circ} \mathrm{C}$, then it was diluted with toluene $(20 \mathrm{~mL})$, and concentrated in vacuo. Purification by HPLC-MS $(52-62 \% \mathrm{~B}$, following the general procedure for HPLC-MS purifications) gave compound 37a (31 $\mathrm{mg}, 0.067 \mathrm{mmol}, 53 \%)$ as a TFA adduct. $[\alpha]_{\mathrm{D}}^{22}=-5.0(c=0.1$, $\mathrm{MeOH}) .{ }^{1} \mathrm{H}$ NMR $\left(600 \mathrm{MHz},\left[\mathrm{D}_{4}\right]\right.$ methanol): $\delta=5.87(\mathrm{dtd}, J=$ 15.0, 6.8, $1.2 \mathrm{~Hz}, 1 \mathrm{H}), 5.48$ (ddt, $J=15.4,6.9,1.5 \mathrm{~Hz}, 1 \mathrm{H}), 4.33-$ 4.29 (m, 2 H), 3.97-3.88 (m, 3 H), 3.66 (m, $1 \mathrm{H}), 3.40-3.32$ (m, 2 $\mathrm{H}), 3.29-2.21(\mathrm{~m} 3 \mathrm{H}), 2.1(\mathrm{q}, J=7.2 \mathrm{~Hz}, 2 \mathrm{H}), 1.42(\mathrm{~m}, 2 \mathrm{H})$, $1.36-1.22(\mathrm{~m}, 20 \mathrm{H}), 0.9(\mathrm{t}, J=7.0 \mathrm{~Hz}, 3 \mathrm{H}) \mathrm{ppm} .{ }^{13} \mathrm{C} \mathrm{NMR}$ : (151 MHz, [D $\mathrm{D}_{4}$ ]methanol): $\delta=136.8,128.4,104.1,78.1,77.9,74.8$, $71.5,70.9,67.3,62.5,56.8,33.4,33.1,30.82,30.81(2 \times), 30.78$, $30.77,30.66,30.50,30.41,30.18,23.6,14.2 \mathrm{ppm}$. IR (neat): $\tilde{v}=$ 3300, 2918, 2850, 1668, 1435, 1202, 1134, 1074, 1026, 800, $721 \mathrm{~cm}^{-1}$. HRMS: calcd. for $\left[\mathrm{C}_{24} \mathrm{H}_{47} \mathrm{NO}_{7}+\mathrm{H}\right]^{+} 462.3431$; found 462.3424 .

Glucosyl-[5,6,7,8,9-13 $\mathbf{C}_{\mathbf{5}}$ ]-sphingosine (37b): Protected glucosyl$\left[5,6,7,8,9-{ }^{13} \mathrm{C}_{5}\right]$-sphingosine $\mathbf{3 6 a}$ (48 $\mathrm{mg}, 47 \mu \mathrm{mol}, 1.0$ equiv.) was dissolved in THF/pyridine (4:1) $(10 \mathrm{~mL})$, and hydrogen fluoride (70\% in pyridine; $20 \mu \mathrm{L}, 94 \mu \mathrm{mol}, 2.0$ equiv.) was added. The reaction mixture was stirred at room temperature until TLC showed full conversion (ca. $2 \mathrm{~h})$ [product $R_{\mathrm{f}}=0.75(40 \%$ EtOAc in $\left.\mathrm{CH}_{2} \mathrm{Cl}_{2}\right)$ ]. The mixture was concentrated in vacuo, the residue was redissolved in EtOAc $(20 \mathrm{~mL})$, and this solution was washed with $\mathrm{HCl}$ (1 м aq.; $20 \mathrm{~mL}$ ), satd. aq. $\mathrm{NaHCO}_{3}(20 \mathrm{~mL})$, and brine $(20 \mathrm{~mL})$. The aqueous layers were extracted with EtOAc $(20 \mathrm{~mL})$, and the combined organic extracts were dried $\left(\mathrm{Na}_{2} \mathrm{SO}_{4}\right)$, filtered, and concentrated in vacuo.

The crude mixture was dissolved in $\mathrm{MeOH}(8 \mathrm{~mL})$, and sodium methoxide ( $30 \%$ in methanol; $6.5 \mu \mathrm{L}, 47 \mu \mathrm{mol}, 1.0$ equiv.) was added. The reaction mixture was stirred overnight at room temperature, and the progress of the reaction was monitored by HPLC-MS. Aqueous potassium hydroxide $(0.5 \mathrm{~m} ; 1.4 \mathrm{~mL}$, $0.7 \mathrm{mmol}, 15$ equiv.) was added, and the reaction mixture was stirred overnight at ambient temperature. The reaction was then quenched with $\mathrm{AcOH}(0.3 \mathrm{~mL}, 4.7 \mathrm{mmol}, 100$ equiv.), and the mixture was concentrated in vacuo. The crude product mixture was coevaporated with toluene.

The residue was cooled in an ice-bath, and then water $(0.3 \mathrm{~mL})$ and TFA $(1 \mathrm{~mL})$ were added. The reaction mixture was stirred for $2 \mathrm{~min}$ at $0{ }^{\circ} \mathrm{C}$, and then it was diluted with toluene $(20 \mathrm{~mL})$, and concentrated in vacuo. Purification by HPLC-MS (52-62\% B, following the general procedure for HPLC-MS purifications) gave compound $37 \mathbf{b}(10.7 \mathrm{mg}, 23 \mu \mathrm{mol}, 49 \%)$ as a TFA adduct. $[\alpha]_{\mathrm{D}}^{22}=-5.1(c=$ $0.1, \mathrm{MeOH}) .{ }^{1} \mathrm{H}$ NMR $\left(600 \mathrm{MHz},\left[\mathrm{D}_{4}\right]\right.$ methanol): $\delta=5.85(\mathrm{dm}, J$ $=150.2 \mathrm{~Hz}, 1 \mathrm{H}), 5.48(\mathrm{dt}, J=15.8,6.4 \mathrm{~Hz}, 1 \mathrm{H}), 4.34-4.29(\mathrm{~m}, 2$ H), 3.97-3.88 (m, $3 \mathrm{H}), 3.66(\mathrm{dd}, J=11.7,6.1 \mathrm{~Hz}, 1 \mathrm{H}), 3.40-3.31$ (m, $2 \mathrm{H}), 3.29-2.21(\mathrm{~m} 3 \mathrm{H}), 2.10(\mathrm{dm}, J=126.9 \mathrm{~Hz}, 2 \mathrm{H}), 1.56-$ 1.15 (m, $22 \mathrm{H}), 0.90$ (t, $J=7.0 \mathrm{~Hz}, 3 \mathrm{H}) \mathrm{ppm} .{ }^{13} \mathrm{C} \mathrm{NMR}(151 \mathrm{MHz}$, $\left[\mathrm{D}_{4}\right]$ methanol): $\delta=136.8(\mathrm{~d}, J=43.0 \mathrm{~Hz}), 128.2(\mathrm{dd}, J=72.5$, 3.5 Hz), 104.1, 78.1, 77.9, 74.9, 71.5, 70.9 (m), 67.3, 62.5, 56.8 (d, $J=3.4 \mathrm{~Hz}), 33.6-32.9(\mathrm{~m}), 30.9-29.6(\mathrm{~m}), 23.4,14.5 \mathrm{ppm}$. IR (neat): $\tilde{v}=3300,2918,2851,1670,1433,1200,1134,1074,1024$, 800, $721 \mathrm{~cm}^{-1}$. HRMS: calcd. for $\left[\mathrm{C}_{19}{ }^{13} \mathrm{C}_{5} \mathrm{H}_{47} \mathrm{NO}_{7}+\mathrm{H}\right]^{+} 467.3598$; found 467.3591 .

Glucosylceramide (38a): See the general procedure for the synthesis of ceramides from sphingosine, yield $(3.1 \mathrm{mg}, 4.4 \mu \mathrm{mol}, 57 \%) . R_{\mathrm{f}}$ $=0.25\left(\mathrm{CHCl}_{3} / \mathrm{MeOH}, 9: 1\right) \cdot[\alpha]_{\mathrm{D}}^{22}=+6.0\left(c=0.1, \mathrm{MeOH} / \mathrm{CHCl}_{3}\right.$, 1:1). ${ }^{1} \mathrm{H}$ NMR $\left(600 \mathrm{MHz}, \mathrm{CDCl}_{3} /\left[\mathrm{D}_{4}\right]\right.$ methanol): $\delta=5.68(\mathrm{dt}, J=$ $13.8,6.9 \mathrm{~Hz}, 1 \mathrm{H}), 5.44(\mathrm{dd}, J=15.3,7.8 \mathrm{~Hz}, 1 \mathrm{H}), 4.26(\mathrm{~d}, J=$ $7.9 \mathrm{~Hz}, 1 \mathrm{H}), 4.16(\mathrm{dd}, J=10.3,4.8 \mathrm{~Hz}, 1 \mathrm{H}), 4.06(\mathrm{t}, J=8.4 \mathrm{~Hz}$, $1 \mathrm{H}), 3.97(\mathrm{dt}, J=8.4,4.0 \mathrm{~Hz}, 1 \mathrm{H}), 3.86(\mathrm{dd}, J=11.9,1.8 \mathrm{~Hz}, 1$ $\mathrm{H}), 3.66(\mathrm{~m} 1 \mathrm{H}), 3.59(\mathrm{dd}, J=10.1,3.3 \mathrm{~Hz}, 1 \mathrm{H}), 3.36(\mathrm{~m}, 1 \mathrm{H})$, $3.29-3.26(\mathrm{~m}, 2 \mathrm{H}), 3.21(\mathrm{dd}, J=9.4,7.8 \mathrm{~Hz}, 1 \mathrm{H}), 2.17(\mathrm{t}, J=$ $7.2 \mathrm{~Hz}, 2 \mathrm{H}), 2.02(\mathrm{~m}, 2 \mathrm{H}), 1.58(\mathrm{~m}, 2 \mathrm{H}), 1.42-1.23(\mathrm{~m}, 46 \mathrm{H})$, $0.90(\mathrm{t}, J=7.0 \mathrm{~Hz}, 6 \mathrm{H}) \mathrm{ppm} .{ }^{13} \mathrm{C} \mathrm{NMR}\left(151 \mathrm{MHz}, \mathrm{CDCl}_{3} /\left[\mathrm{D}_{4}\right]-\right.$ methanol): $\delta=173.9,133.0,129.2,102.5,75.8,75.7,73.0,70.9$, $69.5,67.8,60.5,52.6,35.3,31.4,31.0,28.80,28.77(3 \times), 28.76$ $(4 \times), 28.74(2 \times), 28.73,28.71,28.70,28.64,28.57,28.50,28.43$, $28.42,28.38,28.37,28.34,25.10,21.67,12.4(2 \times)$ ppm. IR (neat): $\tilde{v}=3300,2916,2848,1670,1540,1467,1200,1134,1074,1028$, $721 \mathrm{~cm}^{-1}$. HRMS: calcd. for $\left[\mathrm{C}_{40} \mathrm{H}_{77} \mathrm{NO}_{8}+\mathrm{H}\right]^{+} 700.5727$; found 700.5720

Glucosyl-2- $N-\left(\left[3,4,5-{ }^{13} C_{3}\right]\right.$-hexadecanoyl)-sphingosine (38b): See the general procedure for the synthesis of ceramides from sphingosine, yield (3.2 mg, $4.5 \mu \mathrm{mol}, 59 \%) . R_{\mathrm{f}}=0.25\left(\mathrm{CHCl}_{3} / \mathrm{MeOH}, 9: 1\right)$. $[\alpha]_{\mathrm{D}}^{22}=+4.8\left(c=0.2, \mathrm{MeOH} / \mathrm{CHCl}_{3}, 1: 1\right) .{ }^{1} \mathrm{H} \mathrm{NMR}(600 \mathrm{MHz}$, $\left[\mathrm{D}_{4}\right]$ methanol): $\delta=5.68(\mathrm{dt}, J=13.8,6.9 \mathrm{~Hz}, 1 \mathrm{H}), 5.44(\mathrm{dd}, J=$ $15.3,7.8 \mathrm{~Hz}, 1 \mathrm{H}), 4.26(\mathrm{~d}, J=7.9 \mathrm{~Hz}, 1 \mathrm{H}), 4.16(\mathrm{dd}, J=10.3$, $4.8 \mathrm{~Hz}, 1 \mathrm{H}), 4.06(\mathrm{t}, J=8.4 \mathrm{~Hz}, 1 \mathrm{H}), 3.97(\mathrm{dt}, J=8.4,4.0 \mathrm{~Hz}, 1$ H), $3.86(\mathrm{dd}, J=11.9,1.8 \mathrm{~Hz}, 1 \mathrm{H}), 3.66(\mathrm{~m}, 1 \mathrm{H}), 3.59(\mathrm{dd}, J=$ $10.1,3.3 \mathrm{~Hz}, 1 \mathrm{H}), 3.36(\mathrm{~m}, 1 \mathrm{H}), 3.29-3.26(\mathrm{~m}, 2 \mathrm{H}), 3.21(\mathrm{dd}, J$ $=9.4,7.8 \mathrm{~Hz}, 1 \mathrm{H}), 2.17(\mathrm{~m}, 2 \mathrm{H}), 2.02(\mathrm{~m}, 2 \mathrm{H}), 1.58(\mathrm{dm}, J=$ $130 \mathrm{~Hz}, 2 \mathrm{H}), 1.42-1.16(\mathrm{~m}, 46 \mathrm{H}), 0.90$ (t, $J=7.0 \mathrm{~Hz}, 6 \mathrm{H}) \mathrm{ppm}$. ${ }^{13} \mathrm{C}$ NMR (151 MHz, [D $]$ methanol): $\delta=176.0,135.1,131.3,104.7$, 78.0, 77.9, 75.2, 73.0, 71.6, 69.9, 62.6, 54.7, $34.8(\mathrm{~d}, J=35.0 \mathrm{~Hz})$, $33.1,31.0-30.0(\mathrm{~m}), 27.51,27.4-27.0(\mathrm{~m}), 26.87,23.77,14.4(2 \times)$ ppm. IR (neat): $\tilde{v}=3260,2914,2847,1643,1541,1468,1205,1134$, 1076, 1030, $717 \mathrm{~cm}^{-1}$. HRMS: calcd. for $\left[\mathrm{C}_{37}{ }^{13} \mathrm{C}_{3} \mathrm{H}_{77} \mathrm{NO}_{8}+\mathrm{H}\right]^{+}$ 703.5828; found 703.5821 .

Glucosyl-2- $N$-(hexadecanoyl)-[5,6,7,8,9-13 $\left.\mathrm{C}_{5}\right]$-sphingosine (38c): See the general procedure for the synthesis of ceramides from sphingosine, yield (2.8 mg, $3.9 \mu \mathrm{mol}, 52 \%) . R_{\mathrm{f}}=0.25\left(\mathrm{CHCl}_{3} / \mathrm{MeOH}, 9: 1\right)$. $[a]_{\mathrm{D}}^{22}=+5.4\left(c=0.1, \mathrm{MeOH} / \mathrm{CHCl}_{3}\right) .{ }^{1} \mathrm{H} \mathrm{NMR}\left(600 \mathrm{MHz},\left[\mathrm{D}_{4}\right]-\right.$ methanol): $\delta=5.68(\mathrm{dm}, J=154.0 \mathrm{~Hz}, 1 \mathrm{H}), 5.44(\mathrm{~m}, 1 \mathrm{H}), 4.26$ $(\mathrm{d}, J=7.9 \mathrm{~Hz}, 1 \mathrm{H}), 4.16(\mathrm{dd}, J=10.3,4.8 \mathrm{~Hz}, 1 \mathrm{H}), 4.06(\mathrm{~m}, 1$ H), $3.97(\mathrm{~m}, 1 \mathrm{H}), 3.86(\mathrm{dd}, J=11.9,1.8 \mathrm{~Hz}, 1 \mathrm{H}), 3.66(\mathrm{~m} 1 \mathrm{H})$, $3.59(\mathrm{dd}, J=10.1,3.3 \mathrm{~Hz}, 1 \mathrm{H}), 3.36(\mathrm{~m}, 1 \mathrm{H}), 3.29-3.26(\mathrm{~m}, 2 \mathrm{H})$, $3.21(\mathrm{dd}, J=9.4,7.8 \mathrm{~Hz}, 1 \mathrm{H}), 2.17(\mathrm{~m}, 2 \mathrm{H}), 2.02(\mathrm{dm}, J=$ $128.0 \mathrm{~Hz}, 2 \mathrm{H}), 1.58(\mathrm{dm}, J=130.0 \mathrm{~Hz}, 2 \mathrm{H}), 1.42-1.14(\mathrm{~m}, 46 \mathrm{H})$, $0.90(\mathrm{t}, J=7.0 \mathrm{~Hz}, 6 \mathrm{H}) \mathrm{ppm} .{ }^{13} \mathrm{C} \mathrm{NMR}\left(151 \mathrm{MHz},\left[\mathrm{D}_{4}\right]\right.$ methanol): $\delta=176.0,135.1(\mathrm{~d}, J=44.0 \mathrm{~Hz}), 131.3(\mathrm{~d}, J=72.5 \mathrm{~Hz}), 104.6$, 
$78.0,77.9,75.2,73.0,71.6,69.9,62.6,54.7,37.4,33.9-33.0(\mathrm{~m})$, 31.1-30.1 (m), 27.20, 23.78, $14.5 \mathrm{ppm}$. IR (neat): $\tilde{v}=3300,2913$, 2847, 1643, 1544, 1468, 1260, 1085, 1030, $718 \mathrm{~cm}^{-1}$. HRMS: calcd. for $\left[\mathrm{C}_{35}{ }^{13} \mathrm{C}_{5} \mathrm{H}_{77} \mathrm{NO}_{8}+\mathrm{H}\right]^{+} 705.5895$; found 705.5884 .

Glucosyl-2- $N-\left(\left[3,4,5-{ }^{13} \mathrm{C}_{3}\right]\right.$-hexadecanoyl)-[5,6,7,8,9-13 $\left.\mathrm{C}_{5}\right]$-sphingosine (38d): See the general procedure for the synthesis of ceramides from sphingosine, yield (4.9 mg, $6.9 \mu \mathrm{mol}, 61 \%) . R_{\mathrm{f}}=0.25\left(\mathrm{CHCl}_{3} /\right.$ $\mathrm{MeOH}, 9: 1) \cdot[\alpha]_{\mathrm{D}}^{22}=+5.0\left(c=0.2, \mathrm{MeOH} / \mathrm{CHCl}_{3}, 1: 1\right) .{ }^{1} \mathrm{H} \mathrm{NMR}$ (600 MHz, [D $\left.\mathrm{D}_{4}\right]$ methanol): $\delta=5.68(\mathrm{dm}, J=154.0 \mathrm{~Hz}, 1 \mathrm{H}), 5.44$ $(\mathrm{m}, 1 \mathrm{H}), 4.26(\mathrm{~d}, J=7.9 \mathrm{~Hz}, 1 \mathrm{H}), 4.16(\mathrm{dd}, J=10.3,4.8 \mathrm{~Hz}, 1$ H), $4.06(\mathrm{~m}, 1 \mathrm{H}), 3.97(\mathrm{~m}, 1 \mathrm{H}), 3.86(\mathrm{dd}, J=11.9,1.8 \mathrm{~Hz}, 1 \mathrm{H})$, $3.66(\mathrm{~m} 1 \mathrm{H}), 3.59(\mathrm{dd}, J=10.1,3.3 \mathrm{~Hz}, 1 \mathrm{H}), 3.36(\mathrm{~m}, 1 \mathrm{H}), 3.29$ $3.26(\mathrm{~m}, 2 \mathrm{H}), 3.21(\mathrm{dd}, J=9.4,7.8 \mathrm{~Hz}, 1 \mathrm{H}), 2.17(\mathrm{~m}, 2 \mathrm{H}), 2.02$ $(\mathrm{dm}, J=128.0 \mathrm{~Hz}, 2 \mathrm{H}), 1.58(\mathrm{dm}, J=130.0 \mathrm{~Hz}, 2 \mathrm{H}), 1.42-1.14$ $(\mathrm{m}, 46 \mathrm{H}), 0.90(\mathrm{t}, J=7.0 \mathrm{~Hz}, 6 \mathrm{H}) \mathrm{ppm} .{ }^{13} \mathrm{C} \mathrm{NMR}(151 \mathrm{MHz}$, [D $\left.\mathrm{D}_{4}\right]$ methanol): $\delta=176.0,135.1(\mathrm{~d}, J=44.0 \mathrm{~Hz}), 131.3(\mathrm{~d}, J=$ $72.5 \mathrm{~Hz}), 104.6,78.0,77.9,75.2,73.0,71.6,69.9,62.6,54.7,37.4$ (d, $J=35.0 \mathrm{~Hz}), 33.9-33.0(\mathrm{~m}), 31.1-30.0(\mathrm{~m}), 27.50,27.4-27.0$ (m), 26.87, 23.78, $14.4(2 \times)$ ppm. IR (neat): $\tilde{v}=3295,2913,2847$, 1643, 1545, 1468, 1260, 1086, 1032, $718 \mathrm{~cm}^{-1}$. HRMS: calcd. for $\left[\mathrm{C}_{32}{ }^{13} \mathrm{C}_{8} \mathrm{H}_{77} \mathrm{NO}_{8}+\mathrm{H}\right]^{+}$708.5995; found 708.5989.

Globotriaosylsphingosine (40a): Globotriaosyl imidate donor 39 ( $0.54 \mathrm{~g}, 0.33 \mathrm{mmol}, 1.2$ equiv.) and sphingosine acceptor $23 \mathbf{a}$ ( $0.14 \mathrm{~g}, 0.27 \mathrm{mmol}, 1.0$ equiv.) were coevaporated twice with toluene $(5 \mathrm{~mL})$, and then dissolved in anhydrous $\mathrm{CH}_{2} \mathrm{Cl}_{2}(3 \mathrm{~mL})$. Activated molecular sieves ( $3 \AA$ ) were added, and the mixture was stirred for $1 \mathrm{~h}$ at ambient temperature. The mixture was then cooled to $0{ }^{\circ} \mathrm{C}$, and $\mathrm{BF}_{3} \cdot \mathrm{OEt}_{2}\left(48 \%\right.$ in $\mathrm{Et}_{2} \mathrm{O} ; 38 \mu \mathrm{L}, 0.3 \mathrm{mmol}, 1.1$ equiv.) was added. The reaction mixture was stirred until TLC showed complete conversion of the sphingosine acceptor (ca. $2 \mathrm{~h}$ ). The mixture was then transferred to an extraction funnel with EtOAc $(40 \mathrm{~mL})$, and it was washed with satd. aq. $\mathrm{NaHCO}_{3}(40 \mathrm{~mL})$ and brine $(40 \mathrm{~mL})$. The aqueous layers were extracted with EtOAc $(40 \mathrm{~mL})$, and the combined organic extracts were dried $\left(\mathrm{Na}_{2} \mathrm{SO}_{4}\right)$, filtered, and concentrated in vacuo. Purification by column chromatography $\left(12 \% \mathrm{Et}_{2} \mathrm{O}, 10 \% \mathrm{CH}_{2} \mathrm{Cl}_{2}\right.$ in petroleum ether) gave compound 40a $(0.32 \mathrm{~g}, 0.16 \mathrm{mmol}, 60 \%)$ as an amorphous solid. $R_{\mathrm{f}}=0.54\left(30 \% \mathrm{Et}_{2} \mathrm{O}, 20 \% \mathrm{CH}_{2} \mathrm{Cl}_{2}\right.$ in petroleum ether). $[\alpha]_{\mathrm{D}}^{22}=+31$ $\left(c=1.0, \mathrm{CHCl}_{3}\right) .{ }^{1} \mathrm{H} \mathrm{NMR}\left(400 \mathrm{MHz}, \mathrm{CDCl}_{3}\right): \delta=8.19(\mathrm{~m}, 2 \mathrm{H})$, $7.92(\mathrm{~m}, 2 \mathrm{H}), 7.92-7.85(\mathrm{~m}, 6 \mathrm{H}), 7.68(\mathrm{dm}, J=7.2 \mathrm{~Hz}, 2 \mathrm{H})$, 7.58-7.41 (m, 9 H), 7.40-7.18 (m, 18 H), $7.11(\mathrm{~m}, 2 \mathrm{H}), 5.78$ (t, $J$ $=9.3 \mathrm{~Hz}, 1 \mathrm{H}), 5.72(\mathrm{dd}, J=10.7,3.7 \mathrm{~Hz}, 1 \mathrm{H}), 5.66(\mathrm{~m}, 1 \mathrm{H})$, $5.60(\mathrm{dd}, J=10.8,7.8 \mathrm{~Hz}, 1 \mathrm{H}), 5.50(\mathrm{dd}, J=10.7,3.0, \mathrm{~Hz}, 1 \mathrm{H})$, $5.47-5.32(\mathrm{~m}, 4 \mathrm{H}), 5.25(\mathrm{dd}, J=10.8,2.1 \mathrm{~Hz}, 1 \mathrm{H}), 5.10(\mathrm{~d}, J=$ $2.9 \mathrm{~Hz}, 1 \mathrm{H}), 4.81-4.74(\mathrm{~m}, 2 \mathrm{H}), 4.66(\mathrm{~d}, J=7.8 \mathrm{~Hz}, 1 \mathrm{H}), 4.55$ $(\mathrm{d}, J=11.9 \mathrm{~Hz}, 1 \mathrm{H}), 4.46(\mathrm{~d}, J=11.9 \mathrm{~Hz}, 1 \mathrm{H}), 4.39-4.32(\mathrm{~m}, 3$ H), 4.12 (t, $J=9.3 \mathrm{~Hz}, 1 \mathrm{H}), 4.08$ (br. s, $1 \mathrm{H}), 4.07-4.00$ (m, $2 \mathrm{H})$, $3.97(\mathrm{dd}, J=10.9,5.3 \mathrm{~Hz}, 1 \mathrm{H}), 3.81-3.72(\mathrm{~m}, 2 \mathrm{H}), 3.59(\mathrm{~m}, 1 \mathrm{H})$, $3.53(\mathrm{~m}, 1 \mathrm{H}), 1.88(\mathrm{~m}, 2 \mathrm{H}), 1.33(\mathrm{~s}, 9 \mathrm{H}), 1.30-1.11(\mathrm{~m}, 22 \mathrm{H})$, $1.06(\mathrm{~s}, 9 \mathrm{H}), 1.00(\mathrm{~s}, 9 \mathrm{H}), 0.87(\mathrm{t}, J=6.8 \mathrm{~Hz}, 3 \mathrm{H}) \mathrm{ppm} .{ }^{13} \mathrm{C}$ NMR $\left(100 \mathrm{MHz}_{1} \mathrm{CDCl}_{3}\right): \delta=166.2,165.9,165.7,165.6,165.2$, $164.98,164.95,164.8,164.7,155.2,137.2,133.4,133.13,133.10$, $132.97,132.94,132.87,132.7,130.2,130.1,130.0,129.9,129.8$, $129.64,129.59,129.58,129.5,129.4,129.3,129.2,129.0,128.6$, $128.50,128.47,128.45,128.39,128.35,128.29,128.28,128.16$, $128.12,128.07,124.4,101.3,100.9,98.68,79.3,76.6,76.3,74.3$, $73.02,72.94,72.8,72.6,71.9,71.2,71.0,69.7,69.5,68.3,67.8,66.9$, $62.3,60.5,52.3,32.2,31.9,29.62(3 \times), 29.61,29.5,29.3,29.2,28.7$, $28.2,27.5,27.2,23.2,22.6,20.7,14.1 \mathrm{ppm}$. IR (neat): $\tilde{v}=3070$, 2926, 2856, 1722, 1451, 1267, 1095, 1070, 1028, $708 \mathrm{~cm}^{-1}$. HRMS: calcd. for $\left[\mathrm{C}_{112} \mathrm{H}_{127} \mathrm{NO}_{28} \mathrm{Si}+\mathrm{Na}\right]^{+}$1984.8206; found 1984.8204 .

[5,6,7,8,9-13 $\mathbf{C}_{5}$ ]-Globotriaosylsphingosine (40b): Globotriaosyl imidate donor 39; $158 \mathrm{mg}, 96 \mu \mathrm{mol}, 1.2$ equiv.) and $\left[{ }^{13} \mathrm{C}_{5}\right]$-sphingosine acceptor 23b ( $40.7 \mathrm{mg}, 80 \mu \mathrm{mol}, 1.0$ equiv.) were coevaporated twice with toluene $(5 \mathrm{~mL})$, and then dissolved in anhydrous $\mathrm{CH}_{2} \mathrm{Cl}_{2}$ $(2 \mathrm{~mL})$. Activated molecular sieves ( $3 \AA$ ) were added, and the mixture was stirred at ambient temperature for $1 \mathrm{~h}$. The mixture was then cooled to $0{ }^{\circ} \mathrm{C}$, and then $\mathrm{BF}_{3} \cdot \mathrm{OEt}_{2}\left(48 \%\right.$ in $\mathrm{Et}_{2} \mathrm{O} ; 23 \mu \mathrm{L}$, $88 \mu \mathrm{mol}, 1.1$ equiv.) was added. The reaction mixture was stirred until TLC showed complete conversion of the $\left[{ }^{13} \mathrm{C}_{5}\right]$-sphingosine acceptor (ca. $2 \mathrm{~h}$ ). The mixture was then transferred to an extraction funnel with EtOAc $(40 \mathrm{~mL})$, and it was washed with satd. aq. $\mathrm{NaHCO}_{3}(40 \mathrm{~mL})$ and brine $(30 \mathrm{~mL})$. The aqueous layers were then extracted with EtOAc $(40 \mathrm{~mL})$, and the combined organic extracts were dried $\left(\mathrm{Na}_{2} \mathrm{SO}_{4}\right)$, filtered, and concentrated in vacuo. Purification by column chromatography $\left(12 \% \mathrm{Et}_{2} \mathrm{O}, 10 \% \mathrm{CH}_{2} \mathrm{Cl}_{2}\right.$ in petroleum ether) gave compound $\mathbf{4 0 b}(87 \mathrm{mg}, 44 \mu \mathrm{mol}, 55 \%)$ as an amorphous solid. $R_{\mathrm{f}}=0.54\left(30 \% \mathrm{Et}_{2} \mathrm{O}, 20 \% \mathrm{CH}_{2} \mathrm{Cl}_{2}\right.$ in petroleum ether). $[\alpha]_{\mathrm{D}}^{22}=+30\left(c=1.0, \mathrm{CHCl}_{3}\right) .{ }^{1} \mathrm{H} \mathrm{NMR}\left(400 \mathrm{MHz}, \mathrm{CDCl}_{3}\right)$ : $\delta=8.17(\mathrm{~m}, 2 \mathrm{H}), 8.06-8.00(\mathrm{~m}, 4 \mathrm{H}), 7.95(\mathrm{~m}, 2 \mathrm{H}), 7.92-7.84(\mathrm{~m}$, 6), $7.67(\mathrm{~m}, 2 \mathrm{H}), 7.55(\mathrm{~m}, 2 \mathrm{H}), 7.53-7.42(\mathrm{~m}, 7 \mathrm{H}), 7.40-7.27$ (m, $16 \mathrm{H}), 7.21(\mathrm{~m}, 2 \mathrm{H}), 7.11(\mathrm{~m}, 2 \mathrm{H}), 5.77(\mathrm{t}, J=9.3 \mathrm{~Hz}, 1 \mathrm{H}), 5.71$ (dd, $J=10.7,3.7 \mathrm{~Hz}, 1 \mathrm{H}), 5.67(\mathrm{dm}, J=151.2 \mathrm{~Hz}, 1 \mathrm{H}), 5.59$ (dd, $J=10.8,7.8 \mathrm{~Hz}, 1 \mathrm{H}), 5.49(\mathrm{dd}, J=10.7,3.0 \mathrm{~Hz}, 1 \mathrm{H}), 5.47-5.31$ $(\mathrm{m}, 4 \mathrm{H}), 5.24(\mathrm{dd}, J=10.9,2.1 \mathrm{~Hz}, 1 \mathrm{H}), 5.10(\mathrm{~d}, J=3.0 \mathrm{~Hz}, 1$ $\mathrm{H}), 4.80-4.73(\mathrm{~m}, 2 \mathrm{H}), 4.65(\mathrm{~d}, J=7.8 \mathrm{~Hz}, 1 \mathrm{H}), 4.54(\mathrm{~d}, J=$ $12.0 \mathrm{~Hz}, 1 \mathrm{H}), 4.44(\mathrm{~d}, J=12.0 \mathrm{~Hz}, 1 \mathrm{H}), 4.38-4.30(\mathrm{~m}, 3 \mathrm{H}), 4.12$ $(\mathrm{t}, J=9.4 \mathrm{~Hz}, 1 \mathrm{H}), 4.07(\mathrm{~d}, J=1.5 \mathrm{~Hz}, 1 \mathrm{H}), 4.06-3.99(\mathrm{~m}, 2 \mathrm{H})$, $3.97(\mathrm{dd}, J=10.9,5.4 \mathrm{~Hz}, 1 \mathrm{H}), 3.81-3.71(\mathrm{~m}, 2 \mathrm{H}), 3.58(\mathrm{~m}, 1 \mathrm{H})$, $3.51(\mathrm{dd}, J=13.9,6.9 \mathrm{~Hz}, 1 \mathrm{H}), 1.87(\mathrm{dm}, J=124.6 \mathrm{~Hz}, 2 \mathrm{H})$, 1.40-1.14 (m, $31 \mathrm{H}), 1.05$ (s, $9 \mathrm{H}), 1.00$ (s, $9 \mathrm{H}), 0.87$ (t, $J=6.8 \mathrm{~Hz}$, $3 \mathrm{H}) \mathrm{ppm} .{ }^{13} \mathrm{C} \mathrm{NMR}\left(101 \mathrm{MHz}, \mathrm{CDCl}_{3}\right): \delta=166.2,166.0,165.7$, $165.6,165.2,165.00,164.98,164.79,164.75,155.2,137.2(\mathrm{~d}, J=$ 42.4 Hz), 133.4, 133.2, 133.1, 133.00, 132.99, 132.96, 132.89, 132.7, $130.2,130.1,130.00,129.95,129.8,129.67,129.62,129.60,129.50$, $129.48,129.4,129.2,129.0,128.6,128.53,128.50,128.48,128.41$, $128.37,128.32,128.30,128.18,128.14,128.09,124.4(\mathrm{~d}, J=$ $71.2 \mathrm{~Hz}), 101.3,100.9,98.7,79.4,76.6,76.3,74.3$ (d, $J=5.4 \mathrm{~Hz})$, 73.04, 72.97, 72.8, 72.7, 71.9, 71.2, 71.0, 69.7, 69.6, 68.3, 67.8, 66.9, $62.3,60.5,52.3(\mathrm{~d}, J=2.4 \mathrm{~Hz}), 32.2(\mathrm{~m}), 31.9,29.8-28.1(\mathrm{~m}), 27.5$, 27.2, 23.2, 22.7, 20.7, $14.1 \mathrm{ppm}$. IR (neat): $\tilde{v}=3070,2925,2853$, 1718, 1452, 1266, 1094, 1069, $706 \mathrm{~cm}^{-1}$. HRMS: calcd. for $\left[\mathrm{C}_{107}{ }^{13} \mathrm{C}_{5} \mathrm{H}_{127} \mathrm{O}_{28} \mathrm{Si}+\mathrm{Na}\right]^{+}$1989.8374; found 1989.8370 .

Globotriaosylsphingosine (41a): Protected globotriaosylsphingosine 40a (200 mg, $0.10 \mathrm{mmol}, 1.0$ equiv.) was dissolved in THF/pyridine $(4: 1 ; 20 \mathrm{~mL})$, and hydrogen fluoride $(70 \%$ in pyridine; $53 \mu \mathrm{L}$, $0.26 \mathrm{mmol}$, ca. 20 equiv.) was added. The reaction mixture was stirred at room temperature until TLC showed full conversion into a lower-running spot (ca. $4 \mathrm{~h}$ ). The mixture was then concentrated in vacuo, the residue was redissolved in EtOAc $(50 \mathrm{~mL})$, and this solution was washed with $\mathrm{HCl}\left(1 \mathrm{M}\right.$ aq.; $50 \mathrm{~mL}$ ), satd. aq. $\mathrm{NaHCO}_{3}$ $(50 \mathrm{~mL})$, and brine $(50 \mathrm{~mL})$. The aqueous phases were extracted with EtOAc $(50 \mathrm{~mL})$, and the combined organic extracts were dried $\left(\mathrm{Na}_{2} \mathrm{SO}_{4}\right)$, filtered, and concentrated in vacuo.

The crude mixture was then dissolved in methanol $(20 \mathrm{~mL})$, and sodium methoxide ( $30 \%$ in methanol; $14 \mu \mathrm{L}, 0.10 \mathrm{mmol}, 1.0$ equiv.) was added. The reaction mixture was stirred overnight at ambient temperature, and the progress of the reaction was monitored by HPLC-MS. Aqueous potassium hydroxide $(0.5 \mathrm{~m} ; 4.1 \mathrm{~mL}$, $2.0 \mathrm{mmol}, 20$ equiv.) was added, and the reaction mixture was stirred overnight at ambient temperature. The reaction was then quenched with $\mathrm{AcOH}(0.58 \mathrm{~mL}, 100$ equiv.), and the mixture was concentrated in vacuo. The crude product mixture was coevaporated with toluene.

The residue was cooled in an ice-bath, and then trifluoracetic acid $(5 \mathrm{~mL})$ was added. After $1 \mathrm{~min}$, the residue had completely dis- 
solved, and the reaction mixture was then stirred for a further $1 \mathrm{~min}$ at $0{ }^{\circ} \mathrm{C}$. The solution was then transferred to a round-bottomed flask containing toluene $(50 \mathrm{~mL})$, and the mixture was concentrated to ca. $10 \mathrm{~mL}$ in vacuo. The coevaporation was repeated twice with toluene $(40 \mathrm{~mL})$, then the mixture was concentrated to dryness. The completion of the reaction was confirmed by HPLCMS. The residue was then purified over a short silica column ( $\mathrm{MeOH} / \mathrm{CH}_{2} \mathrm{Cl}_{2}, 1: 9$, followed by $\mathrm{H}_{2} \mathrm{O} / \mathrm{MeOH} / \mathrm{CH}_{2} \mathrm{Cl}_{2}, 3: 27: 70$; TLC visualised with ninhydrin spray). Further purification by HPLC-MS (40-48\% B, following the general procedure for HPLC-MS purifications) gave globotriaosylsphingosine 41a $(43 \mathrm{mg}, 54 \mu \mathrm{mol}, 53 \%)$ as a TFA adduct. $[\alpha]_{\mathrm{D}}^{22}=+34.0(c=0.5$, $\mathrm{MeOH}) .{ }^{1} \mathrm{H}$ NMR $\left(600 \mathrm{MHz},\left[\mathrm{D}_{4}\right]\right.$ methanol): $\delta=5.87(\mathrm{~m}, 1 \mathrm{H})$, $5.49(\mathrm{~m}, 1 \mathrm{H}), 4.94(\mathrm{~d}, J=3.9 \mathrm{~Hz}, 1 \mathrm{H}), 4.40(\mathrm{~d}, J=6.9 \mathrm{~Hz}, 1 \mathrm{H})$, $4.37(\mathrm{~d}, J=7.8 \mathrm{~Hz}, 1 \mathrm{H}), 4.32(\mathrm{ddd}, J=6.8,4.7,1.3 \mathrm{~Hz}, 1 \mathrm{H}), 4.25$ (ddd, $J=7.1,5.2,1.3 \mathrm{~Hz}, 1 \mathrm{H}), 4.01-3.96(\mathrm{~m}, 2 \mathrm{H}), 3.94(\mathrm{dd}, J=$ 11.9, 2.6 Hz, 1 H), 3.93-3.91 (m, $2 \mathrm{H}), 3.89$ (dd, $J=7.7,4.1 \mathrm{~Hz}, 1$ H), 3.88-3.81 (m, $3 \mathrm{H}), 3.77(\mathrm{dd}, J=10.2,3.2 \mathrm{~Hz}, 1 \mathrm{H}), 3.74(\mathrm{dd}$, $J=11.1,7.1 \mathrm{~Hz}, 1 \mathrm{H}), 3.40(\mathrm{ddd}, J=8.5,4.7,3.6 \mathrm{~Hz}, 1 \mathrm{H}), 3.30$ (t, $J=7.7 \mathrm{~Hz}, 1 \mathrm{H}), 2.10(\mathrm{q}, J=7.0 \mathrm{~Hz}, 2 \mathrm{H}), 1.42(\mathrm{~m}, 2 \mathrm{H}), 1.36-$ $1.22(\mathrm{~m}, 20 \mathrm{H}), 0.90(\mathrm{t}, J=7.0 \mathrm{~Hz}, 3 \mathrm{H}) \mathrm{ppm} .{ }^{13} \mathrm{C} \mathrm{NMR}(151 \mathrm{MHz}$, $\left[\mathrm{D}_{4}\right]$ methanol): $\delta=136.8,128.3,105.4,103.7,102.7,80.8,79.8$, 76.6, 76.3, 74.7, 74.6, 72.8, 72.6, 71.3, 71.0, 70.8, 70.5, 67.1, 62.7, $61.6,61.5,56.7,33.4,33.1,30.79(3 \times), 30.76,30.74,30.6,30.5$, 30.4, 30.2, 23.7, 14.4 ppm. IR (neat): $\tilde{v}=3345$ br. s, 2925, 2855 , 1674, 1202, 1134, 1067, 1027, 974, 801, $721 \mathrm{~cm}^{-1}$. HRMS: calcd. for $\left[\mathrm{C}_{36} \mathrm{H}_{67} \mathrm{NO}_{17}+\mathrm{H}\right]^{+}$786.4482; found 786.4485 .

Globotriaosyl-[5,6,7,8,9-13 $\left.\mathrm{C}_{5}\right]$-sphingosine (41b): Globally protected globotriaosyl-[5,6,7,8,9- ${ }^{13} \mathrm{C}_{5}$ ]-sphingosine $40 \mathrm{~b}$ (87 mg, $0.45 \mu \mathrm{mol}$, 1.0 equiv.) was dissolved in THF/pyridine $(4: 1 ; 10 \mathrm{~mL})$, and hydrogen fluoride ( $70 \%$ in pyridine; $24 \mu \mathrm{L}, 0.11 \mathrm{mmol}$, ca. 20 equiv.) was added. The reaction mixture was stirred at room temperature until TLC showed full conversion into a lower-running spot (ca. $4 \mathrm{~h}$ ). The mixture was then concentrated in vacuo, the residue was redissolved in EtOAc $(50 \mathrm{~mL})$, and this solution was washed with $\mathrm{HCl}(1 \mathrm{~N}$ aq.; $50 \mathrm{~mL})$, satd. aq. $\mathrm{NaHCO}_{3}(50 \mathrm{~mL})$, and brine $(50 \mathrm{~mL})$. The aqueous phases were extracted with EtOAc $(50 \mathrm{~mL})$ and the combined organic extracts were dried $\left(\mathrm{Na}_{2} \mathrm{SO}_{4}\right)$, filtered, and concentrated in vacuo.

The crude mixture was then dissolved in methanol $(8 \mathrm{~mL})$, and sodium methoxide ( $30 \%$ in $\mathrm{MeOH} ; 6.2 \mu \mathrm{L}, 0.45 \mu \mathrm{mol}, 1.0$ equiv.) was added. The reaction mixture was stirred overnight at room temperature. The progress of the reaction was monitored by HPLC-MS. Aqueous potassium hydroxide $(0.5 \mathrm{M} ; 1.8 \mathrm{~mL}$, $0.89 \mathrm{mmol}, 20$ equiv.) was added, and the reaction mixture was stirred overnight at room temperature. The reaction was then quenched with $\mathrm{AcOH}$ ( $0.25 \mathrm{~mL}, 100$ equiv.), and the mixture was concentrated in vacuo. The crude reaction mixture was coevaporated with toluene.

The residue was cooled in an ice-bath, and then trifluoroacetic acid $(3 \mathrm{~mL})$ was added. The product had completely dissolved after ca. $1 \mathrm{~min}$, and the reaction mixture was stirred for a further $1 \mathrm{~min}$ at $0{ }^{\circ} \mathrm{C}$. The solution was then transferred to a round-bottomed flask containing toluene $(50 \mathrm{~mL})$, and the mixture was concentrated in vacuo to ca. $10 \mathrm{~mL}$. The coevaporation was repeated twice with toluene $(40 \mathrm{~mL})$, and then the mixture was concentrated to dryness. The completion of the reaction was monitored by HPLC-MS. The reaction mixture was filtered through a small silica column ( $\mathrm{MeOH} / \mathrm{CH}_{2} \mathrm{Cl}_{2}, 1: 9$, then $\mathrm{H}_{2} \mathrm{O} / \mathrm{MeOH} / \mathrm{CH}_{2} \mathrm{Cl}_{2}, 3: 27: 70$; TLC visualised with ninhydrin spray). Further purification by HPLC-MS (40-48\% B, following the general procedure for HPLC-MS purifications) gave globotriaosylsphingosine $\mathbf{4 1 b}$ (17 mg, $21 \mu \mathrm{mol}, 48 \%$ ) as a TFA adduct. $[\alpha]_{\mathrm{D}}^{22}=+33.0(c=0.20, \mathrm{MeOH}) .{ }^{1} \mathrm{H}$ NMR (600 MHz, [D $\left.\left.\mathrm{D}_{4}\right] \mathrm{methanol}\right): \delta=5.85(\mathrm{dm}, J=150.2 \mathrm{~Hz}, 1 \mathrm{H}), 5.47$ $(\mathrm{m}, 1 \mathrm{H}), 4.94(\mathrm{~d}, J=3.8 \mathrm{~Hz}, 1 \mathrm{H}), 4.39$ (d, $J=7.1 \mathrm{~Hz}, 1 \mathrm{H}), 4.36$ (d, $J=7.8 \mathrm{~Hz}, 1 \mathrm{H}), 4.31$ (ddd, $J=6.4,4.8 \mathrm{~Hz}, 1 \mathrm{H}), 4.25$ (ddd, $J$ $=6.8,5.2,1.3 \mathrm{~Hz}, 1 \mathrm{H}), 4.01-3.96(\mathrm{~m}, 2 \mathrm{H}), 3.94(\mathrm{dd}, J=12.0$, $2.4 \mathrm{~Hz}, 1 \mathrm{H}), 3.92-3.90(\mathrm{~m}, 2 \mathrm{H}), 3.89(\mathrm{dd}, J=7.7,4.0 \mathrm{~Hz}, 1 \mathrm{H})$, $3.88-3.79(\mathrm{~m}, 3 \mathrm{H}), 3.77(\mathrm{dd}, J=10.1,3.1 \mathrm{~Hz}, 1 \mathrm{H}), 3.74(\mathrm{dd}, J=$ $11.2,7.3 \mathrm{~Hz}, 1 \mathrm{H}), 3.70-3.65(\mathrm{~m}, 2 \mathrm{H}), 3.58-3.50(\mathrm{~m}, 4 \mathrm{H}, 4-\mathrm{H})$, $3.46(\mathrm{~m}, 1 \mathrm{H}), 3.40$ (ddd, $J=8.5,4.7,3.6 \mathrm{~Hz}, 1 \mathrm{H}), 3.30(\mathrm{~m}, 1 \mathrm{H})$, $2.10(\mathrm{dm}, J=126.9 \mathrm{~Hz}, 2 \mathrm{H}), 1.56-1.14(\mathrm{~m}, 22 \mathrm{H}), 0.89(\mathrm{t}, J=$ $7.0 \mathrm{~Hz}, 3 \mathrm{H}) \mathrm{ppm} .{ }^{13} \mathrm{C} \mathrm{NMR}\left(151 \mathrm{MHz},\left[\mathrm{D}_{4}\right]\right.$ methanol): $\delta=136.8$ $(\mathrm{d}, J=42.8 \mathrm{~Hz}), 128.3(\mathrm{~d}, J=72.3 \mathrm{~Hz}), 105.4,103.7,102.7,80.8$, $79.8,76.6(2 \times), 76.3,74.65,74.2,72.8,72.6,71.3,71.0,70.8(\mathrm{~d}, J$ $=5.1 \mathrm{~Hz}), 70.5,67.1,62.7,61.6,61.5,56.7(\mathrm{~d}, J=2.2 \mathrm{~Hz}), 33.8-$ $32.9(\mathrm{~m}), 30.9-29.8(\mathrm{~m}), 23.7,14.4 \mathrm{ppm}$. IR (neat): $\tilde{\mathrm{v}}=3344 \mathrm{br} . \mathrm{s}$, 2925, 2855, 1674, 1202, 1134, 1067, 1027, 974, 801, $721 \mathrm{~cm}^{-1}$ HRMS: calcd. for $\left[\mathrm{C}_{31}{ }^{13} \mathrm{C}_{5} \mathrm{H}_{67} \mathrm{NO}_{17} \mathrm{H}\right]^{+}$791.4650; found 791.4654 .

Globotriaosylceramide (42a): See the general procedure for the synthesis of ceramides from sphingosine, yield $(6 \mathrm{mg}, 5.8 \mu \mathrm{g}, 49 \%) . R_{\mathrm{f}}$ $=0.35\left(\mathrm{CHCl}_{3} / \mathrm{MeOH} / \mathrm{H}_{2} \mathrm{O}, 70: 27: 3\right) \cdot[\alpha]_{\mathrm{D}}^{22}=+24(c=0.75, \mathrm{MeOH} /$ $\left.\mathrm{CHCl}_{3}, 1: 1\right) .{ }^{1} \mathrm{H} \mathrm{NMR}\left(600 \mathrm{MHz}, \mathrm{CDCl}_{3} /\left[\mathrm{D}_{4}\right]\right.$ methanol): $\delta=5.69$ $(\mathrm{dt}, J=14.7,6.9 \mathrm{~Hz}, 1 \mathrm{H}), 5.45(\mathrm{dd}, J=15.3,7.8 \mathrm{~Hz}, 1 \mathrm{H}), 4.96$ $(\mathrm{d}, J=3.8 \mathrm{~Hz}, 1 \mathrm{H}), 4.41(\mathrm{~d}, J=6.9 \mathrm{~Hz}, 1 \mathrm{H}), 4.30(\mathrm{~d}, J=7.8 \mathrm{~Hz}$, $1 \mathrm{H}), 4.25$ (ddd, $J=6.8,4.7,1.3 \mathrm{~Hz}, 1 \mathrm{H}), 4.19$ (dd, $J=10.1$, $4.5 \mathrm{~Hz}, 1 \mathrm{H}), 4.07(\mathrm{t}, J=8.8 \mathrm{~Hz}, 1 \mathrm{H}), 4.04-3.96(\mathrm{~m}, 4 \mathrm{H}), 3.92(\mathrm{~d}$, $J=3.0 \mathrm{~Hz}, 1 \mathrm{H}) 3.89(\mathrm{~d}, J=3.2 \mathrm{~Hz}, 1 \mathrm{H}), 3.85-3.81(\mathrm{~m}, 3 \mathrm{H})$, 3.79-3.73 (m, 2 H), 3.71-3.3.63 (m, 3 H), 3.60-3.51 (m, $4 \mathrm{H}), 2.17$ (t, $J=7.2 \mathrm{~Hz}, 2 \mathrm{H}), 2.03(\mathrm{~m}, 2 \mathrm{H}), 1.58(\mathrm{~m}, 1 \mathrm{H}), 1.43-1.20(\mathrm{~m}, 46$ $\mathrm{H}), 0.90(\mathrm{t}, J=6.9 \mathrm{~Hz}, 6 \mathrm{H}) \mathrm{ppm} .{ }^{13} \mathrm{C} \mathrm{NMR}\left(151 \mathrm{MHz}, \mathrm{CDCl}_{3} /\right.$ $\left[\mathrm{D}_{4}\right]$ methanol): $\delta=177.5,133.1,132.6,103.3,102.3,100.6,78.8$, 77.7, 74.3, 74.1, 72.8, 72.5, 70.9, 70.7, 70.5, 69.2, 68.4, 67.8, 60.6, $58.8,57.2,52.5,35.3,31.4,31.028 .78(2 \times), 28.77(4 \times), 28.74$ $(2 \times), 28.72(2 \times), 28.71(2 \times), 28.64,28.59,28.54,28.52,28.44$ $(2 \times), 28.41,28.40,28.38,28.36,21.7,12.5 \mathrm{ppm}$. IR (neat): $\tilde{v}=$ 3300, 2918, 2851, 1636, 1465, 1379, 1205, 144, 1070, 1016, $719 \mathrm{~cm}^{-1}$. HRMS: calcd. for $\left[\mathrm{C}_{52} \mathrm{H}_{97} \mathrm{NO}_{18}+\mathrm{H}\right]^{+} 1024.6784$; found 1024.6783.

Globotriaosyl-2- $N-\left(\left[3,4,5-{ }^{13} C_{3}\right]\right.$-hexadecanoyl)-sphingosine (42b): See the general procedure for the synthesis of ceramides from sphingosine, yield $(9 \mathrm{mg}, 8.7 \mu \mathrm{mol}, 71 \%) . R_{\mathrm{f}}=0.35\left(\mathrm{CHCl}_{3} /\right.$ $\left.\mathrm{MeOH} / \mathrm{H}_{2} \mathrm{O}, 70: 27: 3\right) .[\alpha]_{\mathrm{D}}^{22}=+24\left(c=0.25, \mathrm{MeOH} / \mathrm{CHCl}_{3}, 1: 1\right)$. ${ }^{1} \mathrm{H}$ NMR (600 MHz, $\mathrm{CDCl}_{3} /\left[\mathrm{D}_{4}\right]$ methanol): $\delta=5.69(\mathrm{dt}, J=14.7$, $6.9 \mathrm{~Hz}, 1 \mathrm{H}), 5.45(\mathrm{dd}, J=15.3,7.8 \mathrm{~Hz}, 1 \mathrm{H}), 4.96(\mathrm{~d}, J=3.8 \mathrm{~Hz}$, $1 \mathrm{H}), 4.41(\mathrm{~d}, J=6.9 \mathrm{~Hz}, 1 \mathrm{H}), 4.30(\mathrm{~d}, J=7.8 \mathrm{~Hz}, 1 \mathrm{H}), 4.25$ (ddd, $J=6.8,4.7,1.3 \mathrm{~Hz}, 1 \mathrm{H}), 4.19(\mathrm{dd}, J=10.1,4.5 \mathrm{~Hz}, 1 \mathrm{H})$, $4.07(\mathrm{t}, J=8.8 \mathrm{~Hz}, 1 \mathrm{H}), 4.04-3.96(\mathrm{~m}, 4 \mathrm{H}), 3.92(\mathrm{~d}, J=3.0 \mathrm{~Hz}$, $1 \mathrm{H}) 3.89(\mathrm{~d}, J=3.2 \mathrm{~Hz}, 1 \mathrm{H}), 3.85-3.81(\mathrm{~m}, 3 \mathrm{H}), 3.79-3.73(\mathrm{~m}$, 2 H), 3.71-3.3.63 (m, 3 H), 3.60-3.51 (m, $4 \mathrm{H}), 2.17$ (m, $2 \mathrm{H}), 2.03$ $(\mathrm{m}, 2 \mathrm{H}), 1.58(\mathrm{dm}, J=130.0 \mathrm{~Hz}, 1 \mathrm{H}), 1.43-1.14(\mathrm{~m}, 46 \mathrm{H}), 0.90$ $(\mathrm{t}, J=6.9 \mathrm{~Hz}, 6 \mathrm{H}) \mathrm{ppm} .{ }^{13} \mathrm{C} \mathrm{NMR}\left(151 \mathrm{MHz}, \mathrm{CDCl}_{3} /\left[\mathrm{D}_{4}\right]\right.$ methanol): $\delta=133.0,132.7,100.7,78.9,74.8,60.7,52.6,31.5,31.3$, 29.0-28.2 (m), 25.5-24.8 (m), 24.3-24.0 (m), 21.71, 21.60, 19.68, 12.6 ppm. IR (neat): $\tilde{v}=3300,2914,2849,1632,1551,1470,1370$, 1203, 1070, 1024, $716 \mathrm{~cm}^{-1}$. HRMS: calcd. for $\left[\mathrm{C}_{49}{ }^{13} \mathrm{C}_{3} \mathrm{H}_{97} \mathrm{NO}_{18}+\right.$ $\mathrm{H}]^{+}$1027.6884; found 1027.6881 .

Globotriaosyl-2- $N$-(hexadecanoyl)-[5,6,7,8,9-13 $\left.\mathrm{C}_{5}\right]$-sphingosine (42c): See the general procedure for the synthesis of ceramides from sphingosine, yield $(5.5 \mathrm{mg}, 5.3 \mu \mathrm{mol}, 51 \%) . R_{\mathrm{f}}=0.35\left(\mathrm{CHCl}_{3} /\right.$ $\left.\mathrm{MeOH} / \mathrm{H}_{2} \mathrm{O}, 70: 27: 3\right) .[\alpha]_{\mathrm{D}}^{22}=+26\left(c=0.15, \mathrm{MeOH} / \mathrm{CHCl}_{3}, 1: 1\right)$. ${ }^{1} \mathrm{H} \mathrm{NMR}$ (850 MHz, $\mathrm{CDCl}_{3} /\left[\mathrm{D}_{4}\right]$ methanol): $\delta=5.69(\mathrm{dm}, J=$ $150.0 \mathrm{~Hz}, 1 \mathrm{H}), 5.45(\mathrm{~m}, 1 \mathrm{H}), 4.96(\mathrm{~d}, J=3.8 \mathrm{~Hz}, 1 \mathrm{H}), 4.41(\mathrm{~d}, J$ $=6.9 \mathrm{~Hz}, 1 \mathrm{H}), 4.30(\mathrm{~d}, J=7.8 \mathrm{~Hz}, 1 \mathrm{H}), 4.25(\mathrm{ddd}, J=6.8,4.7$, 
$1.3 \mathrm{~Hz}), 4.19(\mathrm{dd}, J=10.1,4.5 \mathrm{~Hz}, 1 \mathrm{H}), 4.07(\mathrm{t}, J=8.8 \mathrm{~Hz}, 1 \mathrm{H}$, $1 \mathrm{H}), 4.04-3.96(\mathrm{~m}, 4 \mathrm{H}), 3.92(\mathrm{~d}, J=3.0 \mathrm{~Hz}, 1 \mathrm{H}) 3.89(\mathrm{~d}, J=$ $3.2 \mathrm{~Hz}, 1 \mathrm{H}), 3.85-3.81$ (m, 3 H), 3.79-3.73 (m, $2 \mathrm{H}), 3.71-3.63$ (m, $3 \mathrm{H}), 3.60-3.51(\mathrm{~m}, 4 \mathrm{H}), 2.17(\mathrm{~m}, 2 \mathrm{H}), 2.03(\mathrm{~m}, 2 \mathrm{H}), 1.58(\mathrm{dm}$, $J=130.0 \mathrm{~Hz}, 1 \mathrm{H}), 1.43-1.14(\mathrm{~m}, 46 \mathrm{H}), 0.90(\mathrm{t}, J=6.9 \mathrm{~Hz}, 6 \mathrm{H})$ ppm. ${ }^{13} \mathrm{C} \mathrm{NMR}\left(213 \mathrm{MHz}, \mathrm{CDCl}_{3} /\left[\mathrm{D}_{4}\right]\right.$ methanol): $\delta=174.0,133.2$ $(\mathrm{d}, J=42.0 \mathrm{~Hz}), 103.4,102.4,100.7,74.4,72.9,72.6,70.9,70.5$, 69.0, 68.4, 67.6, 66.1, 60.8, 38.6 35.6, 31.8-31.0 (m), 29.1-28.1 (m), 25.2, 25.1, 21.8, 21.6, 19.7, 12.6 ppm. IR (neat): $\tilde{v}=3300,2914$, 2849, 1633, 1549, 1468, 1204, 1069, 1026, $719 \mathrm{~cm}^{-1}$. HRMS: calcd. for $\left[\mathrm{C}_{47}{ }^{13} \mathrm{C}_{5} \mathrm{H}_{97} \mathrm{NO}_{18}+\mathrm{H}\right]^{+} 1029.6951$; found 1029.6949 .

Globotriaosyl-2- $N$-([3,4,5-133 $\left.\mathrm{C}_{3}\right]$-hexadecanoyl)-[5,6,7,8,9-1 $\left.{ }^{13} \mathrm{C}_{5}\right]$-sphingosine (42d): See the general procedure for the synthesis of ceramides from sphingosine, yield $(8.6 \mathrm{mg}, 8.3 \mu \mathrm{mol}, 64 \%) . R_{\mathrm{f}}=0.35$ $\left(\mathrm{CHCl}_{3} / \mathrm{MeOH} / \mathrm{H}_{2} \mathrm{O}, 70: 27: 3\right) .[a]_{\mathrm{D}}^{22}=+25\left(c=0.1, \mathrm{MeOH} / \mathrm{CHCl}_{3}\right.$, 1:1). ${ }^{1} \mathrm{H} \mathrm{NMR}\left(850 \mathrm{MHz}, \mathrm{CDCl}_{3} /\left[\mathrm{D}_{4}\right]\right.$ methanol): $\delta=5.69$ (dm, $J$ $=150.0 \mathrm{~Hz}, 1 \mathrm{H}), 5.45(\mathrm{~m}, 1 \mathrm{H}), 4.95(\mathrm{~d}, J=3.8 \mathrm{~Hz}, 1 \mathrm{H}), 4.41(\mathrm{~d}$, $J=6.9 \mathrm{~Hz}, 1 \mathrm{H}), 4.30(\mathrm{~d}, J=7.8 \mathrm{~Hz}, 1 \mathrm{H}), 4.25(\mathrm{~m}, 1 \mathrm{H}), 4.19$ (dd, $J=10.1,4.5 \mathrm{~Hz}, 1 \mathrm{H}), 4.07(\mathrm{~m}, 1 \mathrm{H}), 4.04-3.96(\mathrm{~m}, 4 \mathrm{H}), 3.92$ $(\mathrm{d}, J=3.0 \mathrm{~Hz}, 1 \mathrm{H}) 3.89(\mathrm{~m}, 1 \mathrm{H}), 3.85-3.81(\mathrm{~m}, 3 \mathrm{H}), 3.79-3.73$ (m, $2 \mathrm{H}), 3.71-3.63(\mathrm{~m}, 3 \mathrm{H}), 3.60-3.51(\mathrm{~m}, 4 \mathrm{H}), 2.17(\mathrm{~m}, 2 \mathrm{H})$, $2.02(\mathrm{dm}, J=128.0 \mathrm{~Hz}, 2 \mathrm{H}), 1.65-1.14(\mathrm{~m}, 48 \mathrm{H}), 0.90(\mathrm{t}, J=$ $6.9 \mathrm{~Hz}, 6 \mathrm{H}) \mathrm{ppm} .{ }^{13} \mathrm{C}$ NMR $\left(213 \mathrm{MHz}, \mathrm{CDCl}_{3} /\left[\mathrm{D}_{4}\right]\right.$ methanol $): \delta$ $=133.1(\mathrm{~d}, J=44.6 \mathrm{~Hz}), 31.8-30.8(\mathrm{~m}), 29.8-28.0(\mathrm{~m}), 25.95$, $25.27-24.95(\mathrm{~m}), 21.67,21.52,19.56,12.4 \mathrm{ppm}$. IR (neat): $\tilde{v}=3300$, 2955, 2849, 1634, 1549, 1466, 1070, 1028, $719 \mathrm{~cm}^{-1}$. HRMS: calcd. for $\left[\mathrm{C}_{44}{ }^{13} \mathrm{C}_{8} \mathrm{H}_{97} \mathrm{NO}_{18}+\mathrm{H}\right]^{+}$1032.7052; found 1032.7053 .

Supporting Information (see footnote on the first page of this article): ${ }^{1} \mathrm{H}$ and ${ }^{13} \mathrm{C}$ NMR spectra of all compounds.

\section{Acknowledgments}

The Netherlands Organization for Scientific Research (NWO-CW) , Top grant, to H. S. O. and J. M. A.) and the European Research Council (ERC AdG, to H. S. O.) are acknowledged for financial support.

[1] M. J. Ferraz, W. W. Kallemeijn, D. Herrara Moro, A. Marques, P. Wisse, R. G. Boot, L. I. Willems, H. S. Overkleeft, J. M. Aerts, Biochim. Biophys. Acta 2014, 1841, 811-825.

[2] J. M. Aerts, J. E. Groener, S. Kuiper, W. E. Donker-Koopman, A. Strijland, R. Ottenhoff, C. van Roomen, M. Mirzaian, F. A. Wijburg, G. E. Linthorst, A. C. Vedder, S. M. Rombach, J. Cox-Brinkman, P. Somerharju, R. G. Boot, C. E. Hollak, R. O. Brady, B. J. Poorthuis, Proc. Natl. Acad. Sci. USA 2008, 105, 2812-2817.

[3] N. Dekker, L. van Dussen, C. E. Hollak, H. S. Overkleeft, S. Scheij, K. Ghauharali, M. J. van Breemen, M. J. Ferraz, J. E.
Groener, M. Maas, F. A. Wijburg, D. Speijer, A. Tylki-Szymanska, P. K. Mistry, R. G. Boot, J. M. Aerts, Blood 2011, 118, e118-127.

[4] T. Wennekes, R. J. van den Berg, R. G. Boot, G. A. van der Marel, H. S. Overkleeft, J. M. Aerts, Angew. Chem. Int. Ed. 2009, 48, 8848-8869; Angew. Chem. 2009, 121, 9006-9028.

[5] H. Gold, M. Mirzaian, N. Dekker, M. Joao Ferraz, J. Lugtenburg, J. D. Codée, G. A. van der Marel, H. S. Overkleeft, G. E. Linthorst, J. E. Groener, J. M. Aerts, B. J. Poorthuis, Clin. Chem. 2013, 59, 547-556.

[6] M. J. van Breemen, S. M. Rombach, N. Dekker, B. J. Poorthuis, G. E. Linthorst, A. H. Zwinderman, F. Breunig, C. Wanner, J. M. Aerts, C. E. Hollak, Biochim. Biophys. Acta 2011, 1812, $70-76$.

[7] S. M. Rombach, N. Dekker, M. G. Bouwman, G. E. Linthorst, A. H. Zwinderman, F. A. Wijburg, S. Kuiper, M. A. van den Bergh-Weerman, J. E. Groener, B. J. Poorthuis, C. E. Hollak, J. M. Aerts, Biochim. Biophys. Acta 2010, 1802, 741748.

[8] N. Ouwerkerk, J. H. van Boom, J. Lugtenburg, J. Raap, Eur. J. Org. Chem. 2000, 861-866.

[9] G. Kumar, S. Kaur, V. Singh, Helv. Chim. Acta 2011, 94, 650 655.

[10] For conceptually distinct syntheses of the sphingosine base, see: a) P. Zimmermann, R. R. Schmidt, Liebigs Ann. Chem. 1988, 663-667; b) K. Metz, M. Honda, T. Komori, Liebigs Ann. Chem. 1993, 55-60; c) Y. D. Vankar, R. R. Schmidt, Chem. Soc. Rev. 2000, 29, 201-216; d) Y.-L. Li, Y.-L. Wu, Liebigs Ann. 1996, 2079-2082; e) J.-M. Lee, H.-S. Lim, S.-K. Chung, Tetrahedron: Asymmetry 2002, 13, 343-347; f) A. R. Parameswar, J. A. Hawkins, L. K. Mydock, M. S. Sands, A. V. Demchenko, Eur. J. Org. Chem. 2010, 3269-3274; see also ref. ${ }^{[11-16]}$

[11] C. Peters, A. Bilich, M. Ghobrial, K. Högenauer, T. Ullrich, P. Nussbaumer, J. Org. Chem. 2007, 72, 1842-1845.

[12] P. Nussbaumer, P. Ettmayer, C. Peters, D. Rosenbeiger, K. Högenauer, Chem. Commun. 2005, 5086-5087.

[13] K. P. Bhabak, D. Proksch, S. Redmer, C. Arenz, Bioorg. Med. Chem. 2012, 20, 6154-6161.

[14] T. Ullrih, M. Ghobrial, C. Peters, A. Billich, D. Guerini, P. Nussbaumer, ChemMedChem 2008, 3, 356-360.

[15] S. Torssel, P. Somfai, Org. Biomol. Chem. 2004, 2, 1643-1646.

[16] T. Yamamoto, H. Hasegawa, T. Hakogi, S. Katsumura, Org. Lett. 2006, 8, 5569-5572.

[17] D. Joe, L. E. Overman, Tetrahedron Lett. 1997, 38, 8635-8638.

[18] C. J. Yue, Y. Liu, R. He, J. Mol. Catal. A 2006, 259, 17-23.

[19] D. Bourgeois, A. Pancrazi, S. P. Nolan, J. Prunet, J. Organomet. Chem. 2002, 643-644, 247-252.

[20] S. H. Hong, D. P. Sanders, C. W. Lee, R. H. Grubbs, J. Am. Chem. Soc. 2005, 127, 17160-17161.

[21] H. Gold, R. G. Boot, J. M. F. G. Aerts, H. S. Overkleeft, J. D. C. Codée, G. A. van der Marel, Eur. J. Org. Chem. 2011, 1652-1663.

Received: July 8, 2014

Published Online: March 6, 2015 